NRTSC

NUCLEAR REACTOR TECHNOLOGY

AND SCIENTIFIC COMPUTATIONS

KEYWORDS: LOCA

ECS (EMERGENCY

COOLING SYSTEM)

ASSEMBLY LIMITS

RETENTION: PERMANENT

\title{
FLOWTRAN-TF Code Description (U)
}

edited by

G. P. Flach

with contributions by

S. E. Aleman

G. P. Flach

L. L. Hamm

S. Y. Lee

F. G. Smith, III

V. Van Brunt

ISSUED. December, 1990

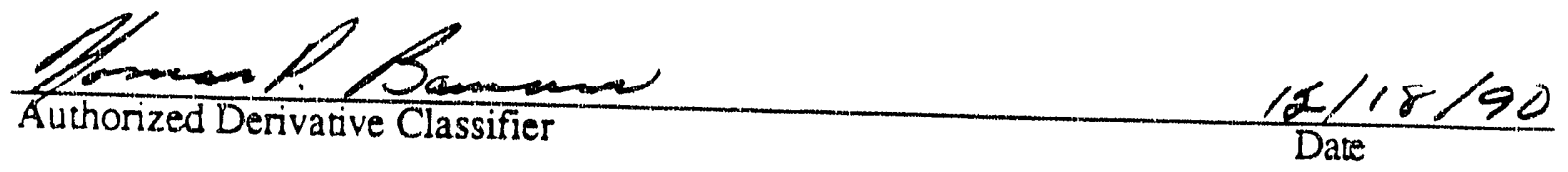

Westinghouse Savannah River Company

Savannih River Laboratory

Aiken, SC 29802 
PROJECT: 89-021-1

DOCUMENT: WSRC.-TR-90-413

TITLE: FLOWTRAN-TF Code Description (U)

REVISION NUMBER: 0

APPROVALS

A. L. KIELPINSKI, TECHINICAL REVIEWER $\frac{1}{\text { DATE }}$

$\frac{2}{\text { J.E. LAURINAT, TECHNICAL REVIEWER }} \frac{12 \cdot 17-5 \sigma}{\text { DATE }}$
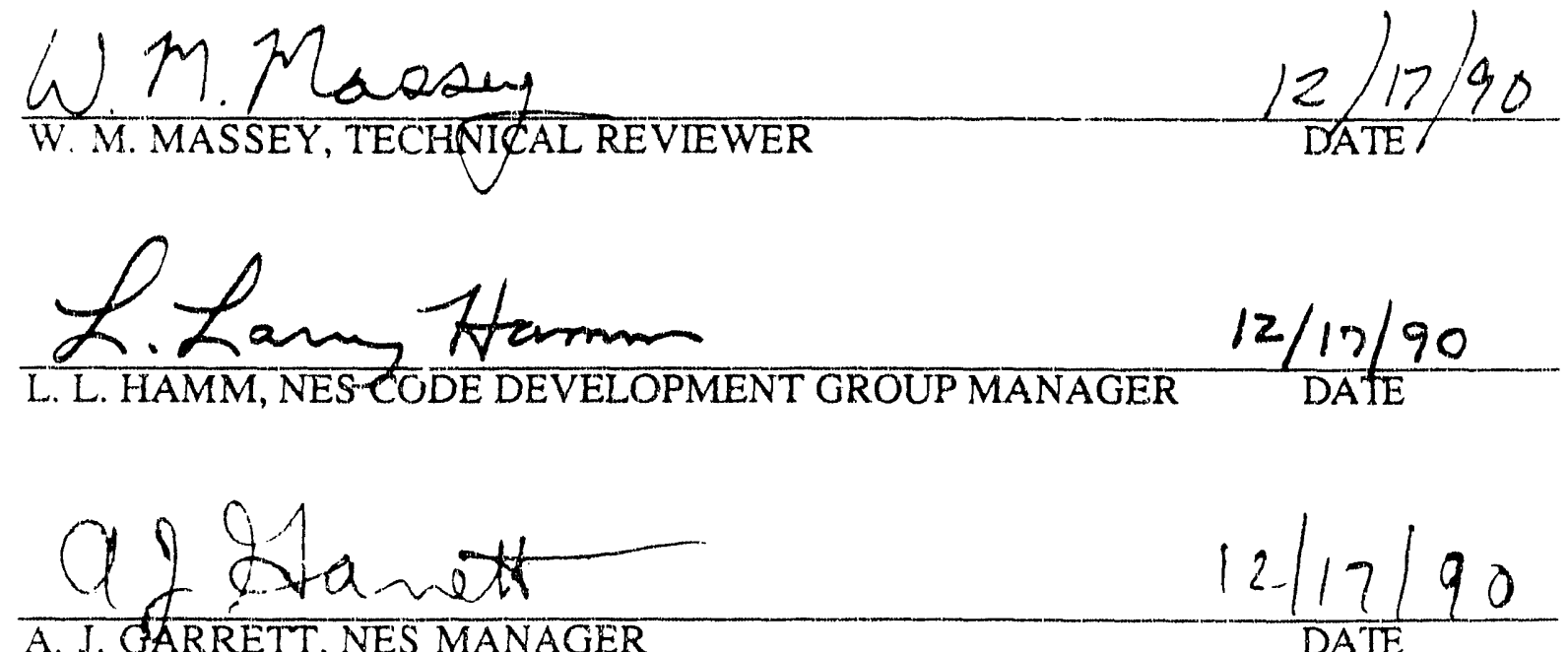


\section{Tahle of Contents}

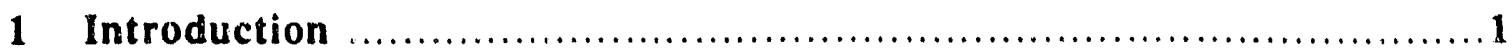

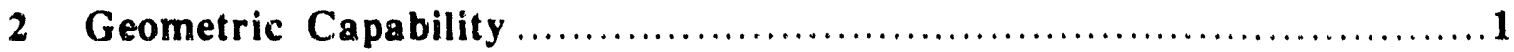

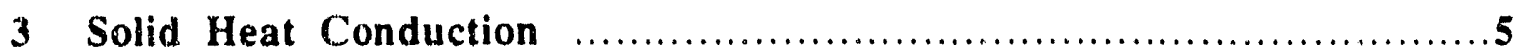

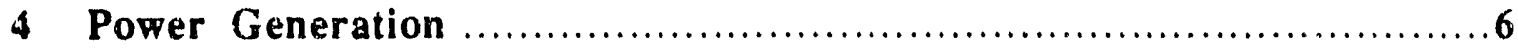

5 Fluid Governing Equations ........................................

6 Wall Heat Transfer ................................................ 1

6.1 Overall Heat Transfer Strategy ......................................1 1

6.2 Heat Transfer Correlations .......................................... 5

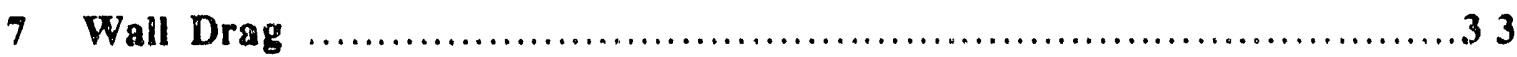

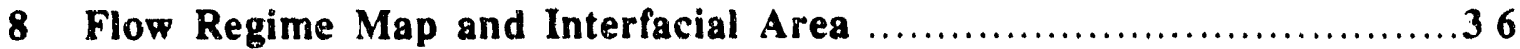

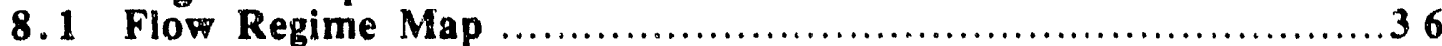

8.2 Interfacial Area Per Unit Volume $\ldots \ldots \ldots \ldots \ldots \ldots \ldots \ldots \ldots \ldots \ldots$

9 Interfacial Heat and Mass Transfer ....................................40

9.1 Interfacial Exchange in Bulk Flow ..................................40

9.2 Interfacial Exchange at Walls ................................. 46

10 Interfacial Drag ....................................................47

10.1 CCFL Correlations ......................................................4 7

10.2 Interfacial Drag Model .........................................5 0

11 Channel Inlet Void Distribution Model for Mark-22 Assembly ........5 3

12 Azimuthal Momentum Donoring Scheme ...............................6 0

13 Boundary Conditions ..............................................6 3

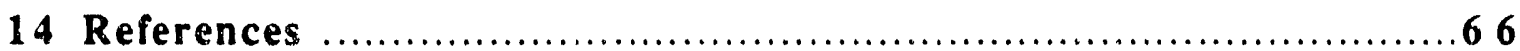




\section{Introduction}

FLOWTRAN-TF is a two-component (air-water), two-phase thermal-hydraulics code designed for performing accident analyses of SRS reactor fuel assemblies during the Emergency Cooling System (ECS) phase of a Double Ended Guillotine Break (DEGB) Loss Of Coolant Accident (LOCA). This report provides a brief description of the physical models in the version of FLOWTRAN-TF used to compute the Recommended K-Reactor Restart E.CS Power Limit,(Smthet at., 1990a; Smith et at., 1990b). This document is viewed as an interim report and should ultimately be superseded by a comprehensive user/programmer manual. In general, only high level discussions of governing equations and constitutive laws are presented. Numerical implementation of these models, code architecture and user infornation are not generally covered. A companion document describing code benchmarking is available,(Ftact et at., 7990 ).

\section{Geometric Capability}

The basic geometric capability of FLOWTRAN-TF is similar to that of FLOWTRAN-FI (Aleman et al., 1989) and illustrated by, but not limited to, the example configuration shown in Figures 2.1 and 2.2. The Middle Section is comprised of one or more axial flow channels separated by solid conductors. Each channel is divided into one or more azimuthal cells. Azimuthal crossflows are allowed within a channel. Figures 2.1 and 2.2 show two channels, each with four azimuthal fluid cells per axial layer, separated by three conductors. Sixteen azimuthal and three radial solid cells per cylinder are also shown. Above and below the middle section are strictly one-dimensional axial Top and Bottom Sections which are not coupled to any solid heat conductors. Currently, FLOWTRAN-TF is restricted to a cylindrical geometry. Within this framework, the Mark-22 assembly and all existing experimental rigs of interest can be suitably modeled.

Figure 2.3 illustrates a cross-sectional $(\mathrm{r}-\theta)$ view of the computational mesh used to model the active core region (Middle Section) of a Mark-22 assembly. The actual Mark-22 assembly consists of five metal cylinders and five flow channels. However, the innermost and outermost flow channels are purge channels that take a negligible fraction of the total assembly flow. Also the Universal Sleeve Housing (the outermost solid cylinder) generates no power. Therefore the two assembly purge channels are neglected and FLOWTRAN-TF calculations are performed for four solid cylinders and three flow channels. Each flow channel contains four subchannels each of which is modeled with a single azimuthal fluid cell. This simplified model assumes that the innermost and outermost surfaces in the mesh are adiabatic.

An exploded view of a section of one metal cylinder in Figure 2.3 is used to indicate a typical solid radial mesh. The cladding layer is represented by a single radial node while the metal core contains three nodes. Figure 2.3 also illustrates how the solid and fluid cells are coupled. For example, in each azimuthal sector, the heat fluxes computed over surfaces 4 and 5 are multiplied by their respective surface areas and summed to calculate the total heat deposited to the fluid in the subchannels of the middle flow channel. Eight azimuthal solid cells are routinely used in the calculations so that two azimuthal cells fall into each fluid subchannel. To simulate a $\pm 20 \%$ azimuthal power tilt, the power distribution factors listed in Table 2.1 are employed.

A schematic representation of the axial mesh used for Mark-22 assembly calculations is illustrated in Fig. 2.4. The model consists of an upper region having four fluid cells, a 
middle region with 15 axial cells in both the fluid and solid mesh, and a lower region with two fluid cells. The middle region contains the three annular flow paths and only the 13 central axial cells in the middle region are heated. Loss coefficients are set in the lower region to model flow through a single pressure plate as illustrated in the figure. Figure 2.4 also indicates the boundary condition information required by FLOWTRAN-TF and the sources of the inpur.

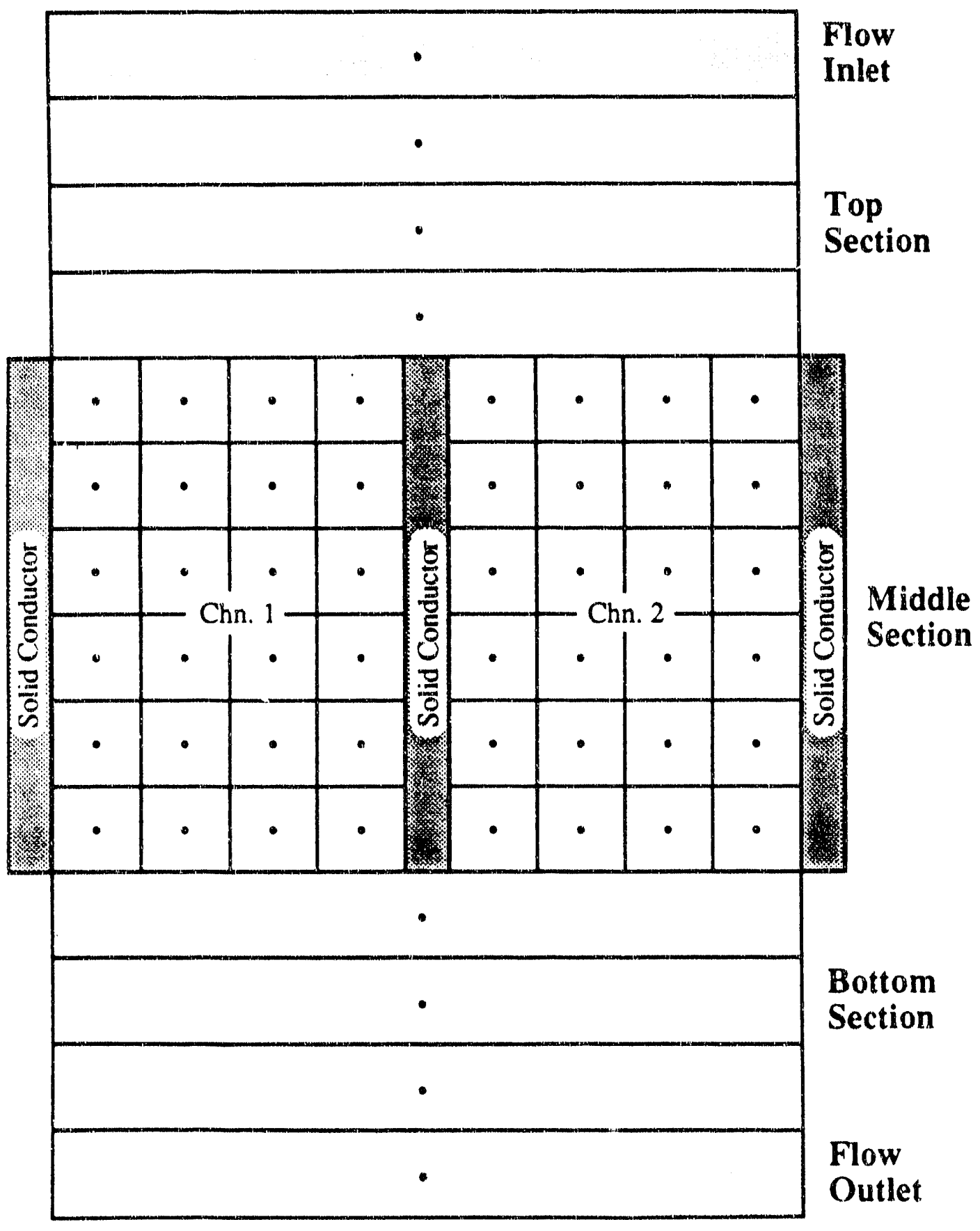

Figure 2.1 Representative example FLOWTRAN-TF geometric configuration - axial view 


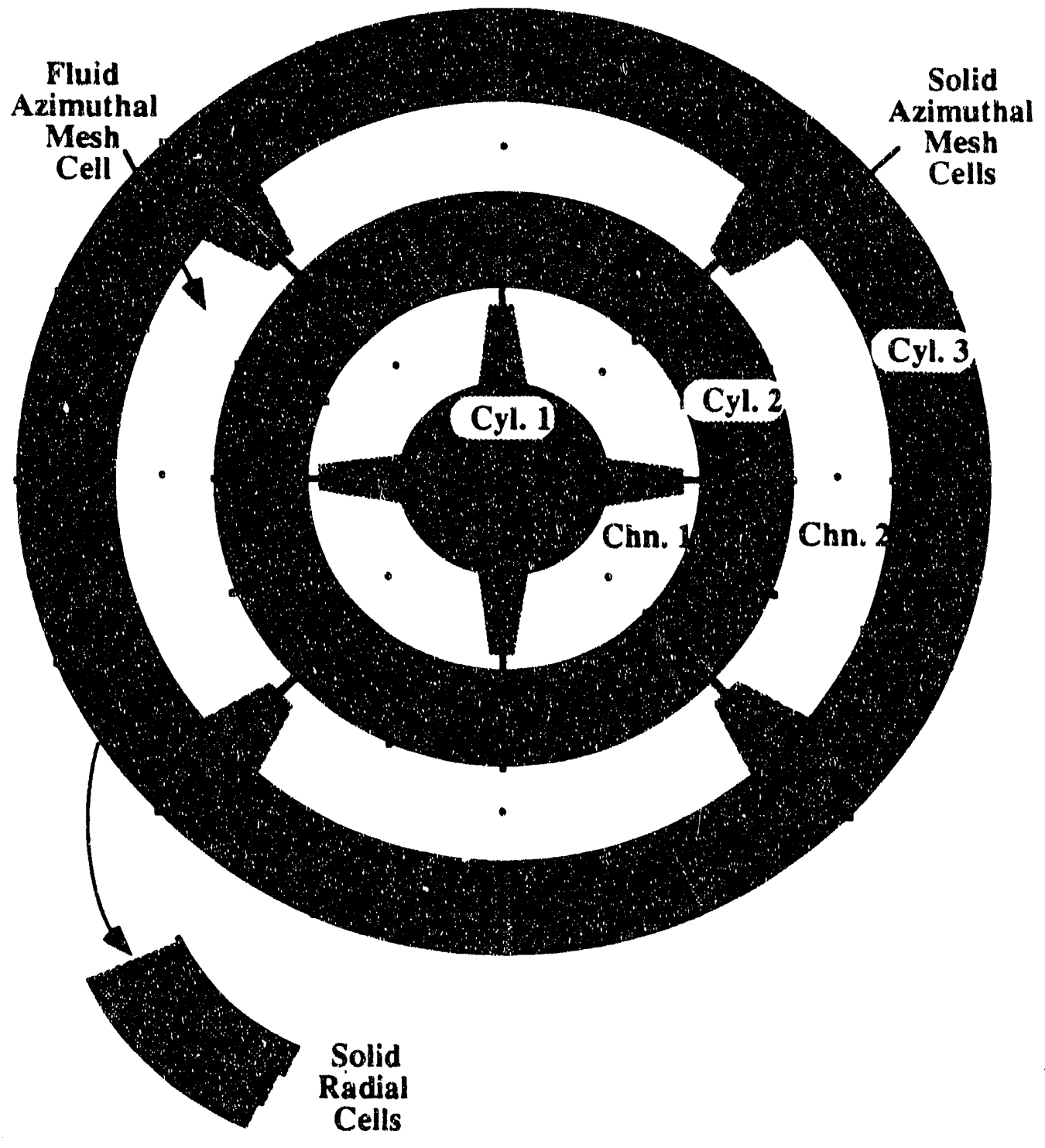

Figu re 2.2 Representative example FLOWTRAN-TF geometric configuration - crosssectional $(r-\theta)$ view 


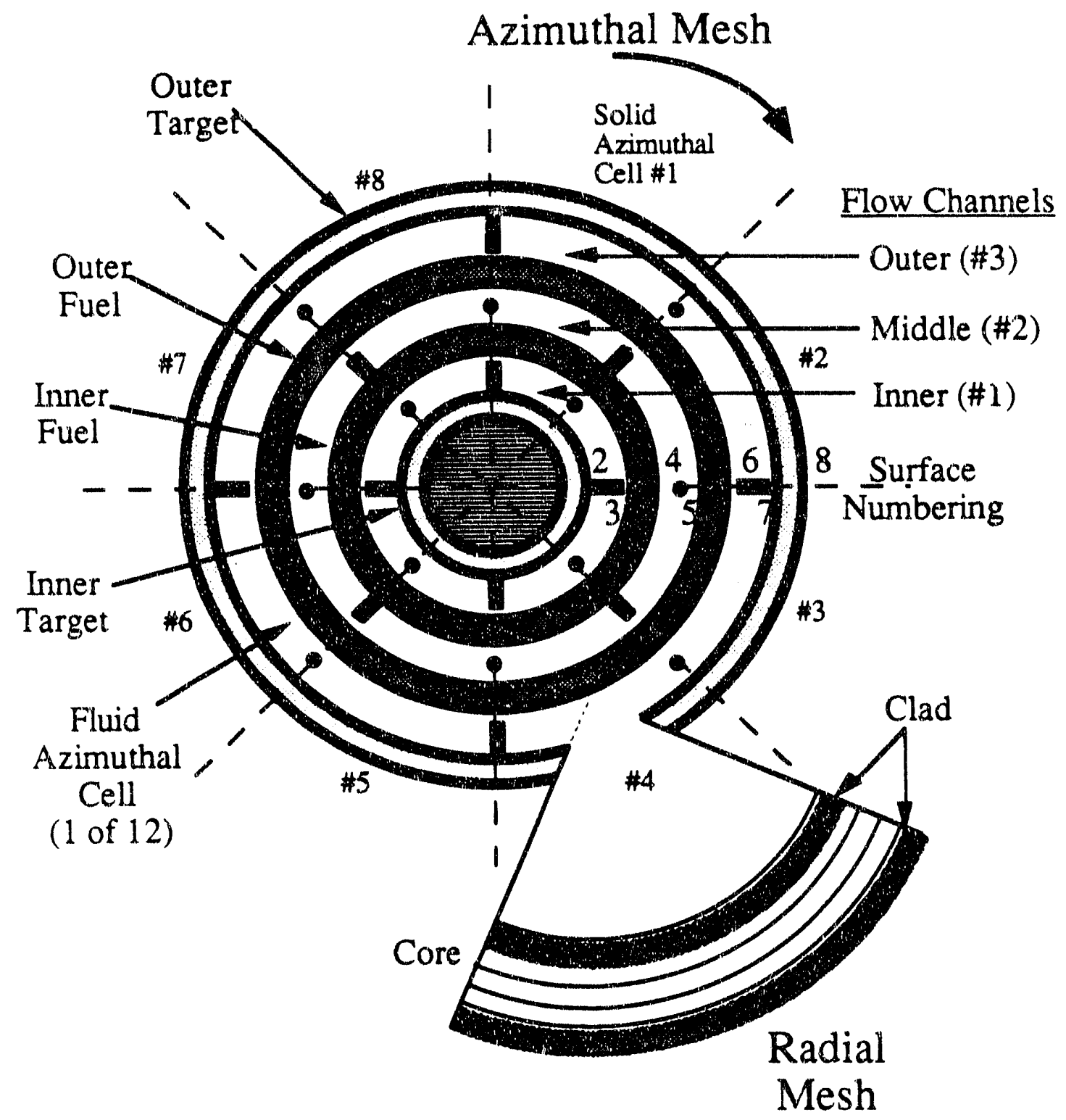

Figure 2.3 Schematic representation of radial and azimuthal mesh used in Mark-22 assembly calculations

Table 2.1 Azimuthal power profile used in Mark-22 assembly calculations

\begin{tabular}{|c|c|}
\hline Azimuthal Cell & Azimuthal Power Factor \\
\hline 1,2 & 1.2 \\
3,4 & 1.0 \\
5,6 & 0.8 \\
7,8 & 1.0 \\
\hline
\end{tabular}




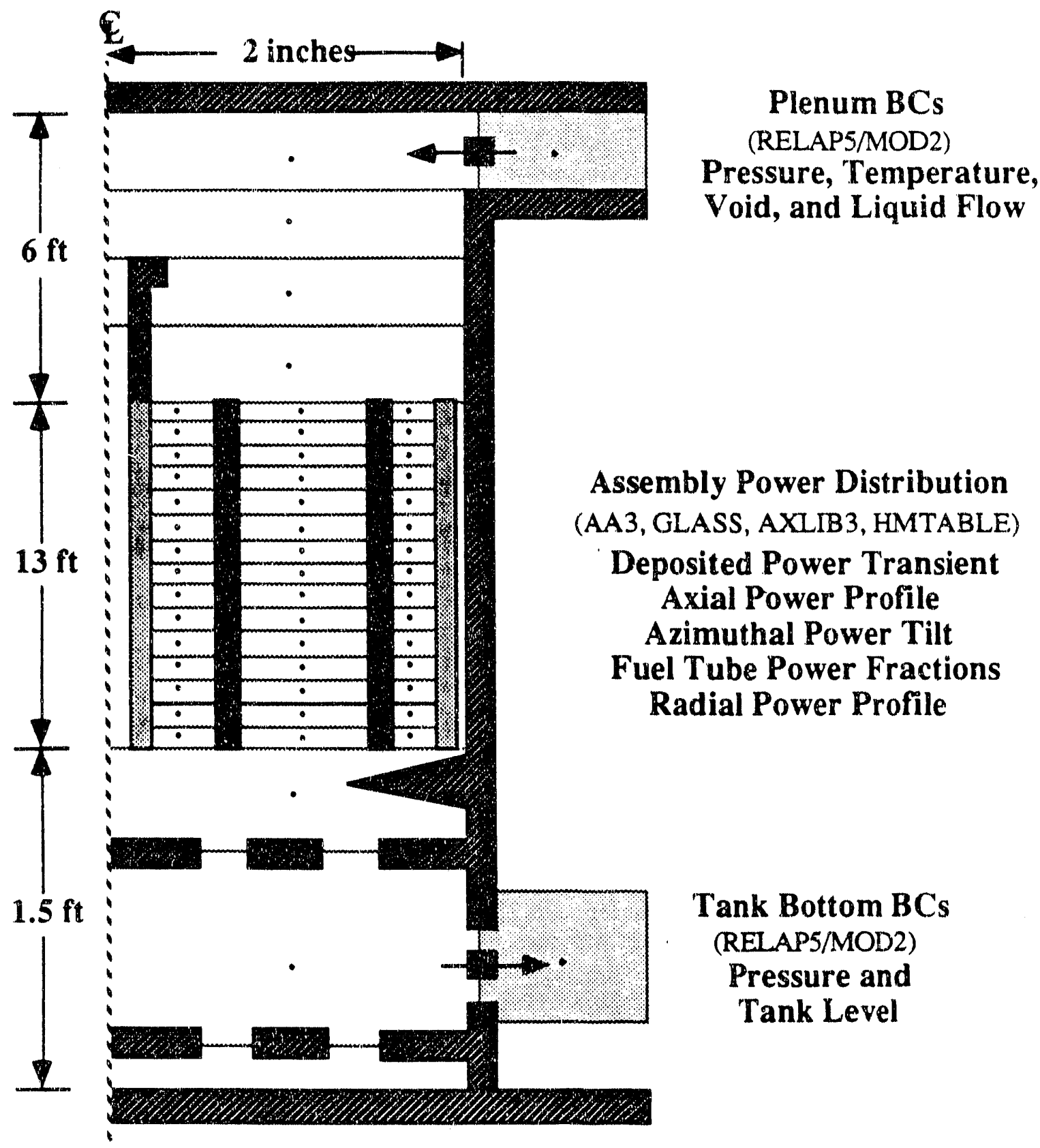

Figure 2.4 Schematic of axial computational mesh used for Mark-22 assembly calculations

\section{Solid Heat Conduction}

The FLOWTRAN-TF code is capable of solving the full unsteady three-dimensional heat conduction equation in a cylindrical geometry to determine the temperature distribution within solid reactor assembly components and the assembly surface temperatures. Twodimensional $r-\theta$ and one-dimensional radial calculations can a!so be chosen. Typically 
axial heat conduction is not considered in order to achieve computational savings. As shown in the exploded view of Fig. 2.3, a composite solid structure consisting of three different materials can be modeled. For reactor assemblies, these solid layers represent the outer cladding, core, and inner cladding. For experimental rigs, these layers can be used to represent the layers of a composite heater. The conduction equations are solved using the same finite difference method used in the FLOWTRAN-FI code. Full details of the governing equations and solution methods are provided in the FLOWTRAN-FI code manual (Aleman et al., 1989). Briefly, the governing equation is given by

$$
\rho c_{p} \frac{\partial T}{\partial t}=\nabla \cdot(k \nabla T)+s(t, r, \theta, z)
$$

where the source term $s(t, r, \theta, z)$ is due to either neutronic heating in the Mark-22 assembly or electrical heating in the various experimental rigs. Power generation calculations to define $s(t, r, \theta, z)$ are discussed in the next section. Surface heat fluxes due to a convective boundary condition are defined as discussed in the Wal! Heat Transfer section.

\section{Power Generation}

The heat conduction calculations in FLOWTRAN-TF require a deposited power source for each computational node in the finite difference formulation. The representation of the deposited power distribution depends upon whether a reactor assembly or an electrically heated experimenta! rig is being modeled. In either case, no fundamental power calculation is performed within FLOWTRAN-TF. Instead, the code takes input power data and unfolds it into a detailed nodal power distribution. Since the identical fornulation used in FLOWTRAN-FI is also used in FLOWTRAN-TF, a complete description of the power distribution calculations including the mathematical equations used is available in the FLOWTRAN-FI code manual (Aleman et al., 1989).

For neutronic heating in a reactor assembly, the input data is generated by four other computer codes. The time response of total reactor power is generated by the reactor system code AA3 (Smith and Church, 1982), which contains a point kinetics model. Detailed assembly power shapes are provided by the GLASS system of codes (Smetana; 1982), which uses two-dimensional intugral transport theory for unit supercell calculations. The response of fission product decay power versus time is generated by the HMTABLE code (Baxter and Apperson, 1982). The time-dependent axial shape is calculated using the one-dimensional space-time kinetics code AXLIB3 (Pevey, 1987). For electric heating in an experimental rig, the input power distribution information is easily generated analytically.

Four basic assumptions are made to derive the expression for the nodal deposited power:

1. The overall power shape is the product of three separable shapes: axial, radial, and azimuthal.

2. Three separate radial power shapes are required, one for the neutronic component, one for the wet tank decay heat component, and one for the dry tank decay heat component. 
3. The neutronic axial shape depends on time, so that we can model the effects of safety rod insertion. The radial and azimuthal power shapes are assumed to be independent of time, but the radial shape is dependent on reactor exposure.

4. The axial decay heat shape is independent of time.

The deposited power calculation can then be represented by

$$
s_{i}(t ; r, \theta, z)=P_{0} F_{i}(t) R_{i}(r) \Theta_{i}(\theta) Z_{i}(t, z)
$$

where the contribution to the total deposited power at time $t$ in node $i$ is equal to the initial power $P_{0}$ multiplied by a time dependent function $F_{i}(t)$, a radial power shape $R_{i}(r)$, an azimuthal power shape $\Theta_{i}(\theta)$, an axial power shape $Z_{i}(t, z)$ that is also a function of time.

\section{Fluid Governing Equations}

Air-steam-water flow is modeled with a set of space-time averaged, two-phase, twocomponent, differential transport equations. Air is assumed to be noncondensable. The gas phase is assumed to be completely mixed so that the air and water vapor components have the same velocity and temperature. As a result of these assumptions, 3 mass, 2 vector momentum, and 2 energy equations are required. In addition, both phases are assumed to have the same pressure. The viscous dissipation term is neglected in the energy equations. Distribution effects are neglected except in interfacial drag modeling. Interfacial momentum exchange due to phase change is also neglected. The resulting transport equation set is (see Lahey and Drew (1988) for example):

Gas (air+steam) mass balance:

$$
\frac{\partial \alpha \rho_{g}}{\partial t}+\nabla \cdot\left[\alpha \rho_{g} \mathbf{v}_{g}\right]=\Gamma_{I}+\Gamma_{w}
$$

Air mass balance:

$$
\frac{\partial r \rho_{g} X_{a}}{\partial t}+\nabla \cdot\left[\alpha \rho_{g} v_{g} X_{g}\right]=0
$$

Liquid mass balance:

$$
\frac{\partial(1-\alpha) \rho_{\mathrm{f}}}{\partial \mathrm{t}}+\nabla \cdot\left[(1-\alpha) \rho_{\mathrm{f}} \mathrm{v}_{\mathrm{f}}\right]=-\Gamma_{\mathrm{I}}-\Gamma_{\mathrm{w}}
$$

Gas momentum balance:

$$
\alpha \rho_{\mathrm{g}} \frac{\partial \mathbf{v}_{\mathrm{g}}}{\partial t}+\alpha \rho_{\mathrm{g}} \mathbf{v}_{\mathrm{g}} \cdot \nabla \mathbf{v}_{\mathrm{g}}=-\alpha \nabla \mathrm{P}+\alpha \rho_{\mathrm{g}} \mathrm{g}-\mathbf{F}_{\mathrm{wg}}-\mathbf{F}_{\mathrm{I}}
$$

Liquid momentum balance: 


$$
(1-\alpha) \rho_{\mathrm{f}} \frac{\partial v_{\mathrm{f}}}{\partial t}+(1-\alpha) \rho_{\mathrm{f}} v_{\mathrm{f}} \nabla v_{\mathrm{f}}=-(1-\alpha) \nabla P+(1-\alpha) \rho_{\mathrm{f}} \mathbf{g}-\mathbf{F}_{\mathrm{wf}}+\mathbf{F}_{\mathrm{I}}
$$

Gas energy balance:

$$
\frac{\partial \alpha \rho_{g} h_{g}}{\partial t}+\nabla \cdot\left[\alpha \rho_{g} h_{g} v_{g}\right]=\alpha \frac{\partial P}{\partial t}+Q_{w g}+E_{I}+E_{w}
$$

Liquid energy balance:

$$
\frac{\partial(1-\alpha) \rho_{f} h_{f}}{\partial t}+\nabla \cdot\left[(1-\alpha) \rho_{f} h_{f} v_{f}\right]=(1-\alpha) \frac{\partial P}{\partial t}+Q_{w f}-E_{I}-E_{w}
$$

The space-time averaging operators have been omitted for brevity in equations (5.1-7). In equations (5.1-7), and throughout the document unless otherwise defined, the following nomenclature is used:

Subscripts:

$$
\begin{aligned}
& \mathrm{g} \equiv \text { gas } \\
& \mathrm{f} \equiv \text { liquid } \\
& \mathrm{a} \equiv \mathrm{air} \\
& \mathrm{s} \equiv \text { steam }
\end{aligned}
$$

Symbols:

$$
\begin{aligned}
\alpha & \equiv \text { void fraction } \\
P & \equiv \text { pressure } \\
T & \equiv \text { temperature } \\
\rho & \equiv \text { mass density } \\
X_{\mathrm{a}} & \equiv \text { mass fraction of air in the gas phase } \\
\mathrm{h} & \equiv \text { enthalpy } \\
v & \equiv \text { phasic velocity vector } \equiv(u, w)^{T} \\
\mathrm{u} & \equiv \text { axial velocity, } v \cdot \mathrm{n}_{\mathrm{z}} \\
w & \equiv \text { azimuthal velocity, } \mathrm{v} \cdot \mathrm{n}_{\theta} \\
\mathrm{g} & \equiv \text { gravitational vector }
\end{aligned}
$$


The fluid constitutive terns contained in the above transport equations are discussed in more detail in subsequent sections and are denoted as

$$
\begin{aligned}
\Gamma_{I} \equiv \text { rate of gas phase mass creation at two-phase interfaces in the bulk flow } \\
\text { per unit volume }
\end{aligned}
$$

The primary variables in FLOVIRAN-TF are taken as total pressure $P$, gas void fraction $\alpha$, gas temperature $T_{g}$, liquid temperature $T_{f}$, air mass fraction $X_{a}$, gas phasic velocity $v_{g}$, and liquid phasic velocity $v_{p}$. State variables other than $P, \alpha, T_{g}, T_{f}$, and $X_{a}$ are computed as functions of the 5 primary state variables. External to the equation of state subroutine in the code, the gas properties are viewed as functions of $\mathrm{P}, \mathrm{T}_{\mathrm{g}}$, and $\mathrm{X}_{\mathrm{a}}$. The liquid properties are functions of $P$ and $T_{f}$. Due to the relatively low pressures and temperatures encountered in SRS reactors, simple mixture rules are sufficient. Internal to the equation of state subroutine, the gas density is computed assuming Dalton's law and ideal gas behavior and the gas enthalpy is computed assuming an ideal solution. The resulting internal equations of state, in functional form, are

$$
\begin{aligned}
& \rho_{\mathrm{f}}=\rho_{\mathrm{f}}\left(\mathrm{P}, \mathrm{T}_{\mathrm{f}}\right) \\
& h_{\mathrm{f}}=\mathrm{h}_{\mathrm{f}}\left(\mathrm{P}, \mathrm{T}_{\mathrm{f}}\right) \\
& \rho_{\mathrm{a}}=\rho_{\mathrm{a}}\left(\mathrm{P}_{\mathrm{a}}, \mathrm{T}_{\mathrm{g}}\right) \\
& \mathrm{h}_{\mathrm{a}}=\mathrm{h}_{\mathrm{a}}\left(\mathrm{P}, \mathrm{T}_{\mathrm{g}}\right)
\end{aligned}
$$




$$
\begin{aligned}
& P_{s}=\rho_{s}\left(P_{s}, T_{g}\right) \\
& h_{s}=h_{s}\left(P, T_{g}\right)
\end{aligned}
$$

and the gas mixture equations are

$$
\begin{gathered}
P=P_{a}+P_{s} \\
P_{a}=X_{a} \rho_{g} \\
\rho_{B}=P_{a}+\rho_{s} \\
l_{B}=X_{a} h_{a}+\left(1-X_{a}\right) h_{3}
\end{gathered}
$$

where

$$
\begin{aligned}
& P_{\mathrm{a}} \equiv \text { partial pressure of air } \\
& P_{\mathrm{s}} \equiv \text { partial pressure of steam } \\
& \rho_{\mathrm{a}} \equiv \text { mass of air per unit total gas volume } \\
& \rho_{\mathrm{s}} \equiv \text { mass of steam per unit total gas volume }
\end{aligned}
$$

Using the ideal gas law and equations (5.14-17) the air and steam partial pressures are computed from

$$
P_{a}=P_{a}\left(P, X_{a}\right)=P \frac{X_{a} M_{s}}{X_{a} M_{s}+\left(1-X_{a}\right) M_{a}}
$$

and

$$
P_{s}=P-P_{a}
$$

respectively, where

$$
\begin{aligned}
& M_{a}=\text { molecular weight of air } \\
& M_{s} \equiv \text { molecular weight of steam }
\end{aligned}
$$

Simple equation of state relations, denoted functionally by equations (5.8-13), were developed taking advantage on the relatively low pressures and temperatures encountered in SRS applications. The liquid thermodynamic property models are valid for pressures up to $1 \mathrm{MPa}$ and temperatures trom $275 \mathrm{~K}$ to $450 \mathrm{~K}$. For gas thermodynamic properties, temperatures up to $700 \mathrm{~K}$ can be handled. Within these ranges of temperature and pressure, the ideal gas assumption is generally quite good. The largest density error occurs for saturated steam at $1 \mathrm{MPa}$ where the code underpredicts by $7 \%$. 


\section{Wall Heat Transfer}

FLOWTRAN-TF contains a complete boiling curve for air-water, two-phase flow. Except for the non-boiling portion of the curve, the wall heat transfer models are largely based on untested adaptations of single-component correlations from the literature; it is an open question whether the models predict correct behavior for two-component (air-water) flows. An extensive literature survey was not made nor have novel models been incorporated into the heat transfer scheme. Rather, we have looked to existing codes to provide guidance in the development of a heat transfer module that uses tested correlations (for singlecomponent flows) capable of modeling a complete boiling curve. In particular, model components have been abstracted from the existing FLOWTRAN-FI (Aleman et al., 1989) code and from the RELAP (Ransom et al., 1985), COBRATTRAC (Thurgood et al., 1983), TRAC (Liles et al., 1988), and THERMIT (Kelly, 1980) codes. We have selected heat transfer correlations appropriate for the low pressure conditions that prevail in SRS reactors.

One of the nonboiling heat transfer models is based on SRS data taken for air-water twophase downflows in a ribbed annulus. Fortunately, boiling at metal surfaces does not occur using the current ECS power limit criterion of $T_{\text {wall }}=T_{3 a t}$ (Smith et al., 1990a; Smith et al., 1990b). For this criterion the maximum surface temperature in the heated assembly core is restricted to remain below the local fluid saturation temperalure. Therefore, a non-boiling heat transfer correlation appropriate for two-phase air-water downflows is sufficient to calculate the wall heat flux throughout the LOCA-ECS trarsient for ECS power limit computations. However, an assessment of the safety margin between the physical damage limit and the conservative $T_{w a l l}=T_{\text {sat }}$ limit requires calculations in the boiling heat transfer regime. For these FLOWTRAN-TF calculations, the entire boiling curve logic may be exercised.

We first discuss the overall wall heat transfer computational strategy and then describe the individual heat transfer correlations selected and indicate their source.

\subsection{Overall Heat Transfer Strategy}

The basic FLOWTRAN-TF heat transfer computational strategy is illustrated in Fig. 6.1. Subroutine QWALL, which is called at the start of each time step from subroutine TRANS, performs all of the heat transfer calculations required to advance the computation another time step. That is, QWALL provides explicit approximations to the calculated quantities. QWALL calculates the heat flux to the liquid phase $\left(\mathrm{q}_{\mathrm{f}}\right)$, heat flux to the gas phase $\left(\mathrm{q}_{\mathrm{g}}\right)$, the derivatives of heat fluxes with respect to wall iemperature $\left(T_{w}\right)$, and the wall vapor generation rate $\left(\Gamma_{w}\right)$ at all computational cell solid surfaces. Subroutine SOLID then uses the total heat flux at each surface to calculate new ime values for the solid temperature $\left(T_{s}\right)$ and wall temperature. With new wall temperatures, the derivative with respect to wall temperature is used to obtain an improved estimate for the surface heat fluxes. The new estimates for the surface heat fluxes are then used to formulate the fluid energy equations. Finally, subroutine NEWTON solves for fluid temperatures at the new time.

The heat transfer correlations are coded in a set of seven subroutines that are called by QWALL. These subroutines (HCONV, SRLHTC, CDENS, MIKIC, CHEN, CHF, and FILMB) are used to solve for heat transfer coefficients and the surface heat fluxes in the various heat transfer regimes considered. In general, the package models a boiling curve with four heat transfer regimes: 
1. Single phase heat transfer to liquid when the surface temperature is below the local fluid saturation temperature $\left(\mathrm{T}_{\text {SAT }}\right)$.

2. Subcooled and saturated nucleate boiling heat transfer when the surface temperature is between saturation and the critical heat flux temperature $\left(\mathrm{T}_{\mathrm{CHF}}\right)$.

3. Transition heat transfer for wall temperatures between the critical heat flux temperature and the minimum stable film boiling temperature ( $\left.T_{M S F B}\right)$.

4. Film heat transfer when surface temperatures are greater than $T_{M S F B}$.

The basic structure of subroutine QWALI is illustrated in Fig. 6.2 which shows the logic used to select a particular heat transfer regime and the subroutines used to perform heat transfer calculations within each regime. An input parameter (IBOII) is specified by the user to select the particular heat transfer options for the calculation. Each of the subroutines and their associated heat transfer correlations is discussed below. For reference, a schematic representation of the general boiling curve is presented in Fig. 6.3.

Subroutine QWALL also contains logic to adjust heat transfer to the moderator space as the tank drains. That is, if the tank level covers the outer surface of the assembly for a given axial cell, heat transfer at that surface is calculated using an input heat transfer coefficient (HMOD) and input moderator temperature (TMOD). As the tank drains and outer surfaces become uncovered, the heat transfer coefficient is adjusted so that for bare surfaces an adiabatic condition applies. For partial coverage, the external heat transfer coefficient is interpolated between the input valu and zero to approximately account for surface dryout. 


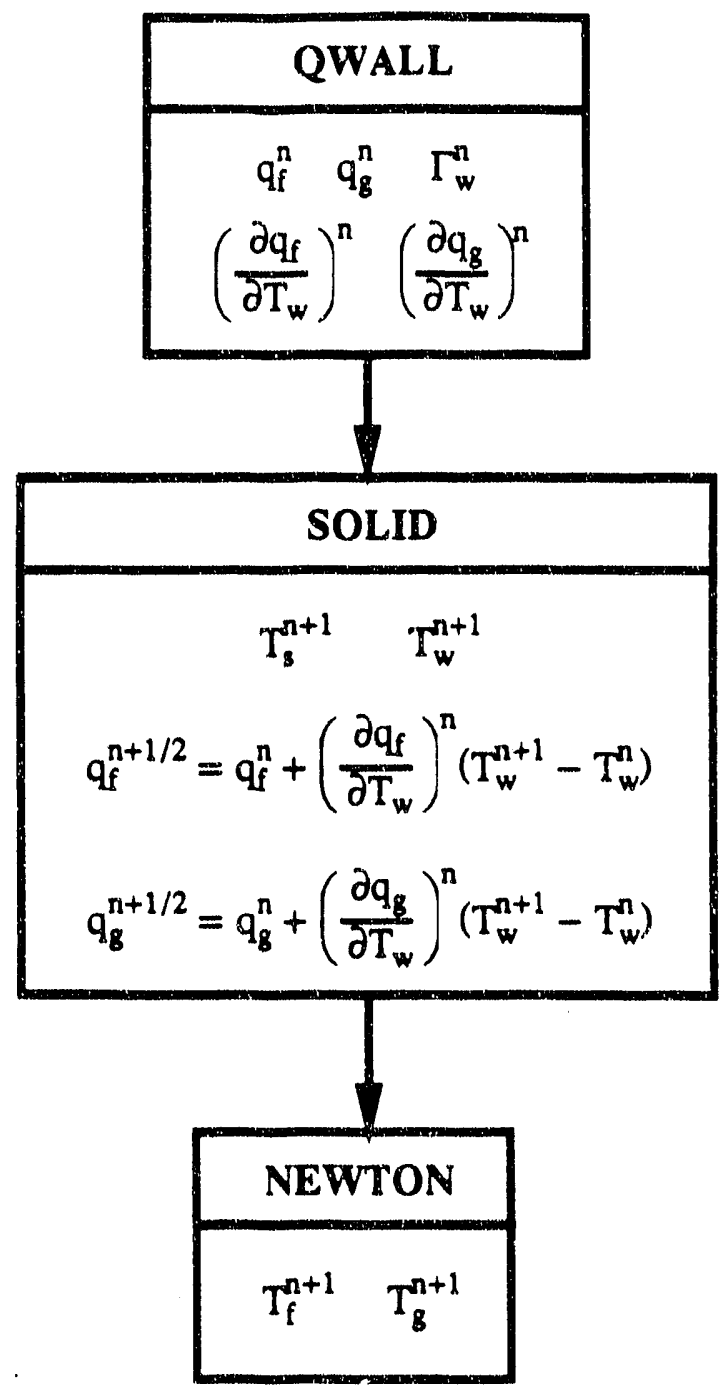

Figure 6.1 FLOWTRAN-TF wall heat flux and temperature computational strategy 


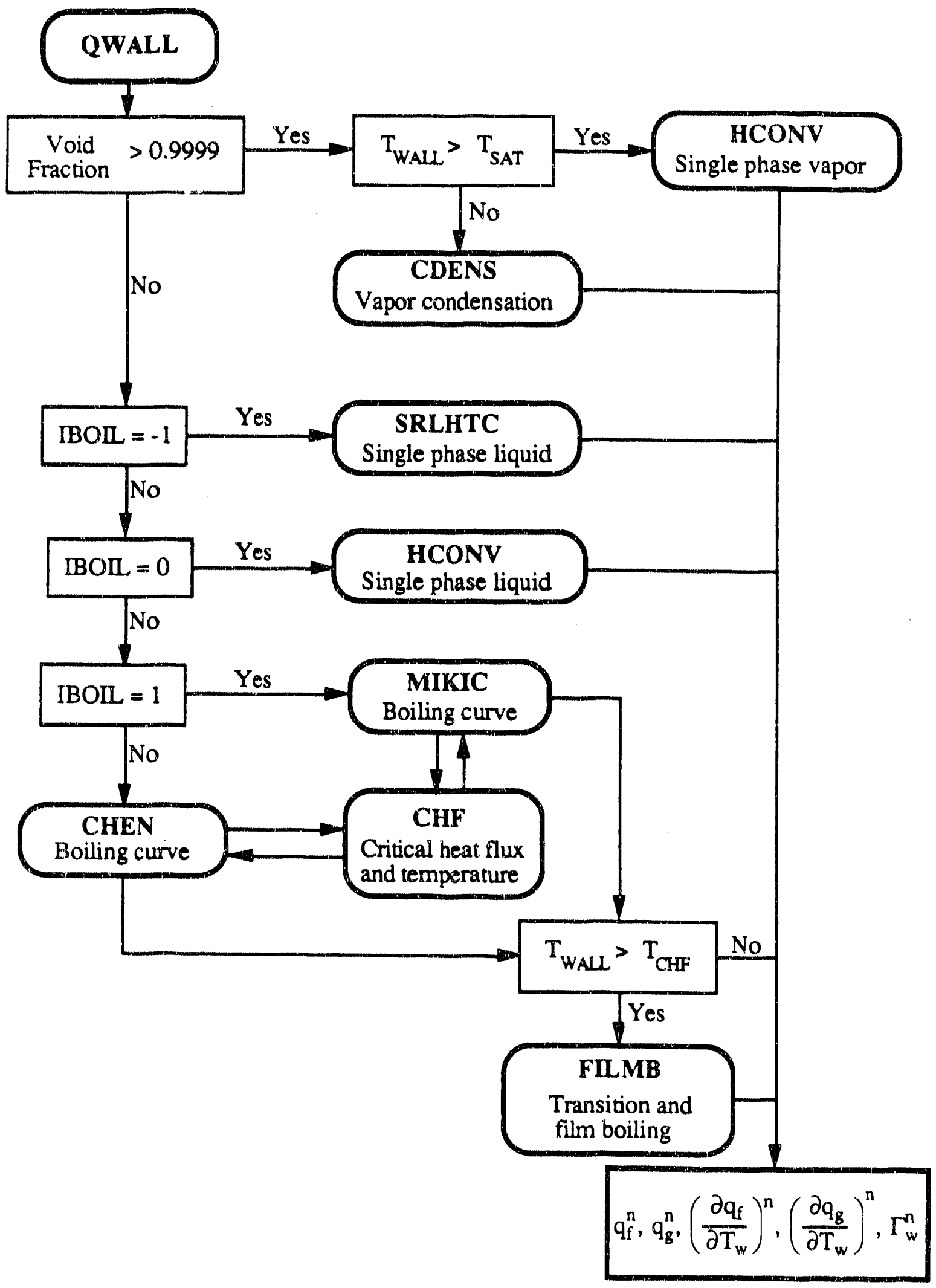

Figure 6.2 Heat transfer regime selection logic in FLOWTRAN-TF 


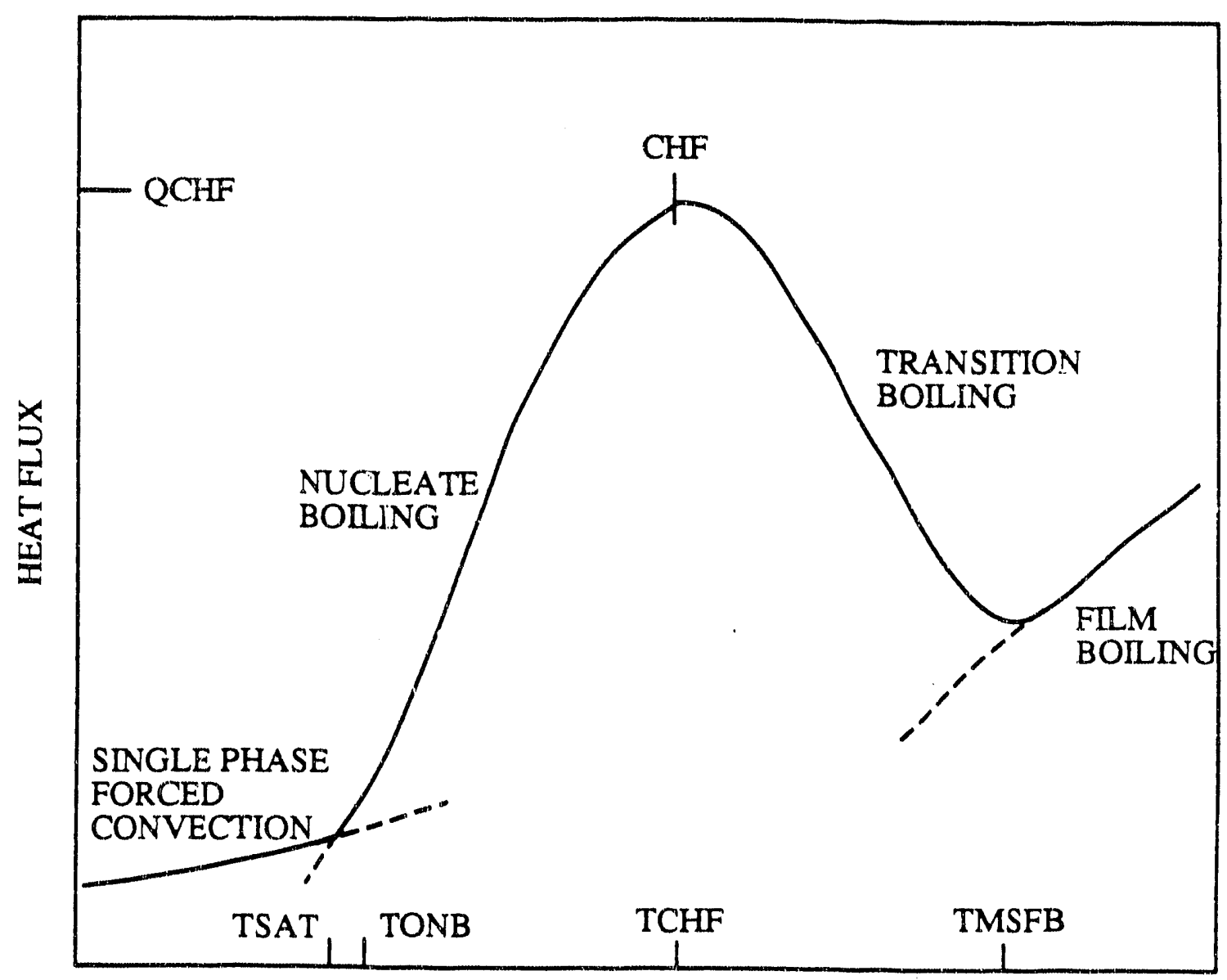

WALL TEMPERATURE

Figure 6.3 Schematic representation of boiling curve

\subsection{Heat Transfer Correlations}

The individual models comprising the overall boiling curve are discussed below. The models are for wall heat $\left(q_{f}, q_{g}\right)$ and mass $\left(\Gamma_{w}\right)$ flux quantities. The wall heat $\left(Q_{w f}, Q_{w g}\right)$ and phase change $\left(\Gamma_{w}\right)$ rates per unit volume are obtained by multiplying the flux quantities by the appropriate cell surface area and dividing by fluid cell volume.

Single-Phase Fluids (HCONV): Heat transfer to a single-phase vapor is assumed to occur when the cell void fraction is greater than 0.9999 and the wall temperature is above saturation. The single-phase heat transfer correlations in subroutine HCONV are also used for the liquid phase when the input parameter IBOIL is set equal to 0 . That is, when the IBOIL parameter is specified as 0 , the code does not test for CHF and will use the singlephase heat transfer correlation in subroutine HCONV to calculate the surface heat flux for any wall temperature. 
For heat transfer to either single-phase gas or liquid in turbulent flow, subroutine HCONV uses the Sieder-Tate (1936) correlation which includes a viscosity correction to account for heated wall effects. The correlation is

$$
h_{F C}=0.023\left(\frac{k}{D_{H}}\right) \operatorname{Re}^{0.8} \operatorname{Pr}^{1 / 3}\left(\frac{\mu}{\mu_{w}}\right)^{0.14}
$$

where

$$
\begin{aligned}
h_{\mathrm{FC}} & \equiv \text { forced convection heat transfer coefficient, } \mathrm{W} / \mathrm{m}^{2}{ }^{\circ} \mathrm{C} \\
\mathrm{k} & \equiv \text { fluid thermal conductivity, } \mathrm{W} / \mathrm{m}{ }^{\circ} \mathrm{C} \\
\mathrm{D}_{\mathrm{H}} & \equiv \text { hydraulic diameter of flow channel, } \mathrm{m} \\
\mathrm{Re} & \equiv \text { superficial Reynolds number }=\mathrm{G} \mathrm{D}_{H} / \mu \\
\mathrm{G} & \equiv \text { fluid (liquid or gas) mass flux, } \mathrm{kg} / \mathrm{m}^{2} \mathrm{~s} \\
\mathrm{Pr} & \equiv \text { Prandtl number }=\mathrm{c}_{\mathrm{p}} \mu / \mathrm{k} \\
\mathrm{C}_{\mathrm{P}} & \equiv \text { fluid specific heat, } \mathrm{J} / \mathrm{kg}{ }^{\circ} \mathrm{C} \\
\mu & \equiv \text { fluid viscosity at bulk temperature, } \mathrm{kg} / \mathrm{m} \mathrm{s} \\
\mu_{\mathrm{w}} & \equiv \text { fluid viscosity at wall temperature, } \mathrm{kg} / \mathrm{m} \mathrm{s}
\end{aligned}
$$

For single-phase laminar flow, the heat transfer coefficient is evaluated using (Rohsenow and Choi, 1961)

$$
h_{L}=4.0\left(\frac{k}{D_{H}}\right)
$$

In practice, the subroutine evaluates both equation (6.1) and equation (6.2) and takes the maximum value for the single-phase heat transfer coefficient. This procedure yields a continuous transition between the flow regimes.

Having obtained the heat transfer coefficient, the heat flux to either liquid or gas is then calculated from

$$
q=h\left(T_{w}-T\right)
$$

where

$$
\begin{aligned}
h & \equiv \max \left(h_{L}, h_{F C}\right) \\
T_{w} & \equiv \text { wall temperature, }{ }^{\circ} \mathrm{C} \\
T & \equiv \text { fluid (gas or liquid) temperature, }{ }^{\circ} \mathrm{C}
\end{aligned}
$$


In the single-phase liquid regime, the surface is assumed to be fully wetted and no vapor generation at the wail takes place.

Single-Phase Liquid or Two.Phase Fluid (SRLHTC): Correlations suitable for air-water downflow in ribbed annuli were developed using experimental data obtained from Rig B at SRS (Guerrero, 1990). Rig B consisted of a single annular channel (divided into four subchannels by non-conducting ribs) that was heated over the outer radial surface. The rig was constructed of stainless steel and had uniform axial and azimuthal power profiles. Experiments were conducted over a wide range of water flowrates and pressure boundary conditions. The data clearly divided into two groups according to void fraction; this was atuributed to a change in flow regime. The void fraction in Rig B for a particular set of operating conditions was estimated from FLOWTRAN-TF calculations. At calculated void fractions less than 0.75 a dispersed (bubbly, slug or churn-turbulent) flow regime was inferred while at higher void fractions the flow regime was assumed to be annular (separated). When the IBOL parameter is set to -1 , the following correlations derived from a statistical analysis of the Rig B data are used.

In the dispersed flow regime, $\alpha<0.75$, FLOWTRAN-TF uses the following slightly modified form of the Dittus-Boelter (1930) correlation for turbulent liquid heat transfer

$$
h_{\mathrm{FC}}=0.0217\left(\frac{k}{D_{\mathrm{H}}}\right) \operatorname{Re}^{0.8} \operatorname{Pr}^{0.4}
$$

with

$$
\operatorname{Re}=G_{\mathrm{f}} D_{\mathrm{H}} / \mu_{\mathrm{f}}(1-\alpha)
$$

As indicated above, phasic liquid velocity is used in calculating the Reynolds number and bulk liquid properties are used to evaluate physical properties. Correlation (6.4a) and the experimental data are shown in Fig. 6.4. The figure legend gives the range of data that the correlation is based on where the indicated pressure is the difference between inlet and outlet pressures. Figure 6.4 also shows $95 \%$ confidence bounds on the correlation, the correlation coefficient for the fit $\left(r^{2}=0.47\right)$, and the standard estimate of the error $\left(s_{e}=\right.$ 18.88). The standard estim 3 te of the error is defined by

$$
s_{e}=\sqrt{\frac{\sum_{i=1}^{n}\left(N u_{i}^{E x p}-N u_{i}^{C a l c}\right)^{2}}{n-2}}
$$

Figure 6.5 shows the dispersed regime data with experimental error bars added along with correlation (6.4a). The error bars on the data were calculated assuming a $1.2 \%$ error in the power measurement and a $2^{\circ} \mathrm{C}$ error in thermocouple readings. Incidentally, we note that the SRS data indicated that the viscosity correction used in the Sieder-Tate model did not improve the correlation.

In the annular flow regime, $\alpha>0.75$, the data were correlated with the equation 


$$
h_{\mathrm{FC}}=6.77 \times 10^{-5}\left(\frac{\mathrm{k}}{\mathrm{D}_{\mathrm{H}}}\right) \operatorname{Re}^{1.5} \mathrm{Pr}^{0.5}
$$

with

$$
\operatorname{Re}=\mathrm{G}_{\mathrm{f}} \mathrm{D}_{\mathrm{H}} / \mu_{\mathrm{f}}
$$

Equation (6.6a), which is based on an analogous expression for annular regime mass transfer (Treybal, 1980), uses the superficial liquid velocity to evaluate the Reynolds number since this is typically used for annular flow correlations. The correlation to the experimental data with corresponding 95\% confidence bounds is shown in Fig. 6.6. The SRS data indicated that the viscosity correction used in the Sieder-Tate model did not improve correlation (6.6a) either.

As in subroutine HCONV, the laminar model given by equation (6.2) is used as a lower bound on the heat transfer coefficient. Since we assume that the surface is wetted, all of the heat is transferred between the surface and the liquid phase.

We account for the presence of ribs on the metal surfaces by using a rib efficiency factor to augment the heat transfer coefficient on the surface where the rib is attached. The gaps between ribs on SRS assemblies and the opposite metal surfaces are quite small (approximately 30 mil diametrical gap). Therefore, water flow in the rib gap is restricted and we assume that the metal surfaces within the gap do not contribute to heat removal. That is, we assume that rib tip and the small surface area immediately across from a rib are adiabatic and heat transter from these surface areas is not included in our calculation.

Using the solution for a rectangular fin insulated on its tip (Holman, 1976), we define the function $\phi$ as

$$
\phi=r_{L} \sqrt{\frac{h_{F C}}{k_{w} r_{T}}}
$$

where

$$
\begin{aligned}
& k_{w} \equiv \text { thermal conductivity of wall, } W / \mathrm{m}^{2}{ }^{\circ} \mathrm{C} \\
& \mathrm{r}_{\mathrm{L}} \equiv \text { rib length, } \mathrm{m} \\
& \mathrm{rT}_{\mathrm{T}} \equiv \text { rib half thickness, } \mathrm{m}
\end{aligned}
$$

The fin efficiency is then given by

$$
\psi=\frac{\tanh (\phi)}{\phi}
$$

and an adjusted heat transfer coefficient is calculated from

$$
\tilde{h}_{\mathrm{FC}}=\mathrm{h}_{\mathrm{FC}}\left[1.0+\mathrm{P}_{\mathrm{rib}}\left(\psi \mathrm{r}_{\mathrm{L}}-\mathrm{r}_{\mathrm{T}}\right)\right]
$$


where

$$
\begin{aligned}
P_{\text {rib }} & \equiv \text { rib perimeter factor }=n_{\text {rib }} / P_{S} \\
n_{\text {rib }} & \equiv \text { number of ribs on solid cell surface } \\
P_{S} & \equiv \text { wetted perimeter of solid cell without ribs, } m
\end{aligned}
$$

Equation (6.9) accounts for rib efficiency and also decreases the effective heat transfer coefficient on surfaces opposite to the rib when $\psi$ equals zero. We account for the decreased heat transfer at the opposite surface by reducing the surface area available for heat transfer. That is, the effective heat transfer area on a surface opposite to a rib is determined by subtracting off the rib area from the true surface area.

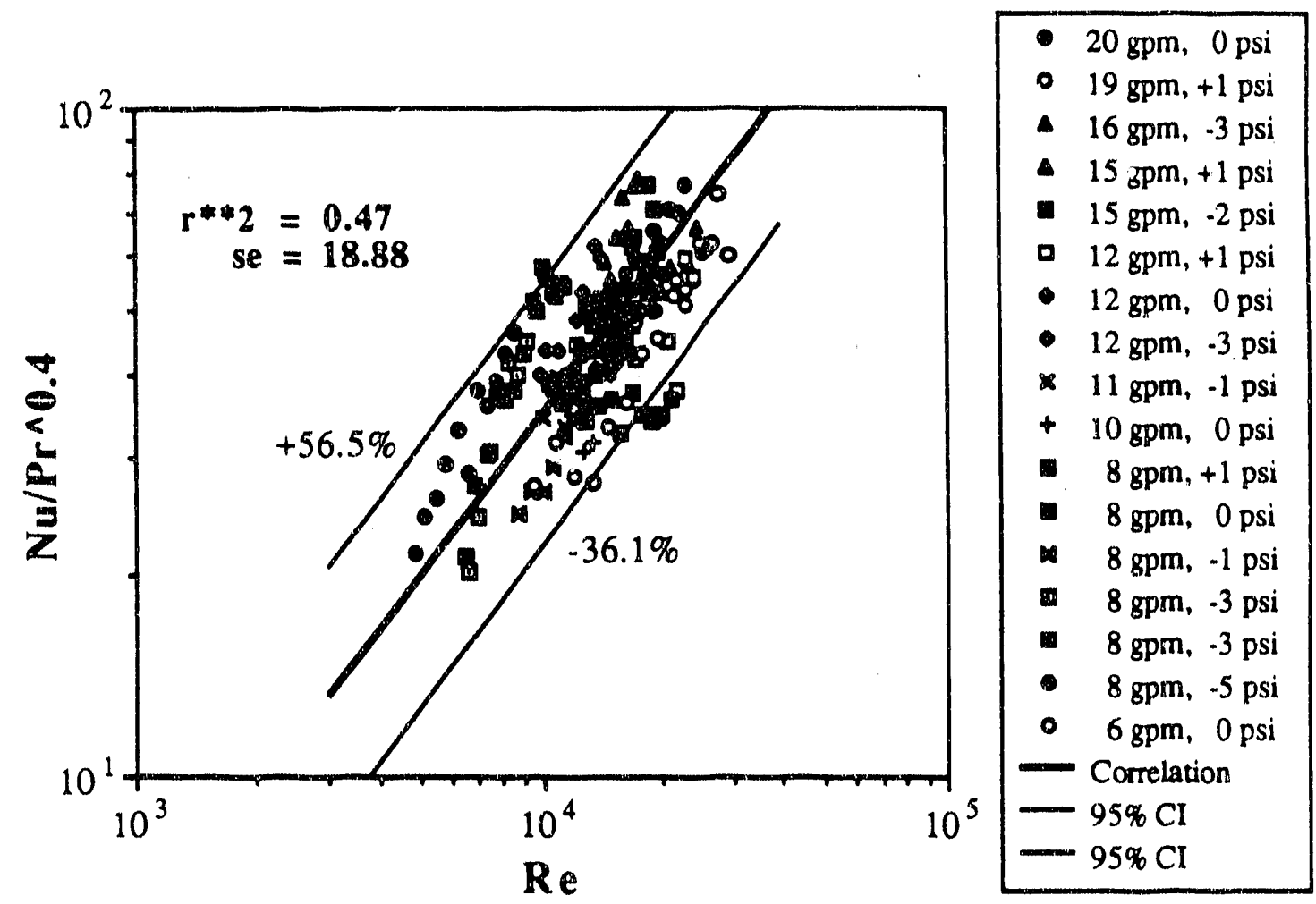

Figure 6.4 Correlation of Rig B dispersed regime heat transfer data $(\alpha<0.75)$ 


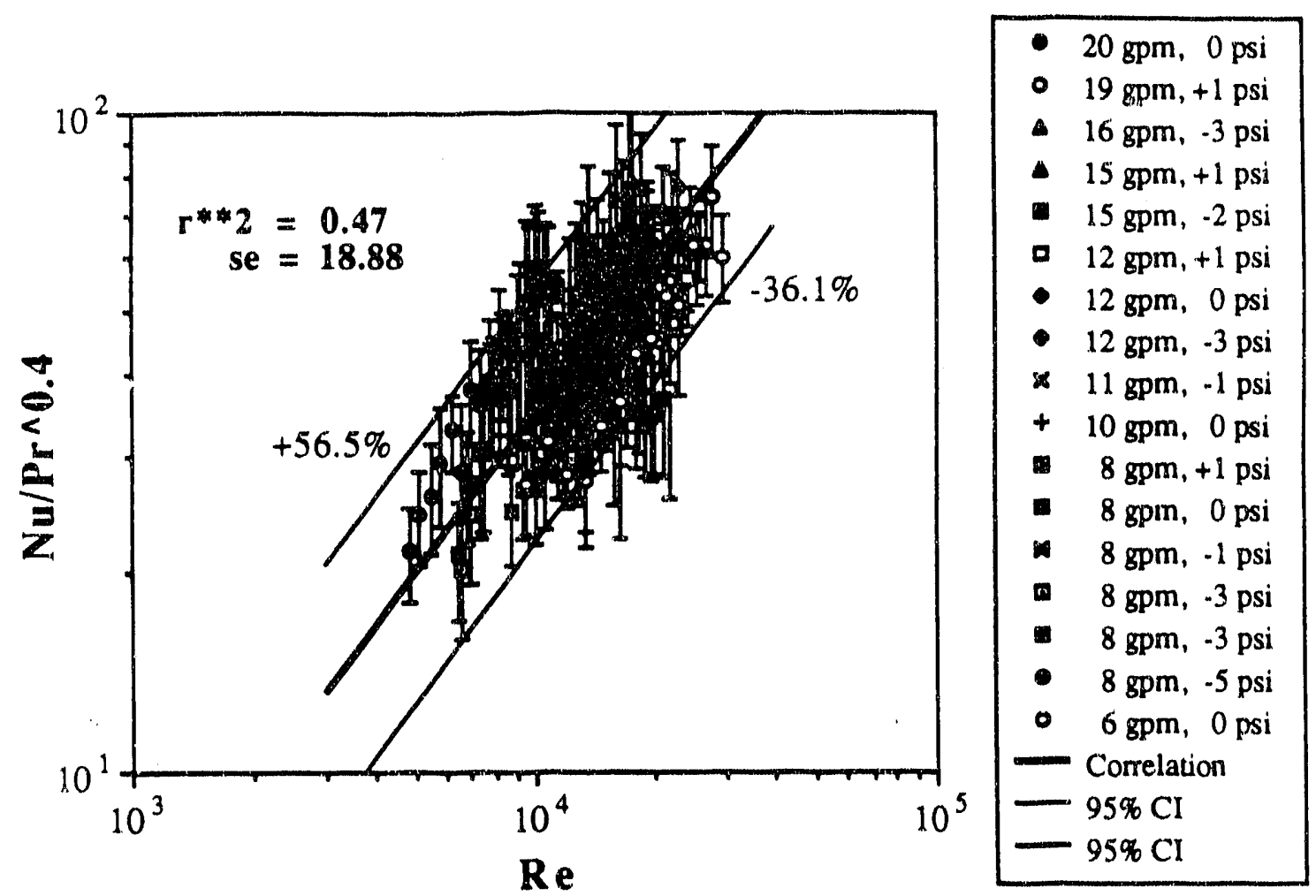

Figure 6.5 Rig B data with experimental error bars shown

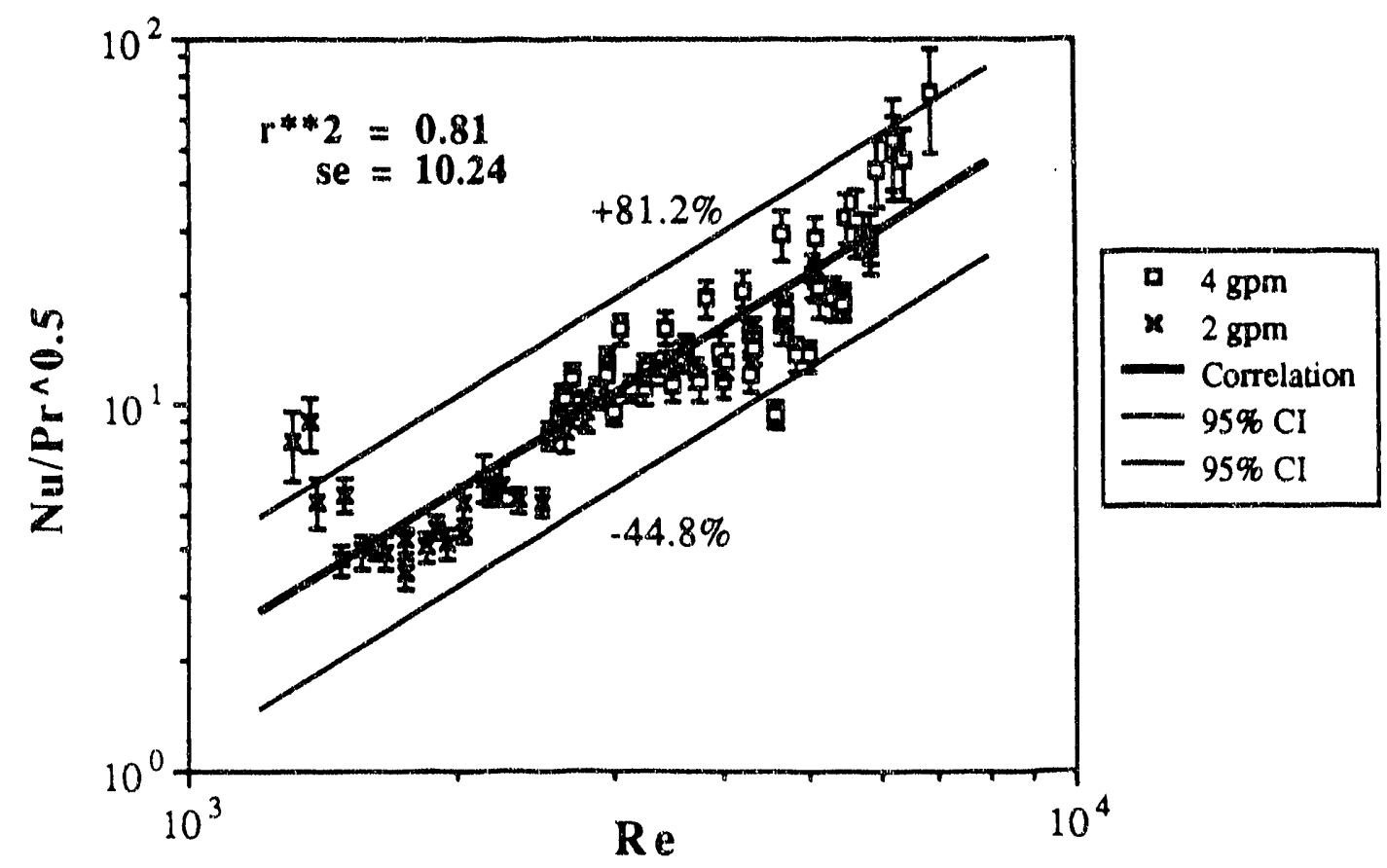

Figure 6.6 Correlation of Rig B annular regime heat transfer data $(\alpha>0.75)$ 
Vapor Condensation (CDENS): When two-phase mixtures are present, vapor condensation is accounted for by the interfacial heat and mass transfer calculations. However, when the fluid phase is entirely vapor $(\alpha>0.9999)$ and the wall temperature is below saturation, the vapor will condense on the wall. To calculate wall condensation heat transfer we adopt the method used by RELAP.

A heat transfer coefficient for condensation on a vertical plane surface with a stationary vapor phase (negligible interfacial shear) is calculated from (Collier, 1972)

$$
h_{\text {conl }}=1.1025 \mathrm{k}_{\mathrm{f}} \operatorname{Re}_{\mathrm{f}}^{-1 / 3}\left[\frac{\rho_{\mathrm{f}}\left(\rho_{\mathrm{f}}-\rho_{\mathrm{g}}\right) \mathrm{g}}{\mu_{\mathrm{f}}^{2}}\right]^{1 / 3}
$$

A correlation for condensation on a vertical tube with significant interfacial shear between the condensate and vapor is (Collier, 1972; Carpenter and Colburn, 1951)

$$
h_{\text {con } 2}=0.065 \frac{k_{f}}{\mu_{f}} \sqrt{\rho_{f} P_{r_{f}} \tau_{i}}
$$

where the term $\tau_{\mathrm{i}}$ in equation $(6.11)$ is defined by

$$
\tau_{i}=0.0792 \operatorname{Re}_{\mathrm{g}}^{-1 / 4}\left(\frac{\rho_{\mathrm{g}} \mathrm{V}_{\mathrm{g}}^{2}}{2}\right)
$$

In the above equations

$$
\begin{aligned}
\mathrm{k}_{\mathrm{f}} & \equiv \text { liquid thermal conductivity, } \mathrm{W} / \mathrm{m}^{\circ} \mathrm{C} \\
\rho_{\mathrm{f}} & \equiv \text { liquid density, } \mathrm{kg} / \mathrm{m}^{3} \\
\rho_{\mathrm{g}} & \equiv \text { gas density, } \mathrm{kg} / \mathrm{m}^{3} \\
\mu_{\mathrm{f}} & \equiv \text { liquid viscosity, } \mathrm{kg} / \mathrm{m} \mathrm{s} \\
\mathrm{g} & \equiv \text { gravitational acceleration, } 9.8066 \mathrm{~m} / \mathrm{s}^{2} \\
\mathrm{~V}_{\mathrm{g}} & \equiv \text { superficial gas velocity, } \mathrm{m} / \mathrm{s} \\
\operatorname{Pr}_{\mathrm{f}} & \equiv \text { Prandtl number for liquid phase }=\mathrm{c}_{\mathrm{pf}} \mu_{\mathrm{f}} / \mathrm{k}_{\mathrm{f}} \\
\operatorname{Re}_{\mathrm{f}} & \equiv \text { superficial liquid Reynolds number }=\mathrm{G}_{\mathrm{f}} D_{\mathrm{H}} / \mu_{\mathrm{f}} \\
\operatorname{Re}_{\mathrm{g}} & \equiv \text { superficial gas Reynolds number }=\mathrm{G}_{\mathrm{g}} \mathrm{D}_{\mathrm{H}} / \mu_{\mathrm{g}}
\end{aligned}
$$

The maximum of these two estimates of the condensation heat transfer coefficient is then used to calculate the wall heat flux in order to cover the range of vapor flow situations:

$$
h_{\text {con }}=\max \left(h_{\text {con } 1}, h_{\text {con } 2}\right)
$$




$$
q_{g}=h_{c o n}\left(T_{w}-T_{g}\right)
$$

The vapor condensation mass flux at the wall is calculated from

$$
\hat{\Gamma}_{w}=\frac{q_{g}}{h_{f g}+0.5\left[c_{p g}\left(T_{g}-T_{s a t}\right)\right]}
$$

where

$$
\begin{aligned}
\hat{\Gamma}_{\mathrm{w}} & \equiv \text { rate of vapor condensation per unit surface area, } \mathrm{kg} / \mathrm{s} \mathrm{m}^{2} \\
\mathrm{~h}_{\mathrm{fg}} & \equiv \text { latent heat of vaporization, } \mathrm{J} / \mathrm{kg} \\
\mathrm{c}_{\mathrm{pg}} & \equiv \text { gas specific heat, } \mathrm{J} / \mathrm{kg}{ }^{\circ} \mathrm{C} \\
\mathrm{T}_{\mathrm{g}} & \equiv \text { gas temperature, }{ }^{\circ} \mathrm{C} \\
\mathrm{T}_{\text {sat }} & \equiv \text { saturation temperature, }{ }^{\circ} \mathrm{C}
\end{aligned}
$$

The second term in the denominator of (6.14) accounts for the energy required to cool vapor at the bulk temperature $T_{g}$ to saturation temperature.

Boiling Heat Transfer - Mikic/Rohsenow Correlation (MIKIC): When the wall temperature exceeds the local saturation temperature but is less than the critical heat flux temperature and liquid is present, the fluid is in the boiling heat transfer regime. We have implemented two procedures to estimate the heat transfer to the liquid under boiling conditions in FLOWTRAN-TF. When IBOL $=1$, the code branches to subroutine MIKIC while any other value of the IBOIL input parameter causes the code to use subroutine CHEN. In this part of the report we describe the MIKIC boiling curve while in the following section the CHEN boiling curve is explained.

In subroutine MIKIC, the interpolation procedure suggested by Bergles and Rohsenow (1964) is used to construct a smooth curve for forced convection boiling. The boiling curve is approximated by the relationship

$$
q_{f}=\sqrt{q_{F C}^{2}+\left(q_{B}^{2}-q_{B i}^{2}\right)}
$$

where

$$
\begin{aligned}
\mathrm{q}_{\mathrm{FC}} & =\text { forced convection heat flux } \\
\mathrm{q}_{\mathrm{B}} & =\text { fully developed boiling heat flux } \\
\mathrm{q}_{\mathrm{B}} & =\text { fully developed boiling heat flux at point of incipient boiling (ONB) }
\end{aligned}
$$

For $\mathrm{qFC}_{\mathrm{FC}}\left(\mathrm{h}_{\mathrm{FC}}\right.$ ) we use the SRS correlations shown in equation (6.4a) and equation (6.6a) above. The Mikic and Rohsenow (1969) correlation 


$$
q_{B}=1.89 \times 10^{-14}\left[\frac{g^{4} h_{f g} k_{f}^{4} \rho_{f}^{17} c_{p f}^{19} \rho_{g}}{g_{c}^{4} \sigma^{9}\left(\varphi_{f}-\rho_{g}\right)^{5} T_{s a t}}\right]^{1 / 8}\left(T_{w}-T_{s a t}\right)^{3}=\dot{h}_{B}\left(T_{w}-T_{s a t}\right)^{3}
$$

is used to calculate the fully developed boiling heat flux where

$$
\begin{aligned}
\mathrm{k}_{\mathrm{f}} & \equiv \text { liquid thermal conductivity, } \mathrm{W} / \mathrm{m}^{\circ} \mathrm{C} \\
\mathrm{h}_{\mathrm{fg}} & \equiv \text { latent heat of vaporization, } \mathrm{J} / \mathrm{kg} \\
\rho_{\mathrm{f}} & \equiv \text { liquid density, } \mathrm{kg} / \mathrm{m}^{3} \\
\rho_{\mathrm{g}} & \equiv \text { gas density, } \mathrm{kg} / \mathrm{m}^{3} \\
\mathrm{c}_{\mathrm{pf}} & \equiv \text { liquid specific heat, } \mathrm{J} / \mathrm{kg}{ }^{\circ} \mathrm{C} \\
\mathrm{g} & \equiv \text { gravitational acceleration, } 9.8066 \mathrm{~m} / \mathrm{s}^{2} \\
\mathrm{~g}_{\mathrm{c}} & \equiv \text { conversion constant } \\
\sigma & \equiv \text { surface tension, } \mathrm{N} / \mathrm{m}
\end{aligned}
$$

All of the fluid properties used in equation (6.16) are evaluated at the local saturation temperature. The heat flux at the point of incipient boiling is calculated from equation (6.16) using the temperature difference at the point of incipient boiling $\left(T_{w}-T_{s a t}\right)_{i}$ :

$$
\mathrm{q}_{\mathrm{Bi}}=\dot{\mathrm{h}}_{\mathrm{B}}\left(\Delta \mathrm{T}_{\mathrm{ONB}}\right)^{3}
$$

The temperature difference at ONB (onset of nucleate boiling) is estimated using the procedure developed by Bjorge and Rohsenow (1982) modified to account for the presence noncondensable gases. A detailed description of this procedure is given by Aleman et. al. (1989). In summary, $\Delta T_{O N B}$ is calculated from the expression

$$
\Delta \mathrm{T}_{\mathrm{ONB}}= \begin{cases}\frac{\Delta \mathrm{T}_{\mathrm{sub}} N \mathrm{u}_{\mathrm{cav}}+\frac{1}{2 N \mathrm{Nu}_{\mathrm{cav}} \Sigma}-\gamma}{1-N \mathrm{u}_{\mathrm{cav}}}, & \mathrm{h}_{\mathrm{FC}}<\mathrm{h}_{\mathrm{tan}} \\ \frac{1}{N u_{\mathrm{tan}} \Sigma}-\gamma, & \mathrm{h}_{\mathrm{FC}} \geq \mathrm{h}_{\mathrm{tan}}\end{cases}
$$

In equation (6.18), $\mathrm{Nu}_{\mathrm{cav}}$ is the nucleation site cavity Nusselt number defined to be

$$
\mathrm{Nu}_{\mathrm{cav}}=\frac{\mathrm{h}_{\mathrm{FC}} \mathrm{r}_{\max }}{\mathrm{k}_{\mathrm{w}}}
$$

and $\mathrm{Nu}_{\tan }$ is the Nusselt number at the point of bubble tangency defined by the expression 


$$
N u_{\text {tan }}=\frac{h_{\tan } r_{\max }}{k_{w}}=\frac{1}{1+\sqrt{\tau}}
$$

where the parameter $\tau$ is given by

$$
\tau=\max \left\{0,1+2\left(\Delta \mathrm{T}_{\text {sub }}-\gamma \Sigma\right)\right.
$$

Equation (6.20) is used to calculate the heat transfer coefficient at the point of bubble tangency $h_{\text {tan }}$. In defining the Nusselt numbers, we have used the parameters:

$$
\begin{aligned}
k_{w} & =\text { thermal conductivity of wall, } \mathrm{W} / \mathrm{m}^{\circ} \mathrm{C} \\
r_{\max } & \equiv \begin{array}{l}
\mathrm{m}_{\mathrm{m}} \text { wximum nucleation site cavity radius, } \mathrm{m} \\
\left(\mathrm{r}_{\max } \text { is taken to be } 1 \mu \mathrm{m}\right)
\end{array} \\
\Delta \mathrm{T}_{\text {sub }} & =\mathrm{T}_{\text {sat }}-\mathrm{T}_{\mathrm{f}}
\end{aligned}
$$

The other terms in equations (6.18) and (6.21) are defined by the relationships

$$
\Sigma=\left(\frac{k_{w}}{4 T_{s a t} h_{F C}}\right)\left(\frac{h_{f g}}{\sigma v_{f g}}\right)_{s a t}
$$

and

$$
\gamma=p_{8} T_{s a t}\left(\frac{v_{f_{g}}}{h_{f_{g}}}\right)_{s a l}
$$

where

$$
\begin{aligned}
& v_{f_{8}} \text { = difference in specific volumes of saturated liquid and saturated gas, } \mathrm{m}^{3} / \mathrm{kg} \\
& \mathrm{p}_{8}=\text { partial pressure of non-condensible gas, } \mathrm{Pa}
\end{aligned}
$$

The $\gamma$ term in the above equations accounts for the presence of non-condensible gas. The partial pressure of the non-condensible component in the gas phase is calculated from an application of Henry's law

$$
\mathrm{P}_{\mathrm{g}}=\mathrm{x}_{\mathrm{c}} \mathrm{H}_{\mathrm{sat}}
$$

where $\mathrm{H}_{\mathrm{sat}}$ is the Henry's law constant at the local saturation temperature. The liquid concentration of the dissolved gas $\left(x_{c}\right)$ is calculated from

$$
x_{c}=y_{c}\left(\frac{p_{s a t}-P}{p_{s a t}-H_{T}}\right)
$$

where

$$
y_{c} \equiv \text { gas phase molar concentration of non-condensible component }
$$




$$
\begin{aligned}
\mathrm{p}_{\text {sat }} & \equiv \text { vapor pressure of pure liquid at } \mathrm{T}_{\mathrm{f}}, \mathrm{Pa} \\
\mathrm{P} & \equiv \text { total local pressure, } \mathrm{Pa} \\
\mathrm{H}_{\mathrm{T}} & \equiv \text { Henry's law constant at local temperature }
\end{aligned}
$$

To calculate the vapor generation rate, we assume that the nucleate boiling heat flux, given by $\left(\mathrm{q}_{\mathrm{f}}-\mathrm{q}_{\mathrm{FC}}\right)$, is available for vapor generation. The amount of vapor generated at the wall is then calculated as

$$
\hat{\Gamma}_{w}=\frac{q_{f}-q_{F C}}{h_{f g}}
$$

Boiling Heat Transfer - Chen Correlation (CHEN): In subroutine CHEN, we use the Chen (1963) correlation for both subcooled and saturated nucleate boiling to calculate a heat flux to the liquid phase. The Chen correlation is used by all of the standard codes mentioned previously in a similar fashion. This correlation assumes a superposition of a forced-convection heat transfer correlation and a pool boiling correlation so that the total heat transfer coefficient and corresponding heat flux are given by

$$
h_{\mathrm{CHEN}}=h_{\mathrm{FC}}+h_{\mathrm{NB}}
$$

and

$$
q_{f}=h_{F C}\left(T_{w}-T_{f}\right)+h_{N B}\left(T_{w}-T_{s a s}\right)
$$

The forced-convection heat transfer coefficient is calculated from a modified Dittus-Boelter correlation

$$
h_{F C}=0.023 F\left(\frac{k_{f}}{D_{H}}\right) \operatorname{Re}^{0.8} \operatorname{Pr}^{0.4}
$$

while the nucleate boiling heat transfer coefficient is obtained using the correlation

$$
h_{N B}=\frac{0.00122 S}{P_{r}^{0.05}}\left[\frac{k_{f} \rho_{f}}{h_{f g} \mu_{f} \rho_{g}}\right]^{0.24}\left[\frac{k_{f} c_{p f} \sqrt{g_{c} \rho_{f}}}{\sigma}\right]^{0.5}\left(T_{w}-T_{s a t}\right)^{0.24}\left(P_{w}-P\right)^{0.75}
$$

which can be rearranged into the equivalent form

$$
h_{N B}=0.00122 \mathrm{~S}\left(\frac{k_{f}}{D_{\mathrm{H}}}\right) W e^{0.5} \operatorname{Re}^{0.5} \operatorname{Pr}^{0.21}\left[\frac{\rho_{\mathrm{f}} c_{p f}\left(T_{\mathrm{w}}-T_{\text {sat }}\right)}{\rho_{\mathrm{g}} h_{\mathrm{fg}}}\right]^{0.24}\left(\frac{\mathrm{P}_{\mathrm{w}}-\mathrm{P}}{\rho_{\mathrm{f}} \mathrm{V}_{\mathrm{f}}^{2}}\right)^{0.75}
$$

In the above equations

$$
F \equiv \text { Reynolds number factor }
$$




$$
\begin{aligned}
S & \equiv \text { suppression factor } \\
k_{f} & \equiv \text { liquid thermal conductivity, } \mathrm{W} / \mathrm{m}^{\circ} \mathrm{C} \\
h_{\mathrm{fg}} & \equiv \text { latent heat of vaporization, } \mathrm{J} / \mathrm{kg} \\
\rho_{\mathrm{f}} & \equiv \text { liquid density, } \mathrm{kg} / \mathrm{m}^{3} \\
\rho_{\mathrm{g}} & \equiv \text { gas density, } \mathrm{kg} / \mathrm{m}^{3} \\
\mu_{\mathrm{f}} & \equiv \text { liquid viscosity, } \mathrm{kg} / \mathrm{m} \mathrm{s} \\
c_{\mathrm{pf}} & \equiv \text { liquid specific heat, } \mathrm{J} / \mathrm{kg}{ }^{\circ} \mathrm{C} \\
\mathrm{g}_{\mathrm{c}} & \equiv \text { gravitational conversion constant } \\
\sigma & \equiv \text { surface tension, } \mathrm{N} / \mathrm{m} \\
\mathrm{P}_{\mathrm{w}} & \equiv \text { saturation pressure corresponding to } \mathrm{T}_{\mathrm{w}}, \mathrm{Pa} \\
\mathrm{P} & \equiv \text { system pressure, } \mathrm{Pa} \\
W_{e} & \equiv \text { Weber number, }\left(\mathrm{V}_{\mathrm{f}}^{2} \rho_{\mathrm{f}} \mathrm{D}_{\mathrm{H}}\right) / \sigma \\
\mathrm{V}_{\mathrm{f}} & \equiv \text { superficial liquid velocity, } \mathrm{m} / \mathrm{s}
\end{aligned}
$$

All liquid properties are evaluated at the saturation temperature. Equation (6.29) is identical to the usual Dittus-Boelter (1930) correlation except that a Reynolds number factor $F$ is included to account for two-phase flow effects. The parameters $F$ and $S$ are in turn obtained using the relationships shown below due to Collier (1981).

We first calculate an inverse Martinelli factor $\mathrm{X}^{-1}$ (Collier, 1972; Lockhart and Martinelli, 1949) as

$$
X_{t t}^{-1}=\left(\frac{x}{1-x}\right)^{0.9}\left(\frac{\rho_{f}}{\rho_{g}}\right)^{0.5}\left(\frac{\mu_{g}}{\mu_{f}}\right)^{0.1}
$$

where

$$
\begin{aligned}
x & \equiv \text { fluid quality } \\
\mu_{8} & \equiv \text { gas viscosity, } \mathrm{kg} / \mathrm{m} \mathrm{s}
\end{aligned}
$$

The Reynolds number factor used in equation (6.29) is then given by the relationship (Collier, 1981)

$$
F= \begin{cases}1.0 & , X_{l l}^{-1} \leq 0.1 \\ 2.34\left(X_{l t}^{-1}+0.213\right)^{0.736} & , X_{t l}^{-1}>0.1\end{cases}
$$


We next calculate an effective two-phase Reynolds number as

$$
\operatorname{Re}_{\mathrm{TP}}=1.0 \times 10^{-4} \operatorname{Re} \mathrm{F}^{1.25}
$$

where $\mathrm{Re}$ is the superficial liquid phase Reynolds number evaluated using saturation properties. The two-phase Reynolds number is used to calculate the suppression factor $S$ from

$$
S= \begin{cases}1.0 /\left[1.0+0.12\left(\operatorname{Re}_{\mathrm{TP}}\right)^{1.14}\right] & , \operatorname{Re}_{\mathrm{TP}}<32.5 \\ 1.0 /\left[1.0+0.42\left(\operatorname{Re}_{\mathrm{TP}}\right)^{0.78}\right] & , 32.5 \leq \operatorname{Re} e_{\mathrm{TP}}<50.9 \\ 0.1 & , \operatorname{Re}_{\mathrm{TP}} \geq 50.9\end{cases}
$$

Following COBRA/TRAC (Thurgood, 1983), we have used an upper limit of 50.9 for $\mathrm{Re}_{\mathrm{TP}}$ rather than the original value of 70.0 used in most other codes. As noted in the COBRA/TRAC manual, the modified Reynolds number limit is used to make the correlation continuous.

The Chen correlation was developed to describe saturated boiling but may also be employed for subcooled nucleate boiling with minor modification (Thurgood, 1983). In the subcooled regime, the suppression factor is computed from equation (6.34) using the single-phase liquid Reynolds number to evaluate $R e_{T P}$ from equation (6.33) with the Reynolds number factor $F$ set equal to unity. Fluid properties in these correlations and in equation (6.29) are evaluated at the subcooled liquid temperature. Equations (6.29) and $(6.30)$ are then used as before.

To calculate the vapor generation rate, we assume that the nucleate boiling heat flux, given by the term

$$
q_{N B}=h_{N B}\left(T_{w}-T_{2 a B}\right)
$$

is available for vapor generation. Rouhani and Axelsson (1970) suggest that a fraction of this energy is used to heat liquid entering the saturated thermal boundary layer. The remaining fraction available for vapor generation is given by

$$
\varepsilon_{\Gamma}=\frac{h_{f_{g}}}{h_{f_{g}}+\left(\rho_{f} / \rho_{g}\right)\left(h_{f}-h_{1}\right)}
$$

where $h_{f}$ is the saturated liquid enthalpy and $h_{l}$ is the liquid enthalpy at bulk fluid conditions. The amount of vapor generated at the wall is then calculated as

$$
\hat{\Gamma}_{w}=\frac{\varepsilon_{\Gamma} h_{\mathrm{NB}}\left(T_{w}-T_{\text {sat }}\right)}{h_{f_{B}}}
$$

Film Boiling (FILMB): When the wall temperature exceeds the minimurn stable film boiling temperature, the fluid enters the film boiling regime. In this regime, we follow the TRAC heat ransfer formulation and calculate separate heat fluxes to the liquid and to the gas phases. When film boiling takes place with relatively low void fractions, we assume 
that the liquid is in an inverted annular flow regime and that heat transfer to the liquid phase occurs by convection through a thin vapor film and by radiation. For convective heat transfer to the liquid in inverted annular flow, we use the Bromley-Pomeranz (Pomeranz, 1964) correlation given by

$$
h_{B P}=0.620\left(\frac{D_{H}}{\lambda_{c}}\right)^{0.172}\left[\frac{k_{g}^{3} \rho_{g}\left(\rho_{f}-\rho_{g}\right) h_{f g} g}{D_{H} \mu_{g}\left(T_{w}-T_{s g t}\right)}\right]^{0.25}
$$

where

$$
\lambda_{c}=2 \pi \sqrt{\frac{\sigma}{g\left(\rho_{\mathrm{f}}-\rho_{\mathrm{g}}\right)}}
$$

and a modified heat of vaporization is defined as

$$
\hat{h}_{f g}=h_{f g}+0.4 c_{p g}\left(T_{w}-T_{f}\right)
$$

At higher void fractions, the liquid will be dispersed as droplets. The model assumes that some liquid will still contact the surface through drop impingement resulting in heat transfer directly to the liquid phase. In this flow regime, subroutine FILMB uses the ForslundRohsenow (1968) correlation for liquid heat transfer. This correlation is

$$
h_{F R}=0.2552(1-\alpha)^{2 / 3}\left[\frac{k_{g}^{3} \rho_{g}\left(\rho_{f}-\rho_{g}\right) h_{f g} g}{D_{D} H_{g}\left(T_{w}-T_{s g l}\right)}\right]^{0.25}
$$

In equation (6.41) $D_{D}$ is the droplet diameter which is estimated from

$$
D_{D}=\frac{4 \sigma}{\rho_{8}\left(u_{g}-u_{f}\right)^{2}}
$$

with the limits that $1.0 \times 10^{-4}<\mathrm{D}_{\mathrm{D}}<3.0 \times 10^{-3} \mathrm{~m}$. To interpolate between the inverted annular flow regime and the dispersed liquid droplet flow regime, we use the parameter $\zeta$ defined by (Liles et al., 1988)

$$
\zeta=\left\{\begin{array}{lr}
0 & \alpha<\alpha_{I A} \\
\frac{\alpha-\alpha_{I A}}{\alpha_{D I S}-\alpha_{I A}} & \alpha_{I A} \leq \alpha \leq \alpha_{\text {DIS }} \\
1 & \alpha>\alpha_{\text {DIS }}
\end{array}\right.
$$

where

$$
\begin{aligned}
\alpha_{I A} & \equiv \text { Void fraction limit for inverted annular flow }=0.5 \\
\alpha_{D I S} & \equiv \text { Void fraction for fully dispersed flow }=0.75
\end{aligned}
$$


For void fractions less than 0.5 we assume that the flow is entirely inverted annular and for void fractions greater than 0.75 we assume that the liquid flow is entirely in the form of dispersed droplets.

For heat transfer to the gas phase, we use the Dougall-Rohsenow (1963) correlation which is simply an application of the Dittus-Boelter correlation using gas properties and a mixture velocity in the Reynolds number. The correlation is

$$
\begin{gathered}
h_{D R}=0.023\left(\frac{k_{f}}{D_{H}}\right) R \theta_{T P}^{0.8} P_{g}^{0.4} \\
R_{\text {TP }}=\frac{D_{H} u_{\text {mix }} P_{g}}{\mu_{g}}
\end{gathered}
$$

with

$$
u_{\operatorname{mix}}=\alpha\left|u_{g}\right|+(1-\alpha)\left|u_{f}\right|
$$

where $\alpha$ is the void fraction and $u_{g}$ and $u_{f}$ are the phasic gas and liquid velocities, respectively. In this high temperature boiling regime, we also inciuds contributions to the gas and liquid phase heat fluxes from radiation heat transfer. Assuming a surface view factor of unity and a surface emissivity of unity, the radiative heat fluxes to each phase are given by

$$
\mathrm{q}_{\mathrm{f}}^{\mathrm{red}}=\varepsilon\left(\mathrm{T}_{\mathrm{w}}^{A}-\mathrm{T}_{\mathrm{sat}}^{4}\right)
$$

and

$$
q_{g}^{r a d}=\varepsilon\left(T_{w}^{4}-T_{g}^{4}\right)
$$

where $\varepsilon$ is Boltzman's constant.

The contributions to the heat fluxes to the gas and liquid are then summed and weighted by their respective volume fractions to obtain total film boiling heat fluxes as

$$
\begin{gathered}
\mathrm{q}_{\mathrm{f}}=(1-\alpha)\left[\left(1-\zeta h_{\mathrm{BP}}\left(\mathrm{T}_{\mathrm{w}}-\mathrm{T}_{\mathrm{sat}}\right)+\zeta \mathrm{h}_{\mathrm{FR}}\left(\mathrm{T}_{\mathrm{w}}-\mathrm{T}_{\mathrm{sat}}\right)+\mathrm{q}_{\mathrm{f}}^{\mathrm{rad}}\right]\right. \\
\mathrm{q}_{\mathrm{g}}=\alpha\left[\mathrm{h}_{\mathrm{DR}}\left(\mathrm{T}_{\mathrm{w}}-\mathrm{T}_{\mathrm{g}}\right)+\mathrm{q}_{\mathrm{g}}^{\mathrm{rad}}\right]
\end{gathered}
$$

Transition Boiling (FILMB): Transition boiling takes place when the surface temperature is greater than the critical heat flux remperature but below the minimum stable film temperature. In this boiling regime, the FLOWTRAN-TF formulation is similar to the TRAC scheme (Liles, 1988) and interpolates a surface heat flux between the critical heat flux and the value at the minirnum stable film temperature. That is, in the transition regime we calculate a heat flux using 


$$
\mathrm{q}_{\mathrm{f}}=(1-\delta) \mathrm{q}_{\mathrm{f}}^{\mathrm{MSFB}}+\delta \mathrm{q}_{\mathrm{CHF}}
$$

and

$$
q_{B}=(1-\delta) q_{g}^{M S F B}
$$

The interpolation parameter $\delta$, which represents the fraction of the surface that is wetted, is given by the relationship

$$
\delta=1-\xi^{2}(3-2 \xi)
$$

where

$$
\xi=\frac{T_{w}-T_{C H F}}{T_{M S F B}-T_{C H F}}
$$

The functional form assumed in equation (6.53) defines a smooth cubic polynomial that interpolates between the CHF heat fluxes ( $\mathrm{q}_{\mathrm{CHF}}$ for the liquid and zero for the gas) and the heat fluxes at the minimum stable film temperature. The interpolating curve has a zero slope at both end points.

Heat fluxes to the liquid and gas at the minimum stable film boiling temperature are calculated from the film boiling correlations given in equations $(6.38)$ through (6.50) using the minimum stable film temperature $\left(T_{M S F B}\right.$ ) in place of $T_{w}$. To determine $T_{M S F B}$. FLOWTRAN-TF uses the empirical relationship developed for water by Groeneveld and Stewart (1983)

$$
\mathrm{T}_{\text {MSFB }}=284.7+\left(4.41 \times 10^{-5}-3.72 \times 10^{-12} \mathrm{P}\right) \mathrm{P}-\frac{1.0 \times 10^{4} \times}{\left(2.82+1.22 \times 10^{-6} \mathrm{P}\right)}
$$

where

$$
\begin{aligned}
\mathrm{T}_{\text {MSFB }} & \equiv \text { minimum stable film boiling temperature, }{ }^{\circ} \mathrm{C} \\
\mathrm{P} & \equiv \text { pressure, } \mathrm{Pa} \\
\mathrm{x} & \equiv \text { quality }
\end{aligned}
$$

This expression is applicable at the lower pressures of interest with SRS assemblies. In practice, the corrections to the leading term in equation (6.55) are small and to a good approximation, we are using $\mathrm{T}_{\mathrm{MSFB}}=285^{\circ} \mathrm{C}$.

Critical Heat Flux and Critical Heat Flux Temperature (CHF): If the wall temperature is greater than the saturation temperature, subroutine CHF is called to calc "ate the critical heat flux temperature and heat flux. All of the standard codes listed above use some form of the Biasi correlation to determine the critical heat flux. The Biasi correlation was develop 1 or commercial nuclear reactor applications. The correlation includes both upflow and dow. Tow conditions but the database is restricted to uniformly heated test 
sections and high pressures. THER MIT supplements this correlation with two others to increase the range of applicability. FLOWTRAN-FI also contains correlations derived from SRS data that may be more directly applicable to aluminum cladded surfaces near atmospheric pressure. We have provided the user option of selecting the Biasi correlation or the SRS correlation. Neither correlation is verified for two-component air-water systems.

The Biasi correlation uses three separate; calculations of the critical heat flux and selects the final value depending on the mass flux.. For high mass fluxes $\left(G>300 \mathrm{~kg} / \mathrm{m}^{2}-\mathrm{s}\right)$, a low quality heat flux is calculated from

$$
q_{c r i t}=\frac{1.883 \times 10^{7}}{D_{H}^{n}} \cdot G^{-1 / 6}\left[F(P) G^{-1 / 6}-X e\right]
$$

and a high quality heat flux is calculated from

$$
q_{c r i t}=\frac{3.78 \times 10^{7}}{D_{H}^{n}} C_{i j}^{-0.6} H(P)[1.0-X e]
$$

The maximum value of the two determinations of $q_{c r i t}$ is then used for $q_{C H F}$. In applying equation (6.56), the pressure function $F(P)$ is given by

$$
F(P)=0.7249+0.099 P \mathrm{e}^{-0.032 P}
$$

Similarly, in applying equation (6.57), the comesponding pressure function $H(P)$ is given by

$$
H(P)=-1.159+0.149 P e^{-0.019 P}+\frac{8.99 P}{\left(10+P^{2}\right)}
$$

In both equations (6.56) and (6.57), Xe is the equilibrium quality and the exponent on the hydraulic diameter $(\mathrm{n})$ is chosen according to

$$
n= \begin{cases}0.4 & , D_{H} \geq 0.01 \mathrm{~m} \\ 0.6 & , D_{H}<0.01 \mathrm{~m}\end{cases}
$$

In evaluating equations (6.56) through (6.59), the mass flux $G$ is in units of $\mathrm{g} / \mathrm{cm}^{2}-\mathrm{s}$, the pressure $P$ is in bars, and the hydraulic diameter is in centimeters. We note that at pressures near one atmosphere (one bar), the function $H(P)$ becomes negative. Therefore, when the Biasi CHF correlation is selected for SRS assemblies, equation (6.56) is actually being used to calculate the critical heat flux.

As a user option, when the mass flux through the flow channel is greater than $300 \mathrm{~kg} / \mathrm{m}^{2}-\mathrm{s}$, the critical heat flux can alternatively be calculated using the correlation developed at SRL (Hodges and Knoebel, 1973). This correlation is based on data taken with light water in a 
narrow rectangular channel having an aluminum surface. The correlation is presented in two parts:

$$
\left.q_{C H F}=5.264 \times 10^{5}(1.0+0.476 V) \times 1.0+0.031\left(T_{\text {sat }}-T_{f}\right)\right]
$$

and

$$
q_{C H F}=2.021 \times 10^{6}(1.0+0.169 V)
$$

where

$$
\begin{aligned}
\text { qCHF } & \equiv \text { critical heat flux, } \mathrm{W} / \mathrm{m}^{2}{ }^{\circ} \mathrm{C} \\
\mathrm{T}_{\text {sat }} & \equiv \text { saturation temperature, }{ }^{\circ} \mathrm{C} \\
\mathrm{T}_{\mathrm{f}} & \equiv \text { fluid temperature, }{ }^{\circ} \mathrm{C} \\
\mathrm{V} & \equiv \text { superficial liquid velocity, } \mathrm{m} / \mathrm{s}
\end{aligned}
$$

Equation (6.61) was found to better represent the data for liquid subcooling above $20^{\circ} \mathrm{C}$ while equation (6.62) applies at lower subcooling. As coded in FLOWTRAN-TF, we evaluate both expressions and take the maximum value as an estimate of the critical heat flux. This procedure transitions from the first equation to the second as the liquid subcooling decreases.

At liquid mass fluxes less than $200 \mathrm{~kg} / \mathrm{m}^{2}-\mathrm{s}$, Griffith's modification (Bjornard and Griffith, 1977 ) of the Zuber pool boiling correlation (Zuber et al., 1961) is used to calculate the critical heat flux:

$$
q_{p o o l}=\frac{0.9 \pi}{24}(1.0-\alpha) h_{f g} p_{g}^{0.5}\left[g_{c} g \sigma\left(p_{f}-p_{g}\right)\right]^{0.25}
$$

We note that this correlation (also employed by COBRA/TRAC) predicts a critioal heat flux proportional to $(1.0-\alpha)$. Therefore, the critical heat flux decreases as the void fraction
increases.

At mass fluxes between 200 and $300 \mathrm{~kg} / \mathrm{m}^{2}-\mathrm{s}$, a linear interpolation between the Biasi or SRL correlation and pool boiling correlation is used to estimate the critical heat flux.

Finally, knowing $q_{C H F}$, we need to determine the wall temperature when the critical heat flux is reached ( $\left.\mathrm{T}_{\mathrm{CHF}}\right)$. This is found by solving for the temperature at which the Chen or Mikic-Rohsenow correlations yield a heat flux equal to $\mathrm{q}_{\mathrm{CHF}}$. The Chen boiling correlations are based on assuming a nucleate boiling and a forced convection contribution to the overall heat flux. Using equations $(6.29)$ and $(6.30)$ to calculate heat transfer coefficients and replacing $T_{w}$ with $T_{C H F}$ yields the expression

$$
\mathrm{q}_{C H F}=h_{L N B}\left(T_{C H F}-T_{f}\right)^{1.24}\left(P_{w}-P\right)^{0.75}+h_{L F C}\left(T_{C H F}-T_{f}\right)
$$

for the total heat flux. In equation (6.64), $h_{L N B}$ and $h_{L F C}$ are the constant portions of the heat transfer coefficients. Since $P_{w}$ will depend upon $T_{C H F}$, the pressure dependence is left 
explicit in equation (6.64). Equation (6.64) is solved using a Newton iteration scheme until the critical heat flux temperature is determined within $0.1^{\circ} \mathrm{C}$. The critical heat flux temperature is restricted to be greater than the local saturation temperature and less than the critical temperature for water $\left(647.14^{\circ} \mathrm{K}\right)$. A similar procedure again involving a Newton iteration is used with the Mikic-Roshenow correlation to determine $\mathrm{T}_{\mathrm{CHF}}$. This completes determination of all points along the boilling curve.

\section{Wall Drag}

The mixture or total wall drag in each coordinate direction (axial or azimuthal) is constructed by summing phasic contributions. For example, the axial mixture drag is defined by

$$
F_{w}^{z}=F_{w f}^{z}+F_{w g}^{z} *
$$

The mixture drag is repartitioned in the Interfacial Drag section into the phasic components $F_{w f}^{z}$ and $F_{v / g}^{z}$ appearing in the momentum balances given by equations (5.5) and (5.4). The phasic components $F_{w f}^{z}$ and $F_{w g}^{z}$, which actually involve both wall and interfacial drag, are not the same as the components $F_{w f}^{z}$ and $F_{w g}^{z}$, respectively, shown above. In the remainder of this section, attention is restricted to defining the phasic contributions to the total wall drag, $F_{w f}^{z}$ and $F_{w g}^{z}$.

The phasic wall drag functional form is largely based on the COBRATRAC formulation (Thurgoond et al., 1983) in which the wall drag force per unit volume on each phase is modeled as the sum of friction and form components in terms of phasic velocity squared. For the axial direction, the liquid and gas models are

$$
\begin{aligned}
& F_{w f}^{z}=\frac{1}{2}\left[\frac{\theta \Phi^{z} f_{f}^{z}}{D_{h}^{z}}+\frac{(1-\alpha) K^{z}}{\Delta z}\right] \rho_{f}\left|u_{f}\right| u_{f} \\
& F_{w g}^{z}=\frac{1}{2}\left[\frac{(1-\theta) \Phi^{z} f_{g}^{z}}{D_{h}^{z}}+\frac{\alpha K^{z}}{\Delta z}\right] \rho_{g}\left|u_{g}\right| u_{g}
\end{aligned}
$$

where

$$
\begin{aligned}
z & \equiv \text { axial coordinate } \\
u & \equiv \text { phasic velocity } \\
\theta & \equiv \text { wetted wall parameter } \\
\Phi & \equiv L / D \text { correction factor } \\
f & \equiv \text { friction factor } \\
D_{h} & \equiv \text { hydraulic diameter } \\
K & \equiv \text { form loss coefficient }
\end{aligned}
$$




$$
\begin{aligned}
\Delta x & \equiv \text { momentum cell length in axial direction } \\
F_{w k}^{z} & =\text { actual wall drag force on } k \text { phase per unit volume }
\end{aligned}
$$

Note that the correct sign is obtained by actually computing the velocity square term as the absolute value of velocity times velocity. The wetted wall parameter, $\theta$, is defined to be the fraction of the wall in contact with the liquid phase. The heat transfer regime defines this parameter. For pre-CHF conditions $\theta=1$ and in the film boiling regime $\theta=0$. In the transition region the wetted wall parameter is set equal to the parameter $\delta$ defined by equation (6.53). Minor differences in channel length between the computational mesh and the actual geometry can be handled with the $L / D$ correction factor, $\Phi$. The friction factors in equations (7.2-3) are defined to be the familiar Darcy-Weisbach friction factors for onedimensional, single-phase flow. The friction factor expressions used in FLOWTRAN-TF are given in Table 7.1. The Reynolds numbers used to the evaluate the friction factor correlations are defined in terms of phasic velocity and use a corrected hydraulic diameter motivated by the work of Jones (1976) and Jones and Leung (1981) (Blevins, 1984). For example, the axial friction factor for the liquid phase is computed in terms of the axial, liquid-phase Reynolds number

$$
R e_{f}^{z}=\frac{\rho_{f} / u_{f} / D_{h}^{z} K_{h}^{z}}{\mu_{f}}
$$

The hydraulic diameter correction factor, $K_{h}^{2}$, depends on the geometry. As an example, the axial hydraulic diameter correction factor for ribbed annular flow channels is defined in Fig. 7.1 (Blevins, 1984).

For the azimuthal direction, the frictional component is modeled analogously to the axial frictional component. The form loss component is modeled differently and is customized for treating azimuthal crossflow through rib gaps in a ribbed annular geometry. The FLOWTRAN-TF model was motivated by the experimental results of Tapucu (1977). The
azimuthal mixture wall drag models are

$$
\begin{aligned}
& F_{w f^{*}}^{x}=\frac{1}{2}\left[\frac{\theta \Phi^{x} f_{f}^{x}}{D_{h}^{x}}\right] \rho_{f}\left|w_{f}\right| w_{f}+\frac{1}{2}\left[\frac{\left(1-\alpha_{r i b}\right) K^{x}}{\Delta x}\left(\frac{a}{R e\left|v_{f}\right|}+b\right)\right] \rho_{f}\left|v_{f}\right| w_{f} \\
& F_{w g}^{x}=\frac{1}{2}\left[\frac{(1-\theta) \Phi^{x} f_{g}^{x}}{D_{h}^{x}}\right] \rho_{g}\left|w_{g}\right| w_{g}+\frac{1}{2}\left[\frac{\alpha_{r i b} K^{x}}{\Delta x}\left(\frac{a}{R e\left|v_{f}\right|}+b\right)\right] \rho_{g}\left|v_{g}\right| w_{g}
\end{aligned}
$$

where

$$
\operatorname{Re}\left|v_{k}\right|=\frac{\rho_{k} D_{h}\left|v_{k}\right|}{\mu_{k}}
$$

and the superscript $x$ is used to denote the azimuthal direction. In equations (7.6-8)

$$
\alpha_{\text {rib }} \equiv \text { void fraction at the rib gap }
$$


$\Delta \mathrm{x} \equiv$ momentum cell length in azimuthal direction

$$
\left|v_{k}\right| \equiv \sqrt{u_{k}^{2}+w_{k}^{2}}
$$

and the other symbols are defined as before. The void fraction at the rib gap is defined in Section 12 of this document. Note that the form loss components of equations (7.6-7) contain a Reynolds number dependence. The values for the parameters a and $b$ were derived from the data of Tapucu (1977) and are chosen as

$$
\begin{gathered}
a=1066 \\
b=0.3391
\end{gathered}
$$

Values for form loss coefficients are quite geometry and mesh dependent and are typically obtained through 'calibration' against single-phase pressure drop data.

Table 7.1 Wall friction factor expressions in FLOWTRAN-TF

\begin{tabular}{|c|c|c|}
\hline Regime & Friction Factor & Reference \\
\hline $\begin{array}{c}\text { Laminar: } \\
\operatorname{Re} \leq 2000\end{array}$ & $\begin{array}{c}\text { Exact solution: } \\
\mathrm{f}_{\mathrm{L}}=\frac{64}{\mathrm{Re}}\end{array}$ & \\
\hline $\begin{array}{c}\text { Interpolation: } \\
2000<\operatorname{Re}<4000\end{array}$ & $\mathrm{f}_{\mathrm{L}-\mathrm{T}}=\left(2-\frac{4000}{\mathrm{Re}}\right)\left(\mathrm{f}_{\mathrm{T}, 4000}-\mathrm{f}_{\mathrm{L}, 2000}\right)+\mathrm{f}_{\mathrm{L}, 2000}$ & \\
\hline $\begin{array}{c}\text { Turbulent: } \\
\operatorname{Re} \geq 4000\end{array}$ & $\begin{array}{c}\text { Explicit approximation to Colebrook-White: } \\
\mathrm{f}_{\mathrm{T}}=\left[1.14-2 \log _{10}\left(\frac{\varepsilon}{\mathrm{D}_{\mathrm{h}} \mathrm{K}_{\mathrm{h}}}+\frac{21.25}{\operatorname{Re}^{0.9}}\right)\right]^{-2}\end{array}$ & $\begin{array}{c}\text { Jain (1976), } \\
\text { Blevins } \\
(1984)\end{array}$ \\
\hline
\end{tabular}

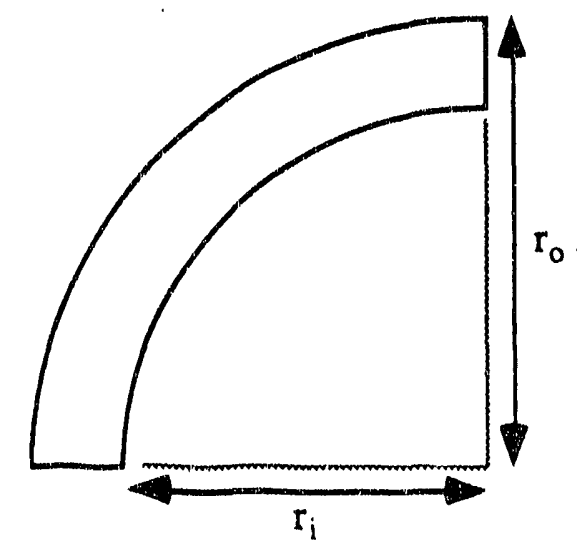

\begin{tabular}{|ll|}
\hline$\frac{r_{1}}{r_{0}}$ & $K_{h}$ \\
\hline 0.1 & 1.081 \\
0.3 & 1.080 \\
0.5 & 0.998 \\
0.7 & 0.859 \\
0.9 & 0.726 \\
\hline
\end{tabular}

Figure 7.1 Hydraulic diameter correction factors for a $90^{\circ}$ annular sector (Blevins, 1984) 


\section{Flow Regime Map and Interfacial Area}

The flow regime map and interfacial area models described in this section are used only for interfacial heat and mass transfer calculations. Earlier FLOW T.MN-TF interfacial drag models also used the map (and interfacial area concentration) described here but now use a different, simpler flow regime map. FLOWTRAN-TF is still under development and we anticipate that the subsequent interfacial drag model will again rely on the flow regime map discussed below.

\subsection{Flow Regime Map}

The FLOWTRAN-TY flow regime map is schematically illustrated in Fig. 8.1. The regime map logic follows the general theory presented by Taitel et al. (1980) and that used in the TRAC and RELAP5 series of codes (see Taylor et al. (1984) and Dimenna et al. (1988) for example). The flow regimes assumed to comprise the map have been confirmed for annular channel cross-sections by Kelessidis and Duckler (1989). The regime transition logic follows that presented by Ishii and Mishima (1980). The total void fraction is the sum of bubble, slug and annular regime void fractions. Transition from the dispersed bubble regime to the annular liquid film regime is defined to occur in the total void fraction range, $0.25<\alpha<0.75$, with a pure slug regime only occurring at a total void fraction of 0.52 . The maximum total void fraction for the pure bubble regime is 0.25 following a maximum bubble density criterion for spherically shaped bubbles (Taitel et al., 1980; Barnea et al., 1982). Similarly, the minimum total void fraction for removal of all liquid bridging is assumed to occur at 0.75 (Barnea et al., 1982) which defines the lower limit for pure annular flow.

The bubble to slug transition logic assumes that the liquid surrounding Taylor bubbles (i.e. those constrained by the physical dimensions of the flow region) contains spherical bubbles at the maximum density. At $\alpha$ equal to 0.52 all spherical bubbles are expected to disappear (Taitel et al., 1980; Dimenna et al., 1988) and pure slug flow is realized. Above 52\% total void fraction, a smooth transition to annular flow is defined assuming an analogy with the transition logic utilized between bubble and slug flow. The transition logic is to define a contribution from one regime and then to subtract that from the total void fraction to obtain the contribution from the other regime. The transition from the bubble to the slug flow regime is defined by

$$
\begin{gathered}
\alpha_{b}^{*}=\alpha_{b}^{* *}\left(\frac{\alpha_{s}^{* *}-\alpha}{\alpha_{s}^{* *}-\alpha_{b}^{* *}}\right)^{n_{b s}} \\
\alpha_{s}=\frac{\alpha-\alpha_{b}^{*}}{1-\alpha_{b}^{*}} \\
\alpha_{b}=\alpha-\alpha_{s}
\end{gathered}
$$

and analogously the slug to annular transition is modeled as 


$$
\begin{gathered}
\alpha_{a}^{* *} \alpha_{a}^{* *(}\left(\frac{\alpha-\alpha_{s}^{* *}}{\alpha_{a}^{* *}-\alpha_{s}^{* *}}\right)^{n_{s a}} \\
\alpha_{s}=\frac{\alpha-\alpha_{a}^{*}}{1-\alpha_{a}^{*}} \\
\alpha_{a}=\alpha-\alpha_{s}
\end{gathered}
$$

where

$$
\begin{aligned}
\alpha_{b}^{* *} & =0.25 \\
\alpha_{s}^{* *} & =0.52 \\
\alpha_{a}^{* *} & =0.75 \\
n_{b s} & =4 \\
n_{s a} & =4
\end{aligned}
$$

Here, $\alpha_{b}^{*}$ represents the local bubble concentration defined to be the bubble regime volume (excluding Taylor bubbles) divided by the bubble regime volume plus liquid volume. Analogously, $\alpha_{\mathrm{a}}$ is the local annular gas core concentration defined to be the annular regime gas phase volume divided by the annular regime gas phase volume plus liquid phase volume. The exponents given by equations (8.10-11) were chosen somewhat arbitrarily. The given selection produces a relatively rapid transition between the three flow regimes. 


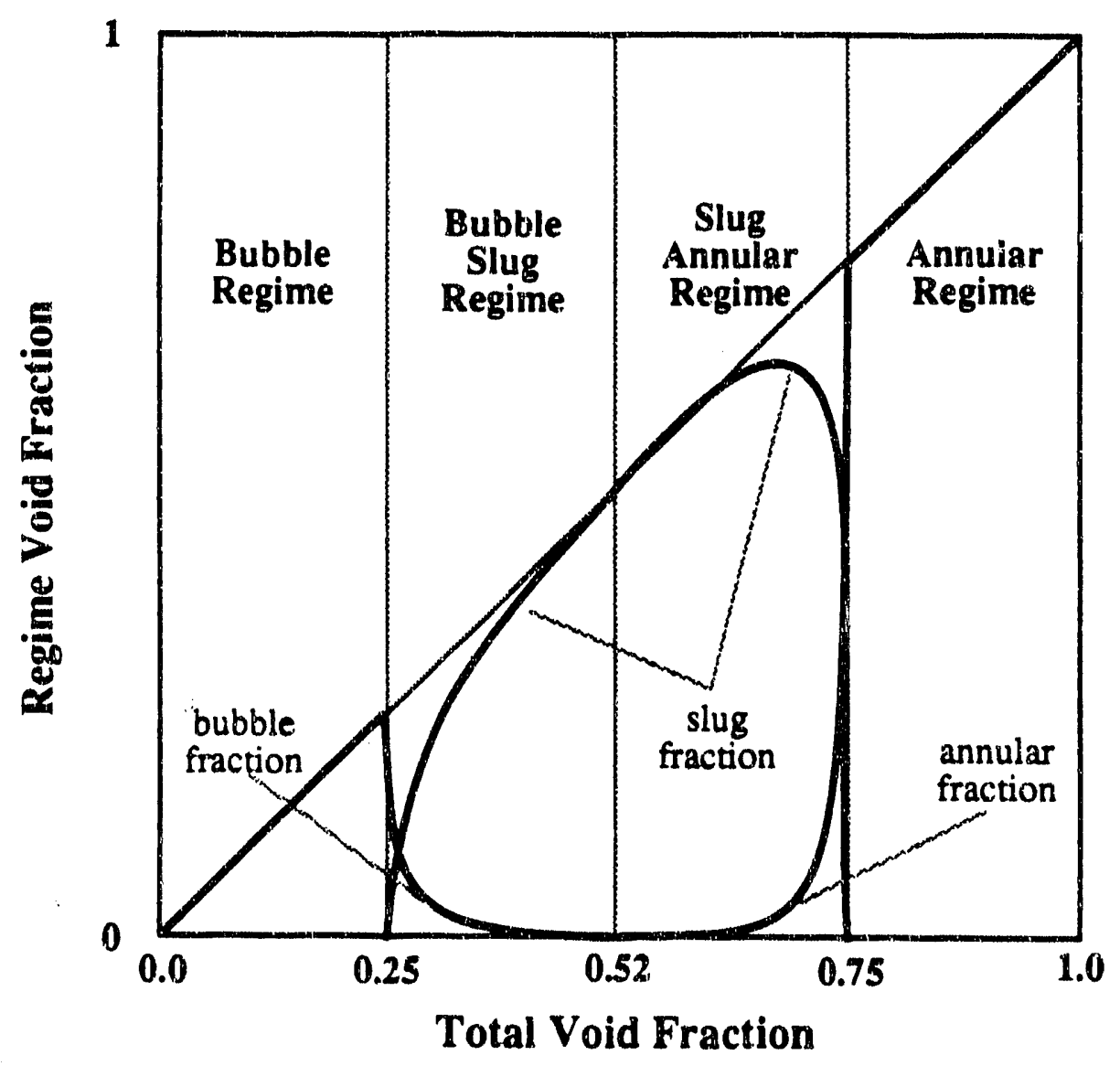

Figure 8.1 Schematic illustration of FLOWTRAN-TF flow regime map

\subsection{Interfacial Area Per Unit Volume}

The total interfacial area per unit volume is defined to be the sum of individual contributions from each regime following RELAP (Ransom, 1985) and Ishii and Mishima (1980):

$$
\frac{A_{I}}{V}=a_{l}=a_{I b}+a_{l s}+a_{l a}
$$

Since all three regimes cannot exist simultaneously according to the flow regime map logic, at least one term on the right hand side of equation (8.12) is always zero. The contribution from each regime (bubble, slug, annular) is defined below in terms of $\alpha_{b}, \alpha_{s}$ and $\alpha_{a}$ defined by equations $(8.1-11)$.

In the bubble regime, the maximum bubble diameter is nominally defined by a critical Weber number criterion

$$
\mathrm{We}_{\mathrm{e}}=\frac{2}{\mathrm{C}_{\mathrm{D}}}
$$


which is obtained by equating drag force with surface tension force for a spherical bubble. The drag coefficient is chosen as

$$
C_{D}=\frac{24}{\operatorname{Re}}\left[1+0.1 \operatorname{Re}^{0.75}\right]
$$

following Ishii and Mishima (1980). Combining equations (8.13) and (8.14) yields a maximum bubble diameter based on the Weber number criterion as

$$
D_{W e}=\left[\frac{2 \sigma-24\left|u_{g}-u_{f}\right| \mu_{f}}{2.4 \mu_{f}^{0.25} \rho_{f}^{0.75}\left|u_{g}-u_{f}\right| 1.75}\right]^{4 / 3}
$$

However, the maximum bubble diameter is assumed to be limited by the hydraulic diameter so the maximum bubble diameter actually becomes

$$
D_{\max }=\min \left(D_{W_{e}}, D_{h}\right)
$$

A distribution of sizes is assumed to exist with the average size determined from

$$
\mathrm{D}_{\text {avg }}=0.5 \mathrm{D}_{\max }
$$

and the collective bubble interfacial area per unit volume is defined by

$$
\mathrm{a}_{\mathrm{Ib}}=\frac{3.6 \alpha_{\mathrm{b}}}{\mathrm{D}_{\mathrm{avg}}}
$$

The slug regime interfacial area per unit volume analysis is based on the average Taylor bubble diameter being constrained by the flow geometry to be $88 \%$ of the hydraulic diameter and takes into account interface roughness (Ishii and Mishima, 1980). The result is

$$
a_{I s}=\frac{(4.5)(1.5) \alpha_{s}}{D_{h}}
$$

The annular regime analysis is based on a narrow rectangular channel approximating one subchanrisl of a ribbed annular conduit. A liquid film on the channel walls with uniform film thickness is assumed to surround a gas phase core. First the wetted perimeter is computed in terms of the FLOWTRAN-TF input variables from the definition of hydraulic diameter.

$$
P_{w}=\frac{4 A_{c}}{D_{h}}
$$

The uniform film thickness is approximated by 


$$
\delta=\frac{\left(1-\alpha_{\mathrm{a}}\right) \mathrm{A}_{\mathrm{c}}}{\mathrm{P}_{\mathrm{w}}}
$$

and the interfacial perimeter by

$$
P_{I}=P_{w}-8 \delta
$$

Finally, the annular interfacial area concentration is modeled as

$$
a_{I_{1}}=\left(1-\frac{\alpha_{s}}{\alpha}\right) \frac{P_{I}}{A_{c}}
$$

\section{Interfacial Heat and Mass Transfer}

Phase change occurs at two distinct locations. At the interfaces between existing gas and liquid phases, interfacial heat and mass exchange occurs due to temperature and concentration gradients in the bulk flow. At a heated wall in contact with the liquid phase, boiling can occur due to local superheating of the liquid which flashes into steam. Similarly, condensation can occur due to local subcooling of the gas phase at a cooled wall. The latter situation is termed interfacial heat and mass transfer at walls. Boiling and condensation rates at solid walls have already been discussed in the Wall Heat Transfer section. Following a discussion of interfacial heat and mass transfer in the bulk flow, we complete the discussion of boiling/condensation at solid walls.

\subsection{Interfacial Exchange in Bulk Flow}

Figure 9.1 illustrates the heat and mass transfer phenomena involved at interfaces in the bulk flow for an example set of conditions. Thermodynamic equilibrium is assumed to exist at the gas-liquid interface with the interface temperature, $T_{i}$, being defined by the vapor-liquid saturation line, the system pressure $P$, and the steam molar concentration at the interface $y_{\text {si }}$. The net mass and energy transfer into the interface from both phases is zero since the interface cannot store mass or energy. In general, temperature and concentration gradients exist between the interface and bulk conditions and, through associated heat and mass transfer coefficients, determine the rates of heat and mass transfer to the interface. The fundamental equations governing interfacial heat and mass transfer in air-water flow when the air component is assumed to be noncondensable are (see Bird et al. (1960) for example)

Vapor-liquid equilibrium:

$$
T_{i}=T_{s a t}\left(y_{s i} P\right)
$$

Gas-liquid interface mass balance:

$$
\Gamma_{8 \mathrm{i}}+\Gamma_{\mathrm{fi}}=0
$$

where in the gas film, steam transport is due to diffusion and bulk flow components 


$$
\Gamma_{g i}=M_{s} a_{1} J_{s}^{*}+y_{s} \Gamma_{g i}
$$

Gas-liquid interface energy balance:

$$
E_{g i}+E_{f i}=0
$$

where the total energy is comprised of heat and mass transfer components

$$
\begin{aligned}
& E_{g i}=Q_{g i}+\Gamma_{g i} h_{s i} \\
& E_{f i}=Q_{f i}+\Gamma_{f i} h_{f i}
\end{aligned}
$$

Steam molar diffusion rate:

$$
J_{s}^{*}=k_{s}^{*}\left(y_{s i}-y_{s}\right)
$$

Gas heat transfer rate:

$$
Q_{g i}=h_{g}^{*} a_{1}\left(T_{i}-T_{g}\right)
$$

ard

Liquid heat transfer rate:

$$
Q_{\text {fi }}=h_{f}^{*} a_{I}\left(T_{i}-T_{f}\right)
$$

The following nomenclature is used in the above equations

$$
\begin{aligned}
P & \equiv \text { pressure } \\
T_{i} & \equiv \text { interface temperature } \\
T_{g} & \equiv \text { bulk gas temperature } \\
T_{f} & \equiv \text { bulk liquid temperature } \\
y_{s} & \equiv \text { bulk steam mole fraction in the gas phase } \\
y_{s i} & \equiv \text { interface steam mole fraction in the gas phase } \\
h_{s i} & \equiv \text { enthalpy of steam at the interface conditions } \\
h_{f i} & \equiv \text { enthalpy of liquid at the interface conditions } \\
M_{s} & \equiv \text { molecular weight of steam } \\
a_{I} & \equiv \text { interfacial area per unit volume }
\end{aligned}
$$


$J_{s}^{*} \equiv$ steam molar diffusion flux

$\Gamma_{\mathbf{g i}} \equiv$ gas (steam) mass flowrate from the interface to bulk gas per unit volume

$\Gamma_{\mathrm{fi}} \equiv$ liquid mass flowrate from the interface to bulk liquid per unit volume

$\mathrm{Q}_{\mathrm{gi}} \equiv$ heat rate from the interface to bulk gas per unit volume

$\mathrm{Q}_{\mathrm{fi}} \equiv$ heat rate from the interface to bulk liquid per unit volume

$\mathrm{E}_{\mathrm{gi}} \equiv$ total energy rate from the interface to bulk gas per unit volume

$\mathrm{E}_{\mathrm{fi}} \equiv$ total energy rate from the interface to bulk liquid per unit volume

$\mathrm{k}_{\mathrm{s}}^{*} \equiv$ steam interfacial mass transfer coefficient

$h_{g}^{*} \equiv$ gas interfacial heat transfer coefficient

$\mathrm{h}_{\mathrm{f}}^{*} \equiv$ liquid interfacial heat transfer coefficient

For brevity the following symbols are defined:

$$
\begin{gathered}
\Gamma_{I} \equiv \Gamma_{g i} \\
E_{I} \equiv E_{g i} \\
H_{g}^{*} \equiv h_{g}^{*} a_{I} \\
H_{f}^{*} \equiv h_{f}^{*} a_{I} \\
K_{g}^{*} \equiv M_{s} k_{s}^{*} a_{I} \\
\lambda_{i} \equiv h_{s i}-h_{f i}
\end{gathered}
$$

The interfacial heat and mass transfer rate coefficients, $\mathrm{H}_{\mathrm{g}}^{*}, \mathrm{H}_{\mathrm{f}}^{*}$ and $\mathrm{K}_{\mathrm{g}}^{*}$, are modeled in terms of low mass transfer coefficients, $\mathrm{H}_{\mathrm{g}}, \mathrm{H}_{\mathrm{f}}$ and $\mathrm{K}$, multiplied with Ackermann-type correction factors (Bird et al., 1960; Ackermann, 1937) accounting for the distortion of temperature and concentration profiles under high mass transfer conditions:

$$
\begin{aligned}
& H_{g}^{*}=H_{g}\left[1-B\left(\frac{c_{p s} \Gamma_{I}}{H_{g}}\right)\right] \\
& H_{f}^{*}=H_{f}\left[1+B\left(\frac{c_{p f} \Gamma_{I}}{H_{f}}\right)\right]
\end{aligned}
$$




$$
\mathrm{K}_{\mathrm{g}}^{*}=\mathrm{K}_{\mathrm{g}}\left[1-\mathrm{B}\left(\frac{\Gamma_{\mathrm{I}}}{\mathrm{K}_{\mathrm{g}}}\right)\right]
$$

where

$$
B=0.625
$$

The correction factors are approximate linearized versions of the exact results from the film, penetration, and boundary layer theories of interfacial transport. The chosen value for $B$ represents an average of values obtained from these models as can be seen from Fig. 21.7-2 in Bird et al. (1960). In the notation of Bird et al., equations (9.16-18) are the straight line $\theta=(1-B \phi)$. The low mass transfer rate coefficients are comprised of contributions from the bubble, slug and annular regimes as defined by the flow regime map logic described previously:

$$
\begin{aligned}
& H_{g}=\sum_{j=b, s, a} h_{g j} a_{I j} \\
& H_{f}=\sum_{j=b, s, a} h_{f j} a_{I j} \\
& K_{g}=\sum_{j=b, s, a} k_{g j} a^{a j}
\end{aligned}
$$

Table 9.1 lists correlations for the flow regime specific rate coefficients used in equations (9.20-22).

Equations (9.1-22) completely determine the interfacial heat and mass transfer rates in the bulk flow. Their solution proceeds along the following lines. The interfacial mass transfer rate per unit volume is obtained from the above equations in terms of the interface temperature, $T_{i}$, as

$$
\Gamma_{I}=\frac{-H_{g}^{*}\left(T_{i}-T_{g}\right)-H_{f}^{*}\left(T_{i}-T_{f}\right)}{\lambda_{i}}
$$

The interface temperature is obtained from equation (9.1) after solving the nonlinear algebraic equation

$$
\frac{-H_{g}^{*}\left(T_{i}-T_{g}\right)-H_{f}^{*}\left(T_{i}-T_{f}\right)}{\lambda_{i}}\left(1-y_{s}\right)-K_{g}^{*}\left(y_{s i}-y_{s}\right)=0
$$

for $y_{s i}$. In functional form, equation (9.24) is

$$
F\left(y_{s i} ; P, T_{g}, T_{f}, y_{s}, H_{g}, H_{f}, K_{g}\right)=0
$$


which is seen to be a function of the bulk properties and heat and mass transfer correlations (which are ultimately defined by the bulk properties).

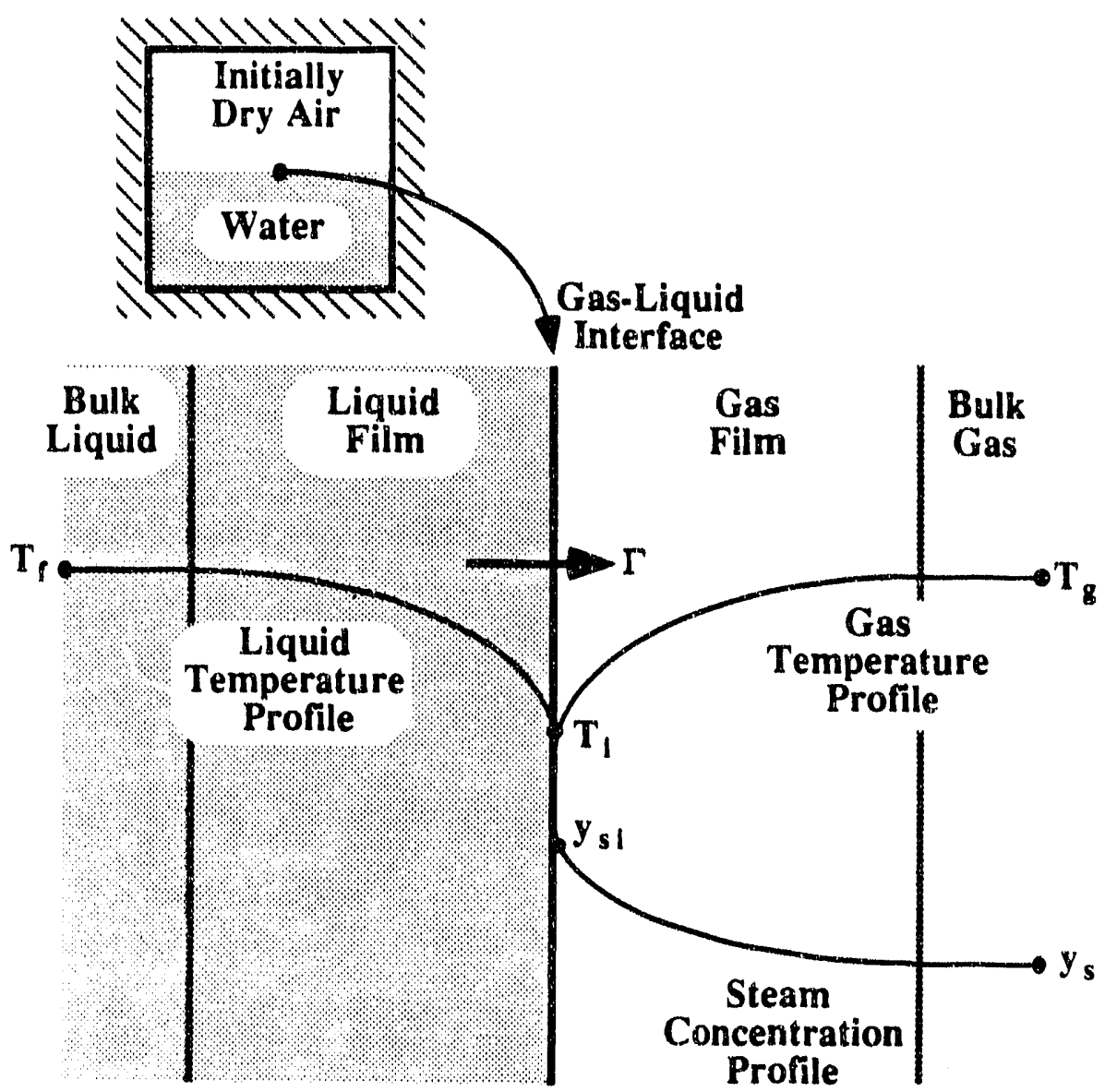

Figure 9.1 Schematic of interfacial heat and mass transfer in bulk flow - case of initially dry air brought in contact with water at same temperature 
Table 9.1 Interfacial heat and mass transfer coefficient correlations in FLOWTRAN-TF

\begin{tabular}{|c|c|c|c|}
\hline $\begin{array}{l}\text { Flow } \\
\text { Regime }\end{array}$ & $\begin{array}{c}\text { Rate } \\
\text { Coefficient }\end{array}$ & Correlation & References \\
\hline \multirow[t]{3}{*}{ Bubble } & $\mathrm{h}_{\mathrm{fb}}$ & $\mathrm{Nu}_{\mathrm{fb}}=1+\left(1+0.564 \mathrm{Pe}^{2 / 3}\right)^{3 / 4}$ & Oellrich et al., 1973 \\
\hline & $\mathrm{h}_{\mathrm{gb}}$ & $\begin{array}{c}\mathrm{Nu}_{\mathrm{gb}}=10^{4} \\
\text { (gas side is not controlling) }\end{array}$ & $\begin{array}{c}\text { Dimenna et al., } \\
\text { 1988; } \\
\text { Treybal, 1980; } \\
\text { Sherwood et al., } \\
1975\end{array}$ \\
\hline & $k_{g b}$ & $\begin{array}{l}\qquad \mathrm{Sh}_{\mathrm{gb}}=\mathrm{Nu}_{\mathrm{gb}} \mathrm{Le}^{1 / 3} \\
\text { (Chilton-Colburm heat and mass trans. analogy) }\end{array}$ & \\
\hline \multirow[t]{3}{*}{ Slug } & $h_{\mathrm{fs}}$ & $\begin{array}{c}\text { Partial turbulence }\left(\operatorname{Re}_{\text {liquid film }} \leq 1200\right) \text { : } \\
\qquad \mathrm{Nu}_{\mathrm{fs}}=1.18942 \mathrm{Pe}^{0.5} \\
\text { Complete turbulence }\left(\operatorname{Re}_{\text {liquid film }}\right. \\
>1200): \\
\mathrm{Nu}_{\mathrm{fs}}=1.76 \times 10^{-5} \operatorname{Re}^{1.506} \mathrm{Pr}^{0.5}\end{array}$ & $\begin{array}{l}\text { Dimenna et al., } \\
1988 \\
\text { Treybal, } 1980\end{array}$ \\
\hline & $\mathrm{h}_{\mathrm{gs}}$ & $\mathrm{Nu}_{\mathrm{gs}}=2+0.74 \mathrm{Re}^{1 / 2} \operatorname{Pr}^{1 / 3}$ & Lee \& Riley, 1968 \\
\hline & $\mathrm{k}_{\mathbf{g s}}$ & $\begin{array}{l}\qquad \mathrm{Sh}_{\mathrm{gs}}=\mathrm{Nu}_{\mathrm{gs}} \mathrm{Le}^{1 / 3} \\
\text { (Chilton-Colburn heat and mass trans. analogy) }\end{array}$ & \\
\hline \multirow[t]{3}{*}{ Annular } & $h_{\mathrm{fa}}$ & $\begin{array}{l}\text { Laminar }\left(\operatorname{Re}_{\text {liquid film }} \leq 1200\right) \text { : } \\
\mathrm{Nu}_{\mathrm{fa}}=(1.5 \delta \mathrm{Pe} / 4.333)^{0.5} \\
\text { where } \delta \text { is the film thickness from flow regime } \\
\text { map logic } \\
\text { Turbulent }\left(\operatorname{Re}_{\text {liquid film }}>1200\right) \text { : } \\
\mathrm{Nu}_{\mathrm{fa}}=1.76 \times 10^{-5} \mathrm{Re}^{1.506} \mathrm{Pr}^{0.5}\end{array}$ & $\begin{array}{l}\text { Treybal, } 1980 \\
\text { Treybal, } 1980\end{array}$ \\
\hline & $h_{g a}$ & $\begin{array}{c}\text { Laminar }(\operatorname{Re}<50,000) \\
N u_{g a}=5.03 \mathrm{Pe}^{1 / 3} \\
\text { Turbulent }(\operatorname{Re} \geq 50,000) \\
\mathrm{Nu}_{\mathrm{ga}}=0.0265 \operatorname{Re}^{0.8} \mathrm{Pr}^{1 / 3}\end{array}$ & $\begin{array}{l}\text { Chapman, } 1974 \\
\text { Chapman, } 1974\end{array}$ \\
\hline & $\mathrm{k}_{\mathrm{ga}}$ & $\begin{array}{l}\qquad \mathrm{Sh}_{\mathrm{ga}}=\mathrm{Nu}_{\mathrm{ga}} \mathrm{Le}^{1 / 3} \\
\text { (Chilion-Colburn heat and mass trars. analogy) }\end{array}$ & \\
\hline
\end{tabular}




\subsection{Interfacial Exchange at Walls}

Vaporization/condensation rates have already been defined in the Wall Heat Transfer section. In this subsection, the corresponding interfacial energy exchange terms are explicitly defined. The overall model resembles the previous formulation with the energy balance given by

$$
E_{g w}+E_{f w}=0
$$

where

$$
\begin{aligned}
& E_{g w} \equiv Q_{g w}+\Gamma_{w} h_{s w} \equiv E_{w} \\
& E_{f w} \equiv Q_{f w}-\Gamma_{w} h_{f w}=-E_{w}
\end{aligned}
$$

The quantities $Q_{g w}$ and $Q_{f w}$ should not be confused with $Q_{w g}$ and $Q_{w f}$, respectively, shown in equations (5.6-7). The steam $\left(h_{s w}\right)$ and liquid $\left(h_{f w}\right)$ enthalpies are evaluated at the wall surface conditions. The rate of phase change (boiling or condensation) per unit total volume becomes

$$
\Gamma_{w}=\frac{-Q_{g w}-Q_{f w}}{\lambda_{w}}
$$

where the heat of vaporization is given by

$$
\lambda_{w}=h_{s w}-h_{f w}
$$

Since the vaporization/condensation rates have been set in the Wall Heat Transfer section by equations (6.14), (6.26) and (6.37), equation (9.29) actually defines the vaporization/condensation heat transfer terms $\mathrm{Q}_{\mathrm{gw}}$ and $\mathrm{Q}_{\mathrm{fw}}$. For subcooled boiling these terms are

$$
Q_{\text {gw }}=0
$$

and

$$
Q_{f w}=-\hat{\Gamma}_{w} \lambda_{w} \frac{A_{w}}{V}
$$

while for condensation

$$
\mathrm{Q}_{\mathrm{fw}}=0
$$

and

$$
\mathrm{Q}_{g w}=-\hat{\Gamma}_{w} \lambda_{w} \frac{A_{w}}{V}
$$




\section{Interfacial Drag}

In the high void region, the FLOWTRAN-TF interfacial drag model is constrained to satisfy a counter-current flow limitation (flooding) correlation appropriate to the geometry of the mesh cell face at hand. We begin by compiling the relevant CCFL correlations and then discuss the overall interfacial drag model.

\subsection{CCFL Correlations}

For some of the channel geometries of interest to SRS (circular, annular, for example), flooding correlations are available in the literature. Unfortunately, no CCFL data for ribbed annular passages have been located to-date nor is any SRS data available. Fortunately, a $90^{\circ}$ sector of a thin ribbed annular section is very similar to a thin rectangular channel, for which literature data are available, as illustrated in Fig. 10.1. Therefore, we assume CCFL data for thin rectangular channels are applicable to the ribbed annular geometry of interest. Literature experimental data for thin rectangular channels of various aspect ratios are shown in Fig. 10.2. The data are for air-water countercurrent flow near atmospheric pressure. The experimental data has been successfully correlated using a Wallis-type formulation (Wallis, 1969)

$$
\sqrt{J_{B}^{*}}+m \sqrt{J_{f}^{*}}=C
$$

where $2 \mathrm{a}$ is taken for the characteristic dimension, $\mathrm{D}_{\mathrm{c}}$, in the definition

$$
J_{k}^{*} \equiv j_{k} \sqrt{\frac{\rho_{k}}{g 2 a\left(\rho_{f}-\rho_{g}\right)}} \quad k=g \text { or } f
$$

and the $m$ and $C$ values are functions of the aspect ratio, b/a, of the channel. For the correlation illustrated in Fig. 10.2, the $\mathrm{m}$ and $\mathrm{C}$ parameters are computed in terms of the aspect ratio (b/a) as

$$
\begin{gathered}
\mathrm{m}=0.5148+3.4435\left(\frac{\mathrm{b}}{\mathrm{a}}\right) \\
\mathrm{C}=0.6581+0.1366 \log _{1.0}\left(\frac{\mathrm{b}}{\mathrm{a}}\right)
\end{gathered}
$$

The choice of twice the channel width, 2a, for the characteristic dimension over other selections, such as hydraulic diameter, has been justified. Using the channel hydraulic diameter as the characteristic dimension failed to collapse the flooding data for various aspect ratios. Also, various analyses indicate that twice the channel width is the appropriate dimension (Mishima and Nishihara, 1985; Cheng, 1990). For example, the liquid flow fraction for a cylindrical channel is

$$
(1-\alpha) \cong \frac{4 \delta}{D}
$$


where $\delta$ is the film thickness of annular liquid downflow and $D$ is the channel hydraulic diameter. The countercurrent flow visualization studies done by Sudo and Kaminaga (1989) indicate that most of the liquid downflow occurred along the narrow side walls of a thin rectangular channel. In this case, the liquid flow fraction is approximately

$$
(1-\alpha) \cong \frac{2 \delta}{a}
$$

where $a$ is the wide span of the rectangular channel. From inspection of equations (10.5) and (10.6), the appropriate characteristic diameter for a thin rectangular channel is apparently $2 \mathrm{a}$.

Table 10.1 lists the flooding correlation parameters used in FLOWTRAN-TF simulations for various geometries of interest.
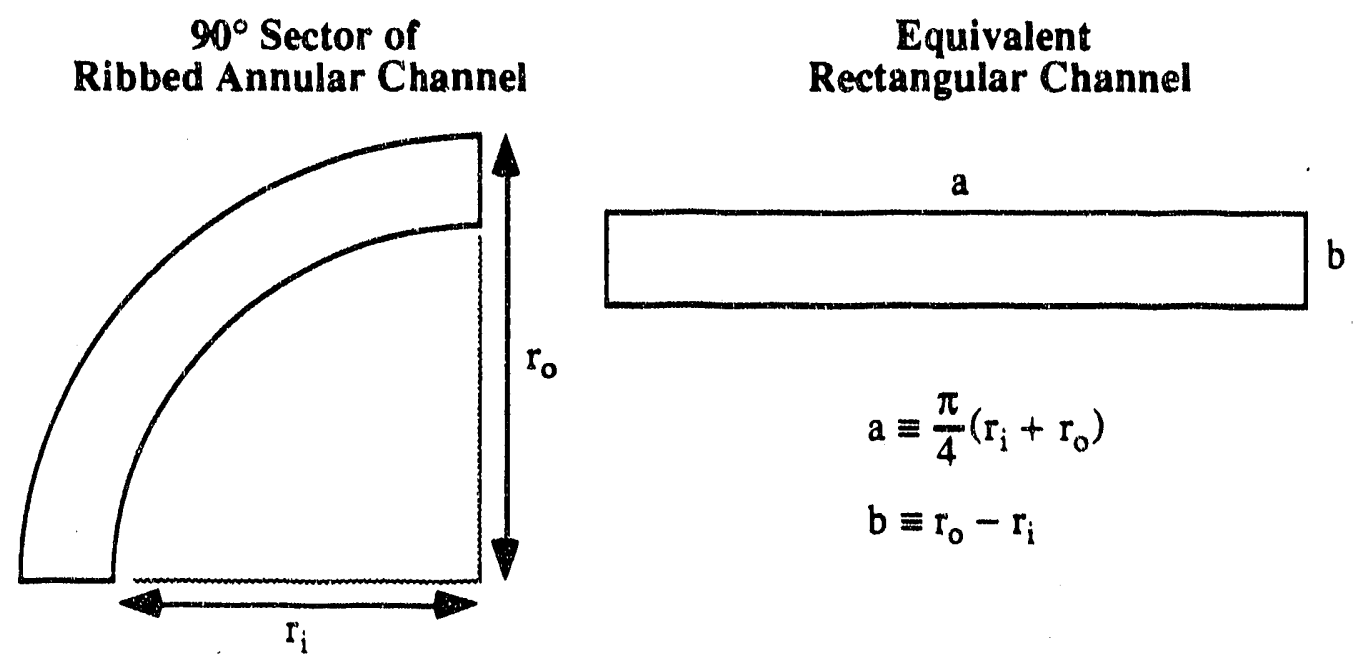

$$
\begin{aligned}
& a \equiv \frac{\pi}{4}\left(r_{i}+r_{0}\right) \\
& b \equiv r_{0}-r_{i}
\end{aligned}
$$

Figure 10.1 Similarity between a $90^{\circ}$ thin annular sector and a thin rectangular channel 


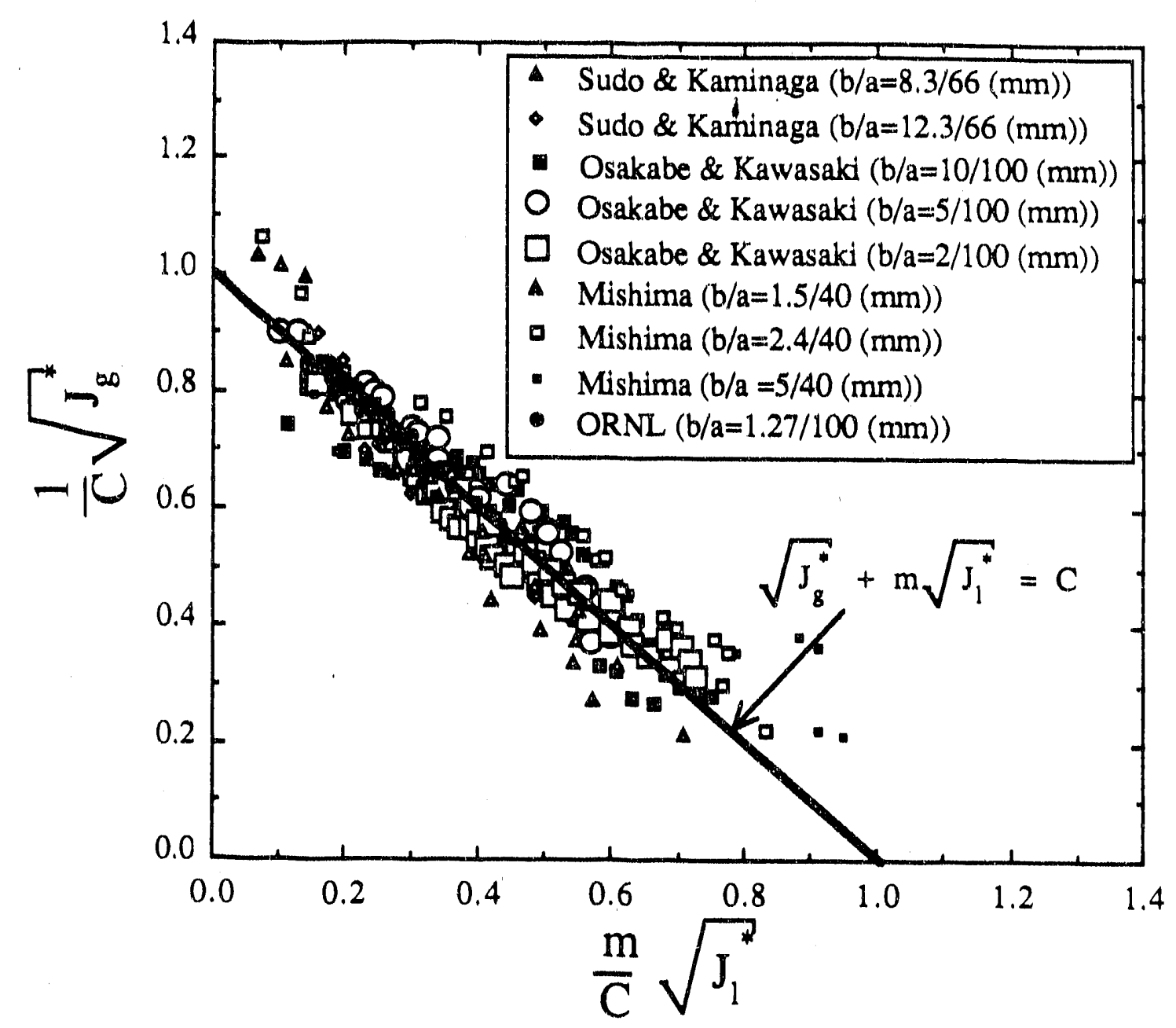

Figure 10.2 Flooding correlation for thin rectangular geometry 
Table 10.1 Interfacial drag/CCFL parameters for SRS geometries of interest

\begin{tabular}{|c|c|c|c|c|}
\hline Geometry & $\mathrm{D}_{\mathrm{c}}$ & $\mathbf{m}$ & $\mathrm{C}$ & References \\
\hline $\begin{array}{l}\text { Thin } \\
\text { Rectangular } \\
\\
\mathrm{a} b\end{array}$ & $2 a$ & $\begin{array}{c}\min [0.5148+ \\
3.4435(\mathrm{~b} / \mathrm{a}), \\
1.0]\end{array}$ & $\begin{array}{c}0.6581+ \\
0.1366 \log _{10}(\mathrm{~b} / \mathrm{a})\end{array}$ & $\begin{array}{c}\text { Sudo \& } \\
\text { Kaminaga, 1989; } \\
\text { Osakabe \& } \\
\text { Kawasaki, 1989; } \\
\text { Mishima, 1984; } \\
\text { Ruggles, 1989 }\end{array}$ \\
\hline $\begin{array}{c}\text { Ribbed } \\
\text { Annulus } \\
\mathrm{a} \equiv \frac{\pi}{4}\left(\mathrm{r}_{\mathrm{i}}+\mathrm{r}_{\mathrm{o}}\right) \\
\mathrm{b} \equiv \mathrm{r}_{\mathrm{o}}-\mathrm{r}_{\mathrm{i}}\end{array}$ & $\frac{\pi}{2}\left(r_{i}+r_{0}\right)=2 a$ & same as above & same as above & \\
\hline Annulus & $\frac{\pi}{2}\left(r_{i}+r_{0}\right)$ & 0.8 & 0.45 & $\begin{array}{c}\text { Osakabe \& } \\
\text { Kawasaki, } 1989\end{array}$ \\
\hline Circular & $\mathrm{D}$ & 1.0 & 0.94 & Wallis, 1969 \\
\hline
\end{tabular}

\subsection{Interfacial Drag Model}

Two distinct interfacial drag models are used in the axial and azimuthal momentum balances. The current axial interfacial drag model is based on adapting one-dimensional drift-flux concepts to the two-fluid formulation (Anderson and Chu, 1982; Ishii and Mishima, 1984). The drift-flux model for downward flow is

$$
u_{g}=C_{0}\left(j_{g}+j_{f}\right)-u_{g j}
$$

where

$$
\begin{aligned}
u_{\mathrm{g}} & \equiv \text { gas phasic velocity } \\
j_{\mathrm{g}} & \equiv \text { gas superficial velocity, } \mathrm{Q}_{\mathrm{g}} / \mathrm{A} \\
\mathrm{j}_{\mathrm{f}} & \equiv \text { liquid superficial velocity, } \mathrm{Q}_{f} / \mathrm{A} \\
\mathrm{C}_{0} & \equiv \text { distribution coefficient } \\
\mathrm{u}_{\mathrm{gj}} & \equiv \text { drift velocity }
\end{aligned}
$$

For drift-flux parameters, $C_{0}$ and $u_{g j}$, which are at most functions of void fraction, a compatible FLOWTRAN-TF two-fluid inodel is constructed as follows. The frictional component of mixture wall drag, $\mathrm{F}_{w}^{z}$, is repartitioned between the gas and liquid momentum balances according to

$$
\begin{aligned}
\left.F_{w g}^{z}\right|_{\text {fric }}=\left.\alpha F_{w}^{z}\right|_{\text {fric }} & =\alpha\left(\left.F_{w g}^{z}\right|_{\text {fric }}+\left.F_{w f}^{z}\right|_{\text {fric }}\right) \\
\left.F_{w f}^{z}\right|_{\text {fric }}=\left.(1-\alpha) F_{w}^{z}\right|_{\text {fric }} & =(1-\alpha)\left(\left.F_{w_{g}}^{z}\right|_{\text {fric }}+\left.F_{w f}^{z}\right|_{\text {fric }}\right)
\end{aligned}
$$

The term $\left.F_{w g}^{2}\right|_{\text {fric }}$ can be interpreted as an 'induced' interfacial drag due to wall friction. The form loss components are left the same as those constructed in Section 7 . That is 


$$
\begin{aligned}
F_{w g}^{z} & =\left.F_{w g}^{z}\right|_{\text {fric }}+\left.F_{w g}^{z}\right|_{\text {form }} \\
F_{w f}^{z} & =\left.F_{w f}^{z}\right|_{\text {fric }}+\left.F_{w f}^{z}\right|_{\text {form }}
\end{aligned}
$$

'Local' interfacial drag, due to the relative motion between the phases, is modeled in terms of the drift-flux parameters as

$$
F_{I}^{z}=C_{I}^{z}\left|u_{\mathrm{r}}\right| u_{\mathrm{r}}=\frac{\alpha(1-\alpha)^{3} \Delta \rho g}{u_{g j}^{2}}\left|\frac{1-C_{0} \alpha}{1-\alpha} u_{g}-C_{0} u_{f}\right|\left(\frac{1-C_{0} \alpha}{1-\alpha} u_{g}-C_{0} u_{f}\right)
$$

where values for the distribution coefficient, $\mathrm{C}_{0}$, and the drift velocity, $\mathrm{u}_{\mathrm{gj}}$, are derived from data. Note that the correct sign is obtained for $\mathrm{F}_{\mathrm{I}}^{\mathrm{z}}$ by forming the product of absolute value of relative velocity and relative velocity. With the interfacial drag models given by equations (10.8-10), the gas momentum balance (5.4) reduces to the drift-flux model (10.7) under steady, axially uniform conditions with no form losses.

For void fractions less than $40 \%$ (dispersed flow regime), the drift velocity in FLOWTRAN-TF is computed from a bubble rise velocity correlation of the form

$$
u_{g j}^{d}=K \sqrt{\frac{\Delta \rho g D_{c}}{\rho_{f}}}
$$

where $D_{c}$ is a geometry specific characteristic dimension. Table 10.1 lists the characteristic dimension for the channel shapes of interest. For void fractions greater than $60 \%$ (separated flow regime), the drift velocity is computed in terms of the distribution coefficient such that the flooding correlation given by equation (10.1) is satisfied (Ohkawa and Lahey, 1980):

$$
u_{g j}^{s}=C^{2} \sqrt{\frac{\Delta \rho g D_{c}}{\rho_{f}}}-\frac{C_{0}}{m^{2}+\frac{C_{0} \alpha}{1-C_{0} \alpha}\left(\frac{\rho_{g}}{\rho_{f}}\right)^{1 / 2}}
$$

Between $40 \%$ and $60 \%$ void, the drift velocity is determined by linearly interpolating between the dispersed and separated regime values according to void fraction.

The distribution parameter was viewed as a piecewise linear function of void fraction to be adjusted to fit the available cocurrent downflow data. The constant $\mathrm{K}$ in equation (10.11) was also chosen to be a free parameter. These parameters were optimized to give a best fit to the VOID Rig cocurrent downflow data (Whatley, 1990) as follows. Eliminating pressure gradient,$\nabla \mathrm{P}$, between the gas and liquid momentum balances, equations $(5.4)$ and (5.5), yields

$$
F_{I}=\alpha(1-\alpha) \Delta \rho g
$$

This expression was used to derive 'experimental' values of interfacial drag, denoted $F_{1}$ EXP, from VOID Rig void fraction data. Equation (10.10) produced 'model' values in terms of the chosen free parameters and can be rewritten in functional form as 


$$
F_{I}^{M O D E}=f c n\left(C_{0}, K\right)
$$

where $\mathrm{K}$ is the coefficient in correlation (10.11) and $\mathbf{C}_{0}$ represents the vector of distribution parameter values. Optimal parameter values were chosen by minimizing a least-squares norm between the experimental $\left(\mathrm{F}_{1} \mathrm{EXP}\right)$ and model $\left(\mathrm{F}_{1} \mathrm{MODEL}\right)$ interfacial drag values, accounting for uncertainties in both the independent and dependent variables. The optimal value of $\mathrm{K}$ was determined to be 0.503 and Fig. 10.3 illustrates the resulting distribution cofficient variation. The corresponding drift velocity variation for the VOID Rig channel geometry is shown in Fig. 10.4.

Tuming to interfacial drag modsling in the azimuthal direction, the wall drag repartitioning is analogous to the axial direction. The local drag is modeled differently however with the local relative velocity computed as the simple difference of the phasic velocities:

$$
F_{I}^{x}=C_{I}^{x}\left|w_{g}-w_{f}\right|\left(w_{g}-w_{f}\right)
$$

In all applications considered to-date, azimuthal flow occurs between subchannels $\left(90^{\circ}\right.$ sectors) through the narrow gap between a longitudinal rib and the adjacent cylinder. For these cases, we assume two-phase flow in the azimuthal direction (x-direction) is homogeneous; that is, we set the interfacial drag coefficient, $C_{I}^{x}$ to a sufficiently large number such that the relative velocity between the phases is nearly zero.

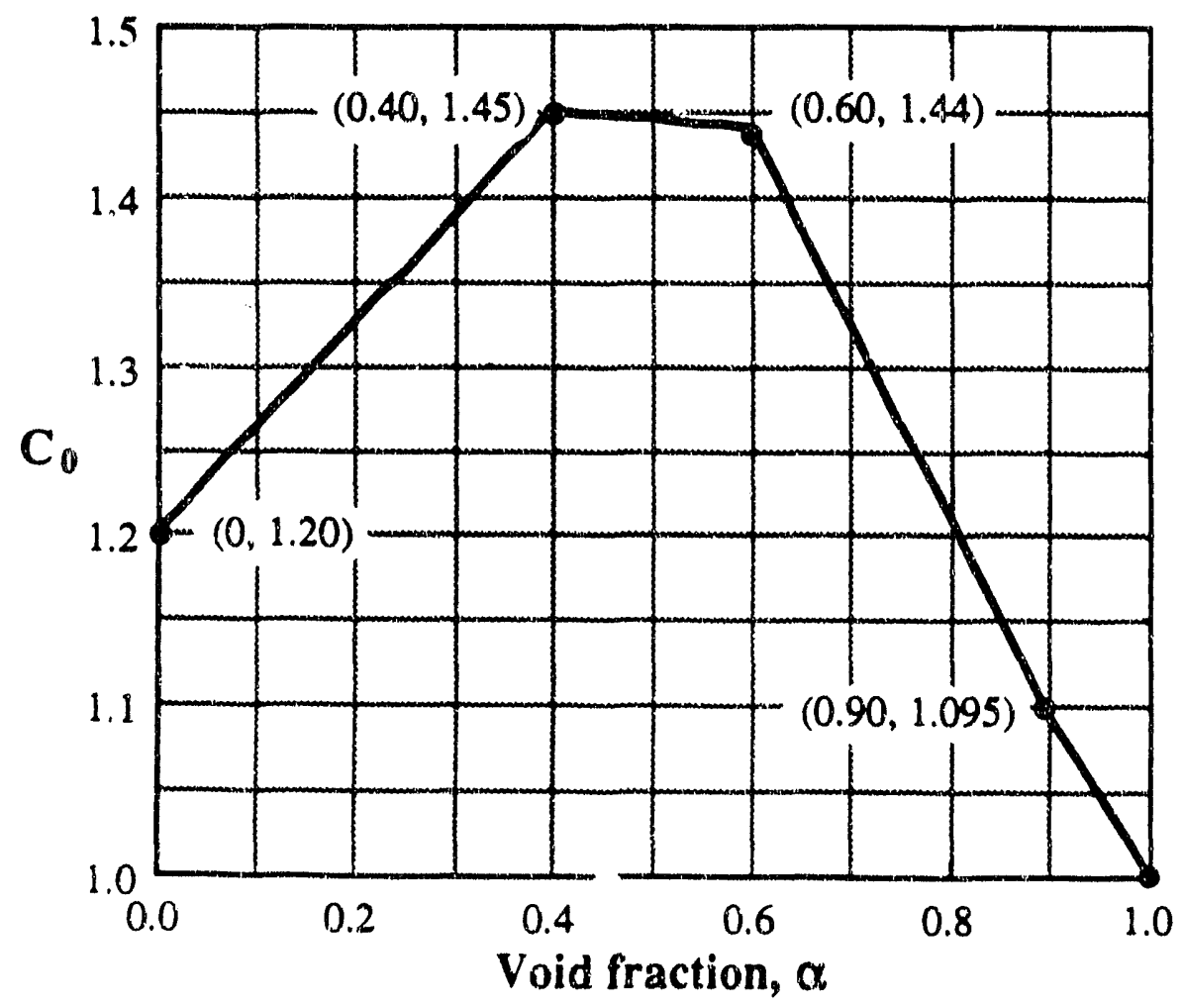

Figure 10.3 Distribution coefficient function in FLOWTRAN-TF 


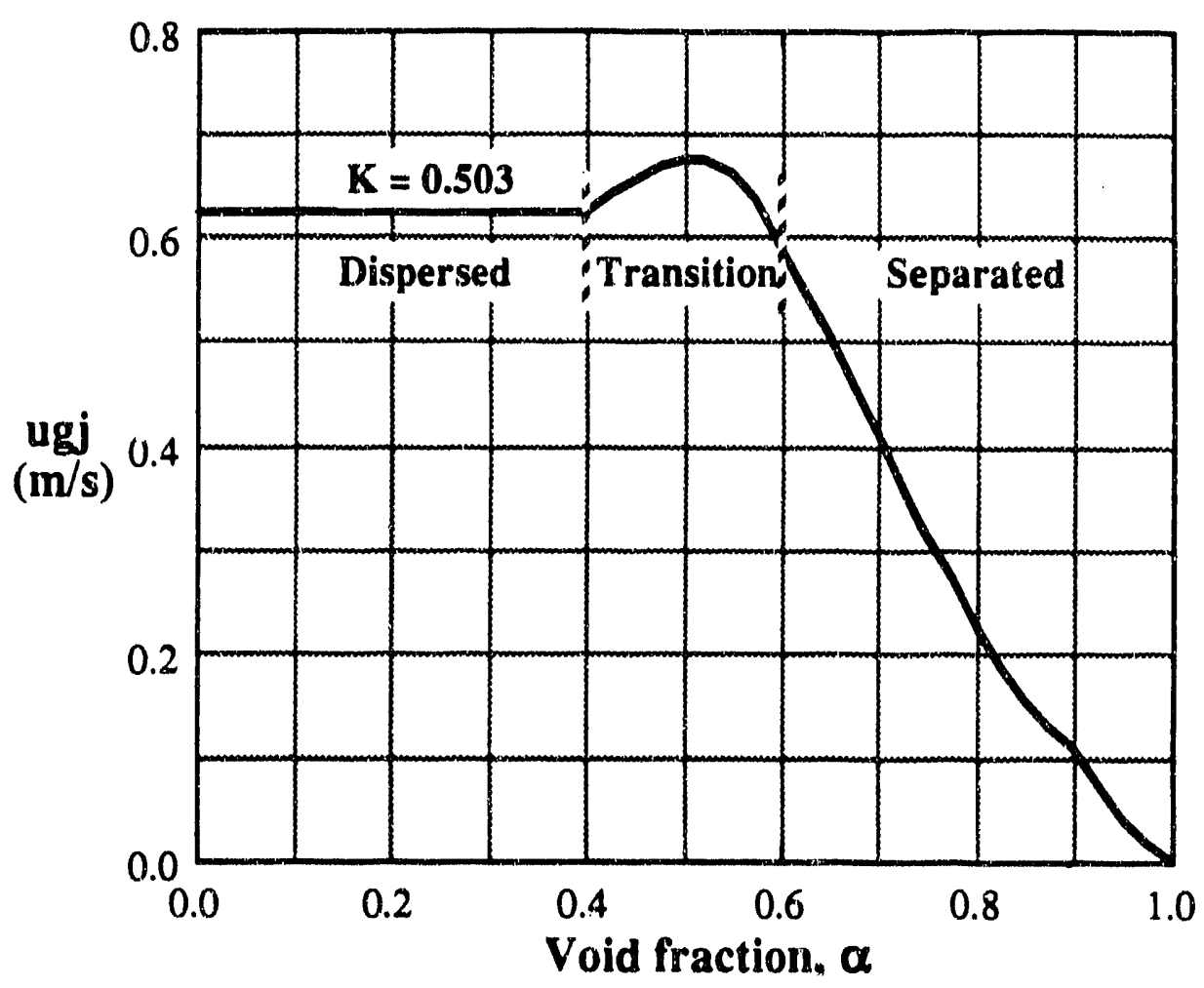

Figure 10.4 Drift velocity model for VOID Rig channel geometry only $\left(D_{c}=0.156 \mathrm{~m}\right.$, $\mathrm{m}=0.69, \mathrm{C}=0.48$ )

\section{Channel Inlet Void Distribution Model for Mark-22 Assembly}

In applications of two-fluid thermal-hydraulic codes such as FLOWTRAN-TF, the spatial nodalization is relatively coarse with mesh cells typically spanning the entire cross-sectional area of the dominant flow direction. Code calculations yield only cross-sectional average values; details of the flow behavior within a mesh cell are inherently imbedded in the constitutive relations. Explicit tracking of the detailed flow within a cell is generally unnecessary to perform the transport calculations. One exception occurs at the junction between the Top and Middle Sections of the Mark-22 assembly mesh, illustrated in Figure 11.1, where the main channel branches into multiple fiow paths (refer to Fig. 2.1 for definitions of Top and Middle Sections). Because the phases are not generally distributed uniformly within a cell, the local void fraction advected across the middle section channel entrances is not equal to the upstream cell-average value available from the normal code computations. In this section, we describe an empirical model for the middle section channel inlet void distribution for the Mark-22 assembly which we use to specify void fraction at the middle section entrance. Liquid flow splits, gas flow splits, and total assembly air flow are all strongly dependent on the channel inlet void distribution for a given total liquid flowrate and pressure boundary condition.

Before presenting the detailed channel inlet void model for the Mark-22 assembly, we first qualitatively describe the expected phase distribution in the upstream cell based on physical reasoning and experimental observation. Because of symmetry in the azimuthal direction, we assume local void fraction does not vary in this direction. In the radial direction, local 
void fraction is presumed to be generally nonuniform. Phase distribution phenomena are known to depend on channel geometry, flow direction and flow conditions (i.e. flowrates, pressure gradient, etc.). For downward flows, void peaking has generally been observed toward the center of the conduit with lowest void near the wall (Oshinowa and Charles, 1974; Wang et al., 1987). Accordingly, we expect the local void advected across the middle channel inlet to tend to be higher than that advected across the inner and outer channel entrances. Also we expect this effect to be more pronounced in the slug and annular flow regimes. A complicating factor is the 'overhang' immediately above the inlet to the outer channel. Under an adverse pressure gradient situation for which the liquid flow is gravity dominated and the gas flow is due to entrainment in the liquid flow, we expect the overhanging lip to tend to divert liquid away from the outer channel. That is, we anticipate a tendency toward higher void at the outer channel inlet due to the Mark-22 geometry for an adverse pressure gradient. For a favorable pressure gradient on the other hand, air flows are relatively high and water is swept along with the air flow. Because of the low inertia of the gas phase, the overhanging lip is not a significant obstacle and we anicipate less impact on the void distribution compared to the adverse pressure gradient case.

An examination of the Annular Flow Distribution (AFD) liquid flow fraction data taken at Babcock \& Wilcox (B\&W) (Childerson et al., 1990) supports the anticipated phase distribution behavior discussed above. Furthermore channel inlet void values inferred from the liquid flow fraction data can be successfully correlated as a function of computed upstream average void fraction and local pressure gradient at the Top/Middle Section junction. The FLOWTRAN-TF Mark-22 channel inlet void model was constructed by assuming the inner and middle channel inlet void could be empirically modeled as

$$
\begin{aligned}
& \alpha_{i}=\operatorname{fcn}(\alpha, \nabla P) \\
& \alpha_{m}=f \operatorname{cn}(\alpha, \nabla P)
\end{aligned}
$$

and the outer channel inlet void fraction could be determined from the mass balance

$$
\alpha=\sum_{k=1, \pi n, 0} \alpha_{k} \frac{V_{k}}{V}=\sum_{k=1, m, 0} \alpha_{k} \frac{A_{k}}{A}
$$

where the upstream cell volume is partitioned by channel inlet flow area. Symbols in the above equations are defined by

$$
\begin{aligned}
\mathrm{i} & \equiv \text { inner channel } \\
\mathrm{m} & \equiv \text { middle channel } \\
0 & \equiv \text { outer channel } \\
\alpha & \equiv \text { average upstream void fraction } \\
\alpha_{\mathrm{k}} & \equiv \mathrm{k}^{\text {th }} \text { channel inlet void; } \mathrm{k}=\mathrm{i}, \mathrm{m}, \mathrm{o} \\
\nabla \mathrm{P} & \equiv \text { local pressure gradient } \\
\mathrm{V} & \equiv \text { upstream cell volume }
\end{aligned}
$$




$$
\begin{aligned}
V_{k} & \equiv \text { volume partitioned to the } k^{\text {th }} \text { channel } \\
A & \equiv \text { total channel inlet area } \\
A_{K} & \equiv k^{\text {th }} \text { channel inlet area }
\end{aligned}
$$

The procedure for inferring 'experimental' channel inlet void fraction values from the AFD data is based on matching experimental and predicted liquid flow splits as shown in Fig. 11.2. The results of this process for a subset of the AFD data are shown in Figs. 11.3 through 11.6. The inferred data was subsequently correlated using polynomial functions of upstream average void. The detailed FLOWTRAN-TF channel inlet void distribution is given below.

For $\Delta \mathrm{P}<0 \mathrm{~Pa}$ (adverse pressure gradient),

$$
\begin{aligned}
& \alpha_{i}^{\mathrm{adv}}=0.3088 \alpha-0.3106 \alpha^{2}+4.4771 \alpha^{3}-7.4838 \alpha^{4}+4.0085 \alpha^{5} \\
& \alpha_{m}^{\mathrm{adv}}=0.9292 \alpha-1.9320 \alpha^{2}+9.9311 \alpha^{3}-12.783 \alpha^{4}+4.8547 \alpha^{5}
\end{aligned}
$$

For $\Delta \mathrm{P}>\Delta \mathrm{P}_{0}=200 \mathrm{~Pa}$ (favorable pressure gradient),

$$
\begin{gathered}
\alpha_{i}^{\mathrm{fav}}=\alpha-2.2029 \alpha^{2}+4.2057 \alpha^{3}-2.0028 \alpha^{4} \\
\alpha_{m}^{\mathrm{fav}}=\alpha-2.5932 \alpha^{2}+14.667 \alpha^{3}-21.131 \alpha^{4}+9.0472 \alpha^{5}
\end{gathered}
$$

The pressure difference $\Delta \mathrm{P}$ is defined to be the upstream cell pressure minus the arithmetic average of the cell pressures in the middle section at the top axial layer. In the pressure gradient transition region, $0<\Delta \mathrm{P}<\Delta \mathrm{P}_{0}$, linear weighting between the adverse and favorable correlations defines the channel inlet void distribution as

$$
\alpha_{k}=\left(1-\frac{\Delta P}{\Delta P_{0}}\right) \alpha_{k}^{a d v}+\left(\frac{\Delta P}{\Delta P_{0}}\right) \alpha_{k}^{f a v}
$$

where $k=i, m$. In developing the equations (11.4-7), the following constraints were imposed on the polynomial forms:

$$
\begin{aligned}
& \alpha_{k}^{l}(0, \Delta P)=0 \\
& \alpha_{k}^{l}(1, \Delta P)=1
\end{aligned}
$$

where $l=a d v$, fav. In addition, continuity of slope with the homogeneous void distribution line $\left(\alpha_{k}=\alpha\right)$ at zero void was required for favorable pressure gradient conditions due to a lack of data in this region. That is, equations (11.6) and (11.7) also satisfy 


$$
\frac{\partial \alpha_{k}^{\mathrm{fav}}}{\partial \alpha}(0, \Delta \mathrm{P})=1
$$

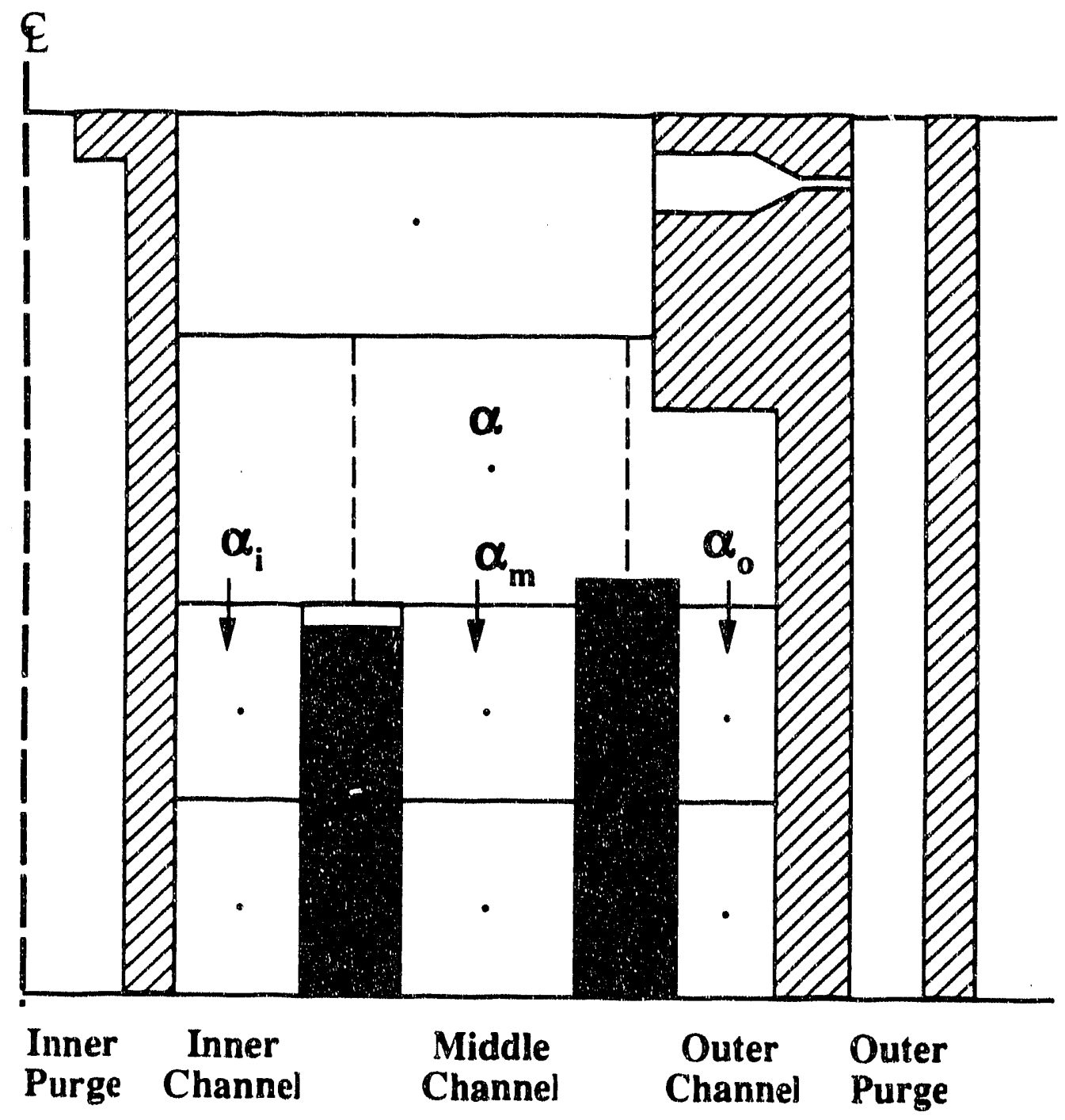

Figure 11.1 Schematic diagram of Mark-22 assembly geometry and FLOWTRAN-TF nodalization in the vicinity of the middle section channel entrance (axisymmetric slice) 


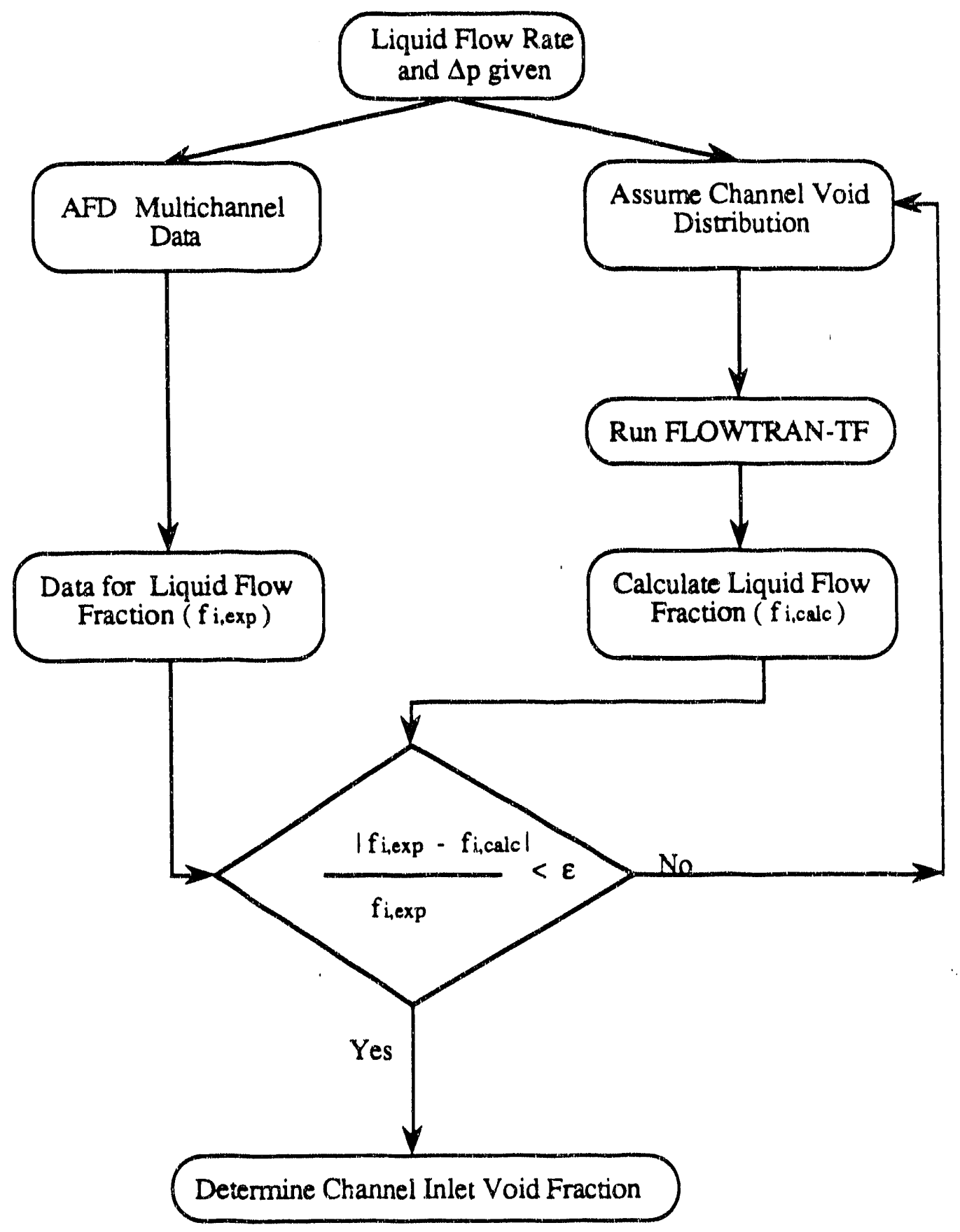

Figure 11.2 Strategy for determining experimental channel inlet void distribution values from AFD data 


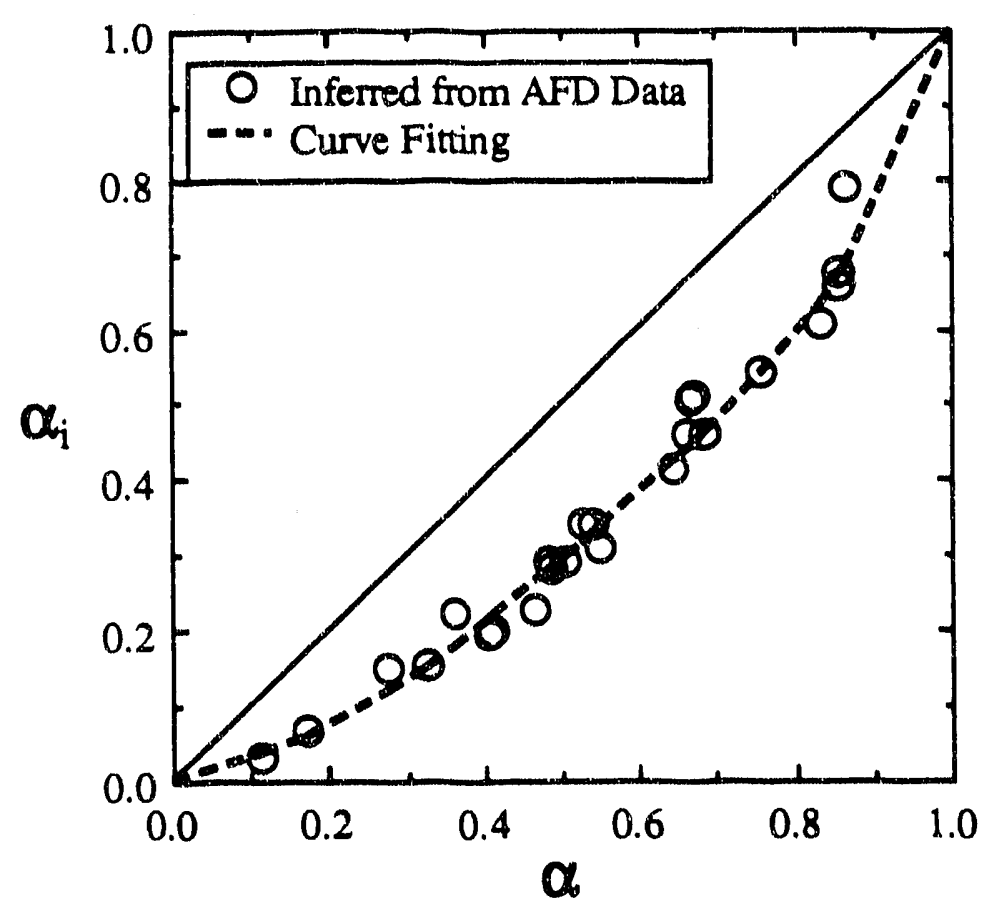

Figure 11.3 Inner channel inlet void fraction versus average upstream void fraction for adverse pressure gradient (__ ; homogeneous void distribution)

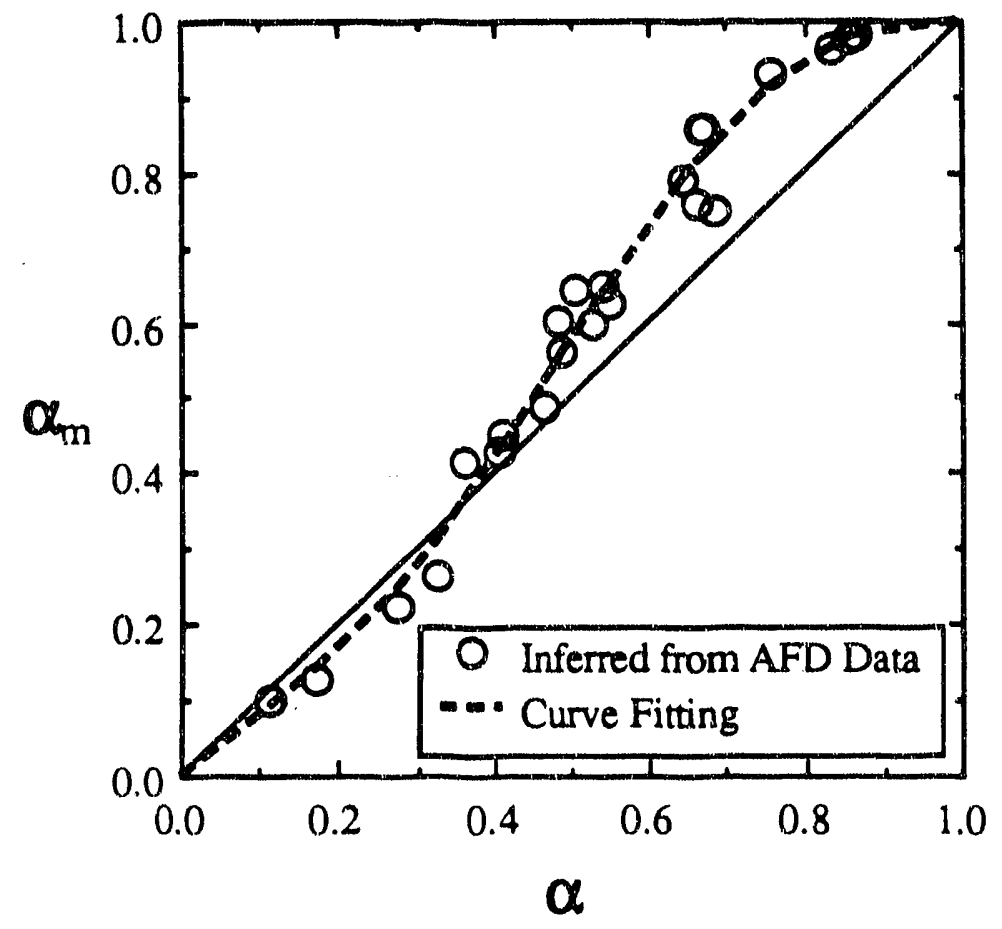

Figure 11.4 Middle channel inlet void fraction versus average upstream void fraction for adverse pressure gradient ( _ ; homogeneous void distribution) 


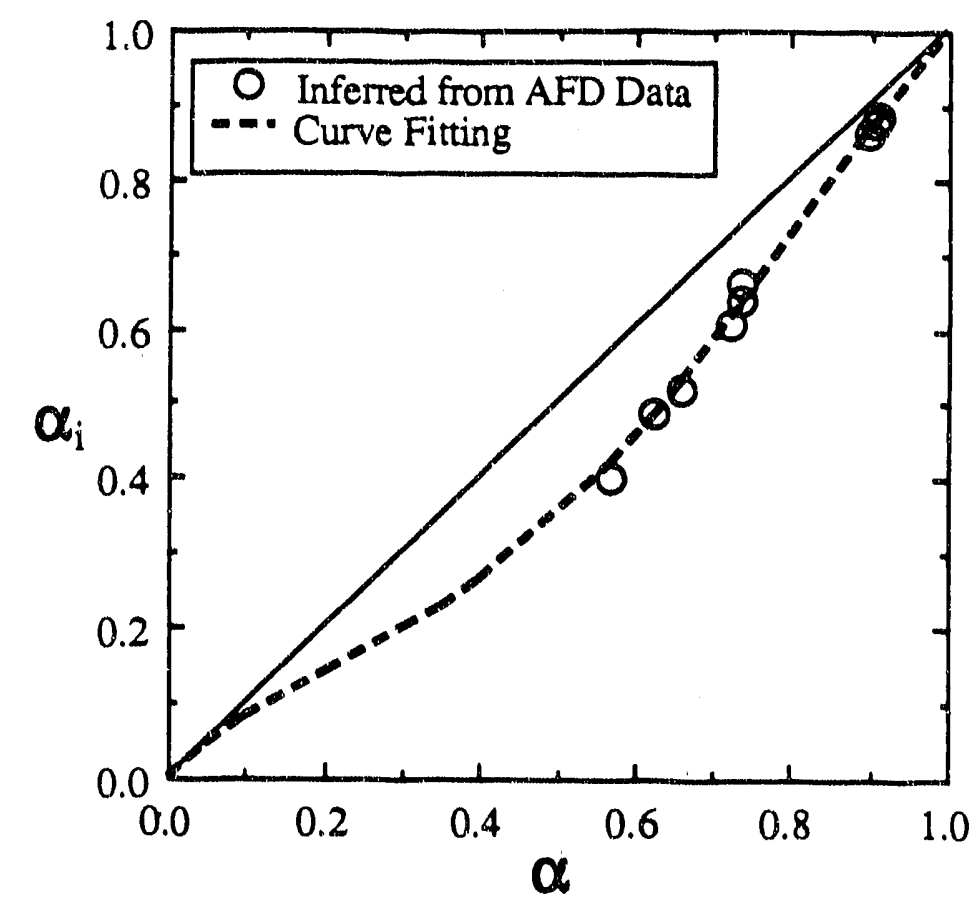

Figure 11.5 Inner channel inlet void fraction versus average upstream void fraction for favorable pressure gradient (__ ; homogeneous void distribution)

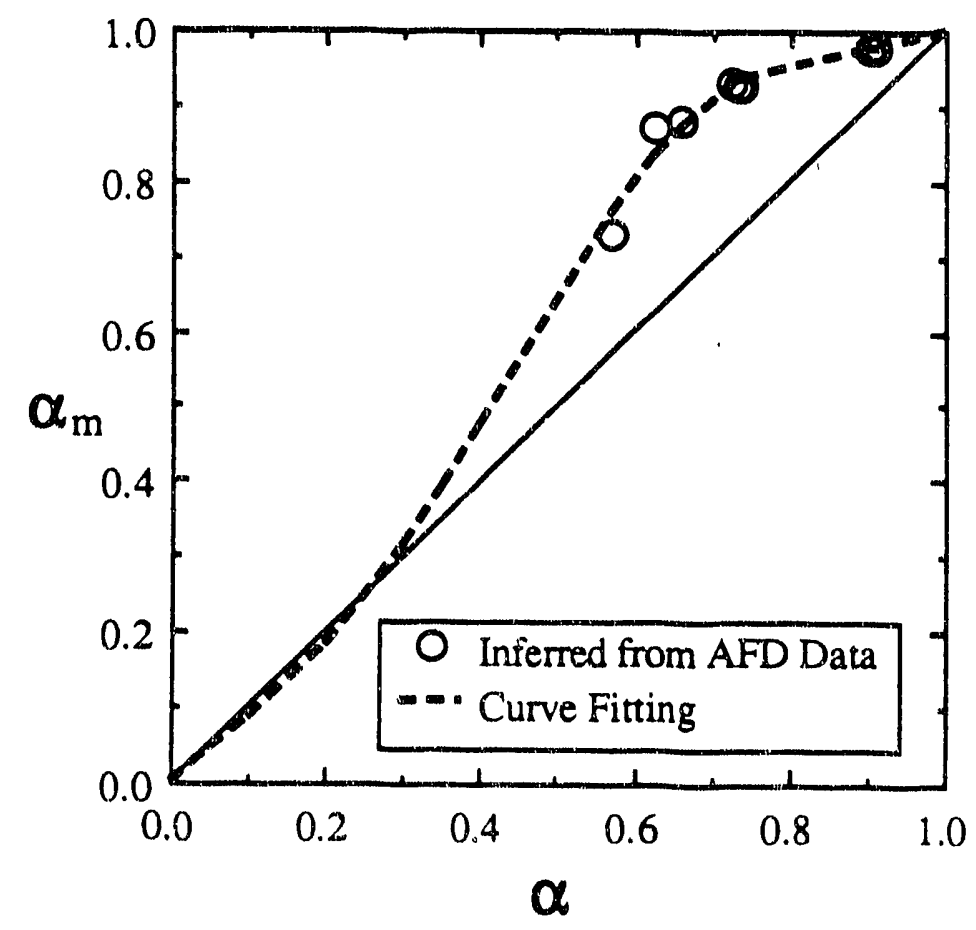

Figure 11.6 Middle channel inlet void fraction versus average upstream void fraction for favorable pressure gradient ( $\_$; homogeneous void distribution) 


\section{Azimuthal Momentum Donoring Scheme}

Another situation in which the detailed phase distribution within a fluid computational cell is important is illustrated schematically in Fig. 12.1. Within each subchannel of a ribbed annular channel, higher local void occurs near the center and a higher fraction of the liquid occupies the region near each rib. Referring to Fig. 12.2, properties at a cell face are usually taken from one of the adjoining cell centers depending on the velocity direction. Specifically, cell face properties are taken to be upwind cell center values and are termed 'donored' properties. For the situation illustrated in Fig. 12.1, the donored local void fraction at the cell face rninciding with a rib gap, $\alpha_{\text {rib }}$, may not be well approximated by the cell average value, $\alpha$. flexible donoring scheme is coded in FLOWTRAN-TF to allow users the option of modifying the normal donoring scheme of $\alpha_{\text {rib }}=\alpha$. For $\alpha \leq \alpha_{1}$ a linear variation is chosen:

$$
\alpha_{\mathrm{rib}}=\left(\frac{\alpha_{\mathrm{rib}, 1}}{\alpha_{1}}\right) \alpha
$$

In the region $\alpha_{1}<\alpha \leq \alpha_{2}$ the form is

$$
\alpha_{\text {rib }}=\alpha_{\mathrm{rib}, 2}+\left(\frac{\alpha_{2}-\alpha}{\alpha_{2}-\alpha_{1}}\right)^{N_{1}}\left(\alpha_{\mathrm{rib}, 1}-\alpha_{\mathrm{rib}, 2}\right)
$$

and for $\alpha>\alpha_{2}$

$$
\alpha_{\mathrm{rib}}=\left(\frac{\alpha-\alpha_{2}}{1-\alpha_{2}}\right)^{N_{2}}\left(1-\alpha_{\mathrm{rib}, 2}\right)+\alpha_{\mathrm{rib}, 2}
$$

The parameters $\alpha_{1}, \alpha_{2}, \alpha_{\text {rib, } 1}, \alpha_{\text {rib }, 2}, N_{1}$, and $N_{2}$ are input parameters. Note that the model is continuous for any selection of the parameters. Figure 12.3 illustrates an example variation which is piecewise linear $\left(\mathrm{N}_{1}=\mathrm{N}_{2}=1\right)$.

Experience with FLOWTRAN-TF indicates that azimuthal crosstlow can be sensitive to the rib void fraction model depending on the selections for other parameters (i.e form loss coefficient, interfacial drag coefficient, rib gap, orientation with respect to gravitational field). A clear choice for the rib void fraction model has not eninerged to-date. The rib void fraction model chosen for the nominal Mark-22 assembly model used to compute the Recommended K-Reactor Restart ECS Power Limit (Smith et al., 1990a; Smith et al., $1990 \mathrm{~b})$ is

$$
\begin{gathered}
\alpha_{1}=0.25 \\
\alpha_{2}=0.75 \\
\alpha_{\text {rib, } 1}=0.25 \\
\alpha_{\text {rib }, 2}=0.75
\end{gathered}
$$




$$
\begin{aligned}
& \mathrm{N}_{1}=1.0 \\
& \mathrm{~N}_{2}=1.0
\end{aligned}
$$

which is simply the 'default' model $\alpha_{\text {rib }}=\alpha$.

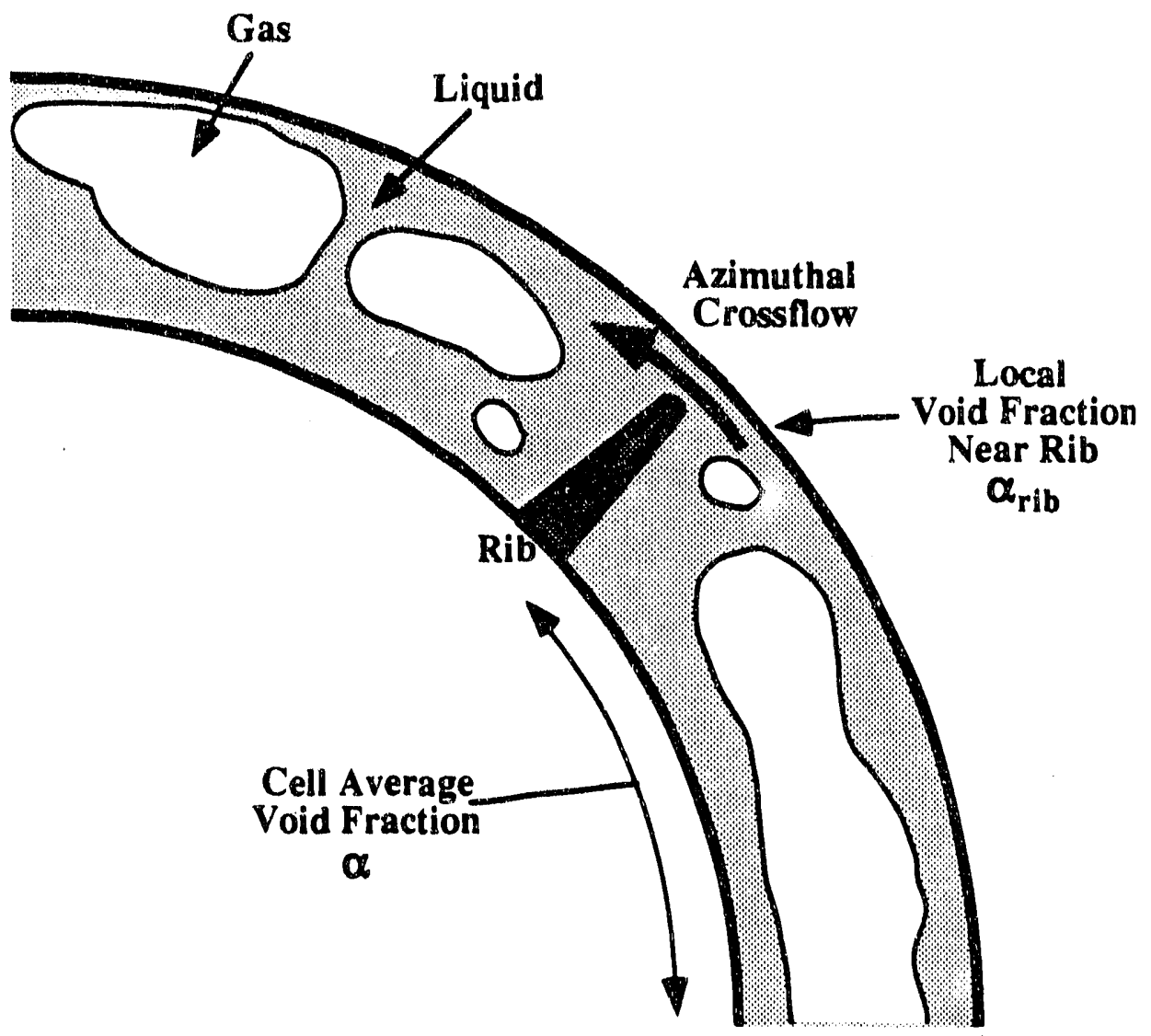

Figure 12.1 Typical void fraction distribution in a ribbed annular channel 


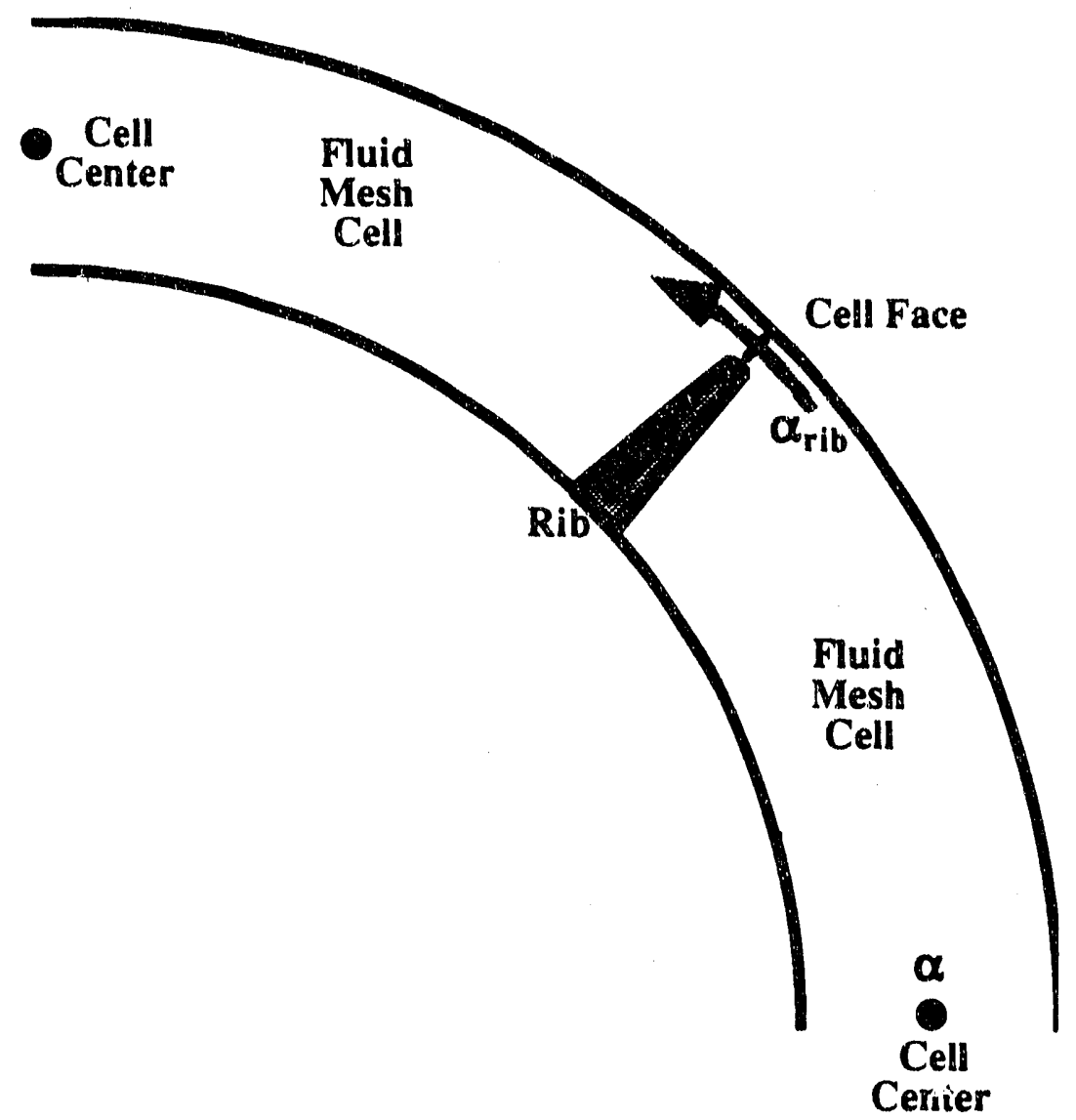

Figure 12.2 Typical fluid computational mesh chosen for ribbed annular channels 


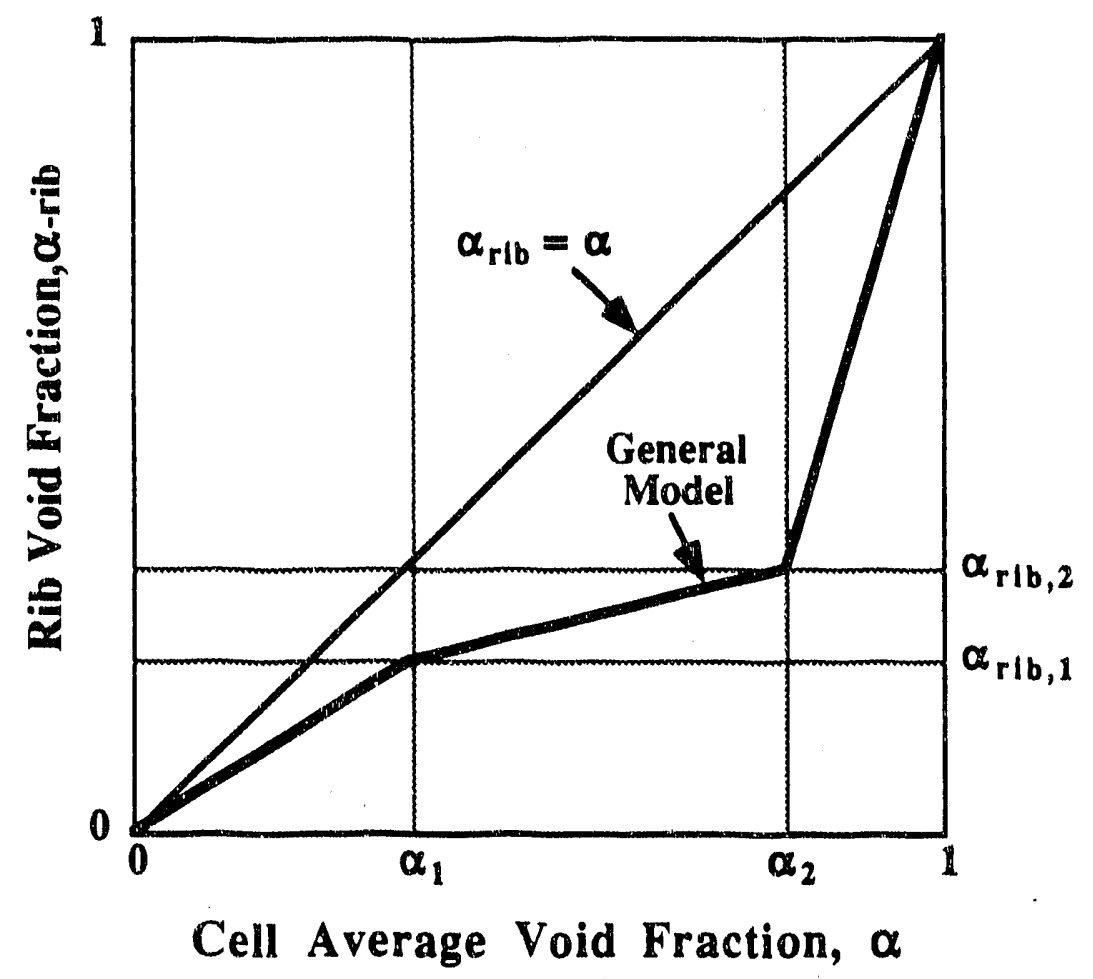

Figure 12.3 Schematic illustration of rib void fraction model

\section{Boundary Conditions}

The basic inlet boundary condition option is prescribed pressure $P$, void fraction $\alpha$, gas temperature $T_{g}$, liquid temperature $T_{f}$, and air mass fraction $X_{\mathrm{g}}$. Inlet densities and enthalpies are computed from these specified five primary variables. For the basic boundary condition option, inlet gas and liquid flowrates are part of the FLOWTRAN-TF solution. In addition to the basic option, inlet liquid and/or gas flowrate can be prescribed in FLOWTRAN-TF giving the user three additional inlet boundary condition options. For prescribed liquid flow, the liquid momentum balance between the inlet boundary (plenum) cell and the first cell in the Top Section is replaced with a specified flowrate equation. Inlet pressure is decoupled from the overall liquid momentum balance but is still used in the overall gas momentum balance and to compute inlet densities and enthalpies. Prescribed gas flowrate is handled in an analogous manner. Finally, liquid flowrates at the entrance of each axial flow path in the middle section can be prescribed. This allows the user to prescribe annular channel or subchannel flow splits for instance.

In both reactor assembly and experimental rig applications, horizontal stratified flow frequently exists at the inlet between the inlet (plenum) boundary cell and the first internal cell in the fluid mesh as shown schematically in Fig. 12.1. For this situation, the phasic $z$-direction momentum balances are modified by adding void gradient terms to account for the pressure gradient in the transverse (vertical) direction at the first mesh cell face. The following terms are added to the right hand side of equations (5.4) and (5.5), respectively, 


$$
\begin{aligned}
& -H \Delta \rho g \alpha(1-\alpha) \nabla \alpha \\
& +H \Delta \rho g \alpha(1-\alpha) \nabla \alpha
\end{aligned}
$$

where $\mathrm{H}$ is the transverse cell (plenum) height. Note that these extra terms do not appear in the mixture (sum) momentum balance since the terms are identical except for sign. Also, the user may modify the interfacial drag coefficient to account for the horizontal, stratified flow regime. Typically, a very small interfacial drag coefficient is selected.

Terms (13.1) and (13.2) are derived as follows. Figure 13.2 illustrates the pressure profile in a horizontal stratified flow. The following pressures are defined

$$
\begin{aligned}
& P_{1} \equiv \text { interface pressure } \\
& \bar{P}_{8} \equiv \text { average pressure in gas phase } \\
& \bar{P}_{f} \equiv \text { average pressure in liquid phase }
\end{aligned}
$$

Assuming the transverse pressure gradients in gas and liquid are due to hydrostatic head and constant properties yields

$$
\begin{aligned}
& \bar{P}_{g}=P_{i}-\frac{1}{2} \rho_{g} g \alpha_{g} H \\
& \bar{P}_{f}=P_{i}+\frac{1}{2} \rho_{f} g \alpha_{f} H
\end{aligned}
$$

The pressure force on the gas phase per unit volume for the control volume shown in Figure 13.2 is

$$
\frac{F_{g}}{V}=\frac{\left(\bar{P}_{g 1} \alpha_{g 1}-\bar{P}_{g 2} \alpha_{g 2}\right) A}{V}-\frac{\left(P_{i 1}+P_{i 2}\right)}{2} \frac{\left(\alpha_{g 1}-\alpha_{g 2}\right) A}{V}
$$

In the limit at $\Delta z$ goes to zero

$$
\lim _{\Delta z \rightarrow 0} \frac{F_{g}}{V}=\frac{\partial \bar{P}_{g} \alpha_{g}}{\partial z}-P_{i} \frac{\partial \alpha_{g}}{\partial z}
$$

Similarly for the liquid phase

$$
\lim _{\Delta z \rightarrow 0} \frac{F_{f}}{V}=\frac{\partial \vec{P}_{f} \alpha_{f}}{\partial z}-P_{i} \frac{\partial \alpha_{f}}{\partial z}
$$

The pressure force per unit volume on the mixture is the sum of equations (13.5) and (13.6): 


$$
\lim _{\Delta z \rightarrow 0} \frac{F}{V}=\frac{\partial}{\partial z}\left(\alpha_{g} \bar{P}_{g}+\alpha_{f} \bar{P}_{f}\right)
$$

Equation (13.8) motivates defining an average mixture pressure as

$$
\overrightarrow{\mathrm{P}} \equiv \alpha_{\mathrm{g}} \overline{\mathrm{P}}_{\mathrm{g}}+\alpha_{\mathrm{f}} \overline{\mathrm{P}}_{\mathrm{f}}
$$

In terms of the average mixture pressure, the interface, average gas, and average liquid pressures are

$$
\begin{aligned}
& P_{i}=\bar{P}+\frac{1}{2} \rho_{g} g \alpha_{g}^{2} H-\frac{1}{2} \rho_{f} g \alpha_{f}^{2} H \\
& \bar{P}_{g}=\bar{P}-\frac{1}{2} \rho_{g} g \alpha_{g} \alpha_{f} H-\frac{1}{2} \rho_{f} g \alpha_{f}^{2} H \\
& \bar{P}_{f}=\bar{P}+\frac{1}{2} \rho_{g} g \alpha_{g}^{2} H+\frac{1}{2} \rho_{f} g \alpha_{g} \alpha_{f} H
\end{aligned}
$$

Substituting equations $(13.10-12)$ into equations $(13.6-7)$ yields

$$
\begin{aligned}
& \lim _{\Delta z \rightarrow 0} \frac{F_{g}}{V}=\alpha_{g} \frac{\partial \bar{P}}{\partial z}+\Delta \rho g H \alpha_{g} \alpha_{f} \frac{\partial \alpha_{g}}{\partial z} \\
& \lim _{\Delta z \rightarrow 0} \frac{F_{f}}{V}=\alpha_{f} \frac{\partial \bar{P}}{\partial z}-\Delta \rho g H \alpha_{g} \alpha_{f} \frac{\partial \alpha_{g}}{\partial z}
\end{aligned}
$$

Moving these terms to the r.h.s. of the momentum balance as they appear in equations (5.4) and (5.5) (i.e. change the sign) and replacing $\alpha_{g}$ with $\alpha, \alpha_{f}$ with $(1-\alpha)$, and $\partial / \partial z$ with $\nabla$ yields the terms given by (13.1-2). 


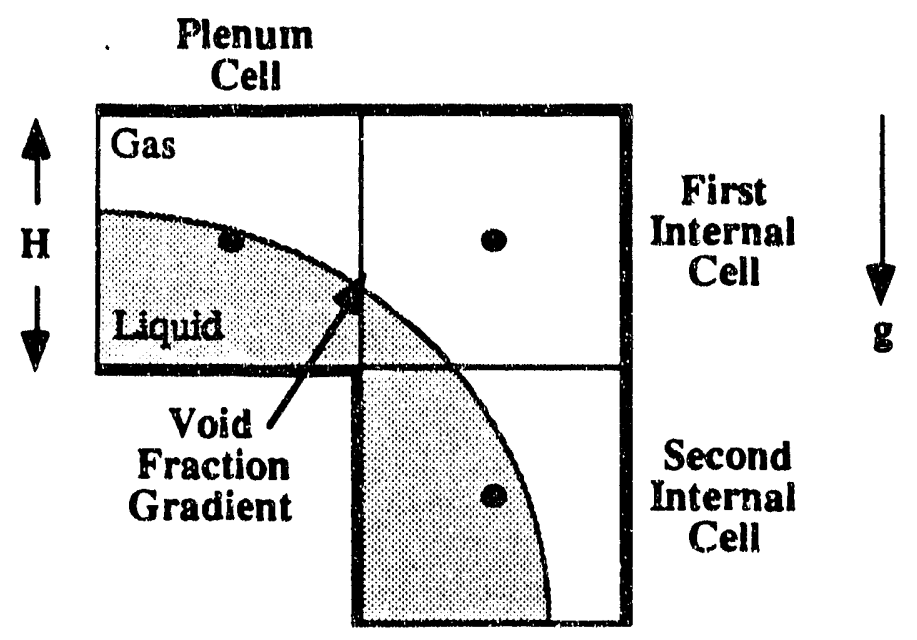

Figure 13.1 Horizontal stratified flow at first mesh cell face

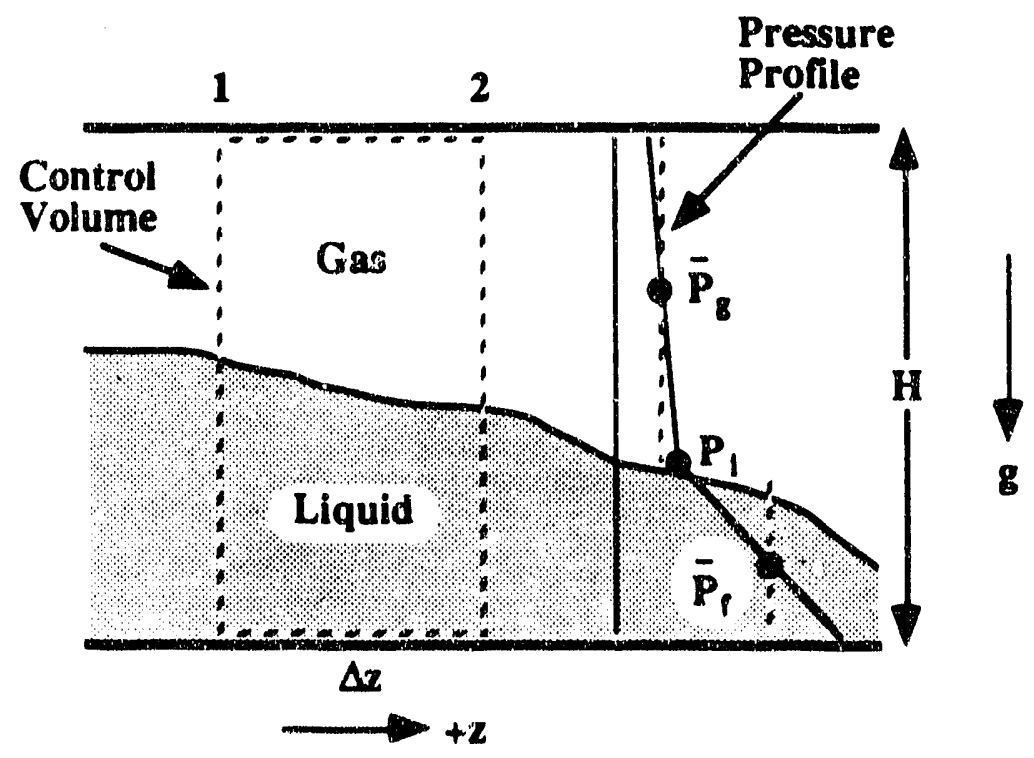

Figure 13.2 Control volume and nomenclature for horizontal, stratified flow derivation

\section{References}

\section{Introduction:}

Smith, F. G., III, Hamm, L. L., and Koffman, L. D., 1990, "DEGB LOCA ECS Limits Methodology (U)", WSRC-TR-90-411.

Smith, F. G., III, Aleman, S. E., Flach, G. P., Hamm, L. L., Koffman, L. D., and Lee, S. Y., 1990, "DEGB LOCA ECS Power Limit Recommendation for K-14.1 Subcycle (U)", WSRC-TR-90-412. 
Flach, G. P., Aleman, S. E., Lee, S. Y., and Smith, F. G., III, 1990, "FLOWTRAN-TF Code Benchmarking", WSRC-TR-90-414.

Geometric Capability:

Aleman, S. E., Gregory, M. V., Hamm, L. L., Koffman, L. D., Pevey, R. E, Reed, W. H., and Smith, III, F. G., 1989, "FLOWTRAN: An Algorithm for Describing the Thermal-Hydraulic Behavior of SRP Assemblies", DPSTM-140.

\section{Solid Heat Conduction:}

Aleman, S. E., Gregory, M. V., Hamm, L. L., Koffman, L. D., Pevey, R. E, Reed, W. H., and Smith, F. G., III, 1989, "FLOWTRAN: An Algorithm for Describing the Thermal-Hydraulic Behavior of SRP Assemblies", DPSTM-140.

\section{Power Generation:}

Aleman, S. E., Gregory, M. V., Hamm, L. L., Koffman, L. D., Pevey, R. E, Reed, W. H., and Smith, F. G., III, 1989, "FLOWTRAN: An Algorithm for Describing the Thermal-Hydraulic Behavior of SRP Assemblies", DPSTM-140.

Baxter, C. A., and Apperson, Jr., C. E., 1982, "Revision of the Hydraulic Manual Decay Heat Tables", DPST-82-646. (see DPST-81-785 and DPST-82-432 also).

Pevey, R. E., 1987, "Axial Power Profiles in SRP Reactors During LOCA", DPST-87. 511.

Smetana, A. O., 1982, "GLASS Conversion to FORTRAN Q Compiler" DPST-82-209.

Smith, J. A., and Church, J. P., 1982, "Accident Analysis Computer Program," DPSTM120.

\section{Fluid Governing Equations:}

Lahey, R. T., Jr., and Drew, D. A., 1988, "The Three-Dimensional Time and Volume Averaged Conservation Equations of Two-Phase Flows", in Advances in Nuclear Science and Technology, Volume 20, edited by J. Lewins and M. Becker.

\section{Wall Heat Transfer:}

Aleman, S. E., Gregory, M. V., Hamm, L. L., Koffman, L. D., Pevey, R. E, Reed, W. H., and Smith, III, F. G., 1989, "FLOWTRAN: An Algorithm for Describing the Thermal-Hydraulic Behavior of SRP Assemblies", DPSTM-140.

Bergles, A. E., and Rohsenow, W. M., 1964, "The Determination of Forced-Convection Surface Boiling Heat Transfer", J. Heat Transfer 86, p. 365.

Biasi, L., Clerici, G. C., Garribba, S., Sala, R., and Tozzi, A., 1967, "Studies on Burnout, Part 3: A New Correlation for Round Ducts and Uniform Heating and Its Comparison with World Data" Energia Nucleare 14, p. 530.

Bjorge, R. W., and Rohsenow, W. M., 1982, "Correlation of Forced Convection Boiling Heat Transfer Data", Int. J. Heat and Mass Transfer 25 (6), p. 753. 
Bjornard, T. A., and Griffith, P., 1977, "PWR Blowdown Heat Transfer", in Thermal and Hydraulic Aspects of Nuclear Reactor Safety 1, American Society of Mechanical Engincers, New York, p. 17.

Carpenter, E. F., and Colburn, A. P., 1951, "The Effect of Vapour Velocity on Condensation Inside Tubes", Proc. of General Discussion on Heat Transfer, 2026, IMechE/ASME.

Chen, J. C., 1963, "A Correlation for Boiling Heat Transfer to Saturated Fluids in Convective Flow", ASME 63-HT-34, American Society of Mechanical Engineers.

Collier, J. G., 1972, Convertive Boiling and Condensation, 2nd edition, McGraw-Hill Book Company, Inc., p. 330.

Collier, J. G., 1981, "Forced Convection Boiling", in Two Phase Flow and Heat Transfer, ed. A. E. Bergles, J. G. Collier, J. M. Delhaye, G. F. Hewitt, and F. Mayinger, Chap. 8, Hemisphere, Washington.

Dittus, F. W., and Boelter, L. M. K., 1930, "Heat Transfer in Automobile Radiators of the Tubular Type", University of California (Berkley), Publications in Engineering 2, p. 443.

Dougall, R. S., and Rohsenow, W. M., 1963, "Film Boiling on the Inside of Vertical Tubes with Upward Flow of the Fluid at Low Qualities", Massachusetts Institute of Technology Report 9079-76.

Forslund, R. P., and Rohsenow, W. M., 1968, "Dispersed Flow Film Builing", J. Heat Transfer 90 (6), p. 399.

Groeneveld, D. C., and Stewart, J. C., 1983, "The Minimum Film Boiling Temperature for Water During Film Boiling Collapse", in Proc. 2nd Int. Topical Meeting on Nuclear Reactor Thermal-Hydraulics, Santa Barbara, Calif., p. 393.

Guerrero, H. N., 1990, private communication.

Hodges, M. W., and Knoebel, D. H., 1973, "Subcooled Burnout Phenomena Adjacent to a Spacer Rib", ASME 73-HT-40, American Society of Mechanical Engineers.

Holman, J. P., 1976, Heat Transfer, 4th edition, McGraw-Hill Book Company, Inc., p. 38.

Kelly, J. E., 1980, "Development of a Two-Fluid, Two-Phase Model for Light Water Reactor Subchannel Analysis," PhD. Thesis, Massachusetts Institute of Technology.

Liles, D. R., Spore, J. W., Knight, T. D., Nelson, R. A., Cappiello, M. W., Pasamehmetoglu, K. O., Mahaffy, J. H., Guffee, L. A., Stumpf, H. J., Dotson, P. J., Steinke, R. G., Shire, P. R., Greiner, S. E., and Sherwood, K. B., 1988, "TRAN-PFI/MODI Correlations and Models", NUREG/CR-5069.

Lockhart, R. W., and Martinelli, R. C., 1949, "Proposed Correlation of Data for Isothermal Two-Phase Two-Component Flow in Pipes", Chem. Eng. Prog. 45, p. 39. 
Mikic, B. B., and Rohsenow, W. M., 1969, "A New Correlation of Pool Boiling Data Including the Effect of Heating Surface Characteristics", Trans. Am. Soc. Mech. Engrs., Series C, J. Heat Transfer 91, p. 245.

Pomeranz, M. L., 1964, "Film Boiling on a Horizontal Tube in Increased Gravity Fields", J. Heat Transfer 86, p. 213.

Ransom, V. H., Wagner, R. J., Trapp, J. A., Feinauer, L. R., Johnsen, G. W., Kiser, D. M., and Riemke, R. A., 1985, "RELAP5/MOD2 Code Manual Volume 1: Code Structure, System Models, and Solution Methods", NUREG/CR-4312, EG\&G Idaho, Inc.

Rohsenow, W. M., and Choi, H., 1961, Heat, Mass, and Momentum Transfer, PrenticeHall, Inc.

Rouhani, S. Z., and Axelsson, E., 1970, "Calculation of Void Volume Fraction in Subcooled and Quality Boiling Regions", Int. J. Heat and Mass Transfer 13, p. 383.

Sieder, E. N., and Tate,.C. E., 1936, "Heat Transfer and Pressure Drop of Liquids in Tubes", Ind. Eng. Chem. 28, p. 1429.

Thurgood, M. J., Kelly, J. M., Guidotti, T. E., Kohrt, R. J., and Crowell, K. R., 1983, "COBRA/TRAC - A Thermal Hydraulics Code for Transient Analysis of Nuclear Reactor Vessels and Primary Coolant Systems", NUREG/CR-3046, Pacific Northwest Laboratory.

Treybal, R. E., 1980, Mass-Transfer Operations, 3rd edition, McGraw-Hill Book Company, Inc.

Zuber, N., Tribus, M., and Westwater, J. W., 1961, "The Hydrodynamic Crisis in Pool Boiling of Saturated and Subcooled Liquids", International Developments in Heat Transfer, Part II, p. 230.

\section{Wall Drag:}

Blevins, R. D., 1984, Applied Fluid Dynamics Handbook, Van Nostrand Reinhold, New York.

Jain, A. K., 1976, "Accurate Explicit Equation for Friction Factor," ASCE J. Hydraulics Div. 102, pp. 674-677.

Jones, O. C., Jr., 1976, "An Improvement in the Calculation of Turbulent Friction in Rectangular Ducts", J. Fluids Engr. 98, pp. 173-180.

Jones, O. C., Jr., and Leung, J. C. M., 1981, "An Improvement in the Calculation of Turbulent Friction in Smooth Concentric Annuli", J. Fluids Engr. 103, pp. 615. 623.

Tapucu, A., 1977, "Studies on Diversion Cross-Flow Between Two Parallel Channels Communicating by a Lateral Slot. I: Transverse Flow Resistance Coefficient", Nucl. Engr. Design 42, pp. 297-306. 
Thurgood, M. J., Kelly, J. M., Guidotti, T. E., Kohrt, R. J., and Crowell, K. R., 1983, "COBRA/TRAC - A Thermal-Hydraulics Code for Transient Analysis of Nuclear Reactor Vessels and Primary Coolant Systems", NUREG/CR-3046, Volume 1, p. 3.29 .

Flow Regime Map and Interfacial Area:

Barnea, D., Shoham, O., and Taitel, Y., 1982, "Flow Pattern Transition for Downflow Inclined Two Phase Flow; Horizontal to Vertical", Chem. Eng. Sci. 37, pp. 735740.

Dimenna, R. A., Larson, J. R., Johnson, R. W., Larson, T. K., Miller, C. S., Streit, J. E., Hanson, R. G., and Kiser, D. M., 1988, "RELAP5/MOD2 Models and Correlations", NUREG/CR-5194, EGG-2531.

Ishii, M. and Mishima, K., 1980, "Study of Two-Fluid Model and Interfacial Area", NUREG/CR-1873.

Kelessidis, V. C., and Duckler, A. E., 1989, "Modeling Flow Pattern Transitions for Upflow Gas-Liquid Flow in Vertical Concentric and Eccentric Annuli", Int.J.Multiphase Flow 15, pp. 173-191.

Ransom, V. H., Wagner, R. J., Trapp, J. A., Feinauer, L. R., Johnsen, G. W., Kiser, D. M., and Riemke, R. A., 1985, "RELAP5/MOD2 Code Manual Volume 1: Code Structure, System Models, and Solution Methods", NUREG/CR-4312, EG\&G Idaho, Inc.

Taitel, Y., Bornea, D., and Duckler, A. E., 1980, "Modelling Flow Pattern Transitions for Steady Upflow Gas-Liquid Flow in Vertical Tubes", AIChE Journ. 26, pp. 345254.

Taylor, D. D., et al., 1984, "TRAC-BD1/MOD1: An Advanced Best Estimate Computer Program for Boiling Water Reactor Transient Analysis", NUREG/CR-3633, Volume 1.

Interfacial Heat and Mass Transfer:

Ackermann, G., 1937, "Waermeuebergang und Molekulare Stoffuebertragung in Gleichen Feld", Ver. Dtsch. Ing. Forschungsh. 382, pp. 1-16.

Bird, R. B., Stewart, W. E., and Lightfoot, E. N., 1960, Transport Phenomena, Wiley, New York.

Chapman, H., 1974, Heat Transfer, 3rd. ed., Macmillan, New York.

Lee, K., and Riley, D.J., 1968, "The Evaporation of Water Droplets in Superheated Steam", J. Heat Trans. 90, pp. 445-451.

Oellrich, L., Schmidt-Traub, H., and Brauer, H., 1973, "Theoretische Berechnung des Stoffransports in der Umgebung einer Einzelblase", Chem. Engr. Sci. 28, pp. 711.721. 
Sherwood, T. K., Pigford, R. L., and Wilke, C. R., 1975, Mass Transfer, McGraw-Hill, New York.

Treybal, R. E., 1980, Mass Transfer Operations, 3rd. ed., McGraw-Hill, New York.

\section{Interfacial Drag:}

Anderson, J. G. M., and Chu, K. H., 1982, "BWR Refill-Reflood Program, Task 4.7: Constitutive Correlations For Shear and Heat Transfer For the BWR Version of TRAC", NUREG/CR-2134.

Cheng, L. Y., 1990, "Counter-current Flow Limitation in Thin Rectangular Channels", submitted to the International Topical Meeting on the Safety, Status, and Future of Non-commercial Reactors and Irradiation Facilities, September 30 - October 4, 1990, Boise, Idaho.

Ishii, M., and Mishima, K., 1984, "Two-Fluid Model and Hydrodynamic Constitutive Relations", Nucl. Engr. Design 82, pp. 107-126.

Mishima, K., 1984, "Boiling Burnout at Low Flow Rate and Low Pressure Conditions", Ph.D. Thesis, Research Reactor Inst., Kyoto University, Japan.

Mishima, K., and Nishihara, H., 1985, "The Effect of Flow Direction and Magnitude on CHF for Low Pressure Water in Thin Rectangular Channels", Nucl. Engr. Design 86, pp. 165-181.

Ohkawa, K., and Lahey, R. T., Jr., 1980, "The Analysis of CCFL Using Drift-Flux Models", Nucl. Engr. Design 61, pp. 245-255.

Osakabe, M., and Kawasak, Y., 1989, "Top Flooding in Thin Rectangular and Annular Passages", Int. J. Multiphase Flow 15, pp. 747-754.

Richter, H. J., 1981, "Flooding in Tubes and Annuli", Int. J. Multiphase Flow 7, pp. 647-658.

Ruggles, A. E., 1989, "Countercurrent Flow Limited Heat Flux Isotope Reactor (HFIR) Fuel Element", ORNL/TM-9662 Draft.

Sudo, Y., and Kaminaga, M., 1989, "A CHF Characteristic for Downward Flow in a Narrow Vertical Rectangular Channel Heated for Both Sides", Int. J. Multiphase Flow 15, pp. $755-766$.

Wallis, G. B., 1969, "One-Dimensional Two-phase Flow", McGraw-Hill, New York.

Whatley, V., 1990, "Measurements of Void Fractions and Pressure Profiles for Downward Flowing Air-Water Mixtures in Single Test Annulus", WSRC-TR-90-328.

Channel Inlet Void Distribution Model for Mark-22 Assembly:

Childerson, M. T., Manolescu, M. I., and Parkinson, J. R., 1990, "Annular Flow Distribution Test - Interim Report", Babcock and Wilcox Alliance Research Center Report RDD:90:4558-05-01:01 and WSRC-TR-90-149. 
Oshinowa, T., and Charles, M. E., 1974, "Vertical Two-Phase Flow, Part 1, Flow Pattern Correlations", Can. J. Chem. Engr. 52, pp. 25-35.

Wang, S. K., Lce, S. J., Jones, O. C., Jr., and Lahey, R. T., Jr., 1987, "3-D Turbulence Structure and Phase Distribution Measurements in Bubbly Two-Phase Flows", Int. J. Multiphase Flow 13, pp. 327-343. 

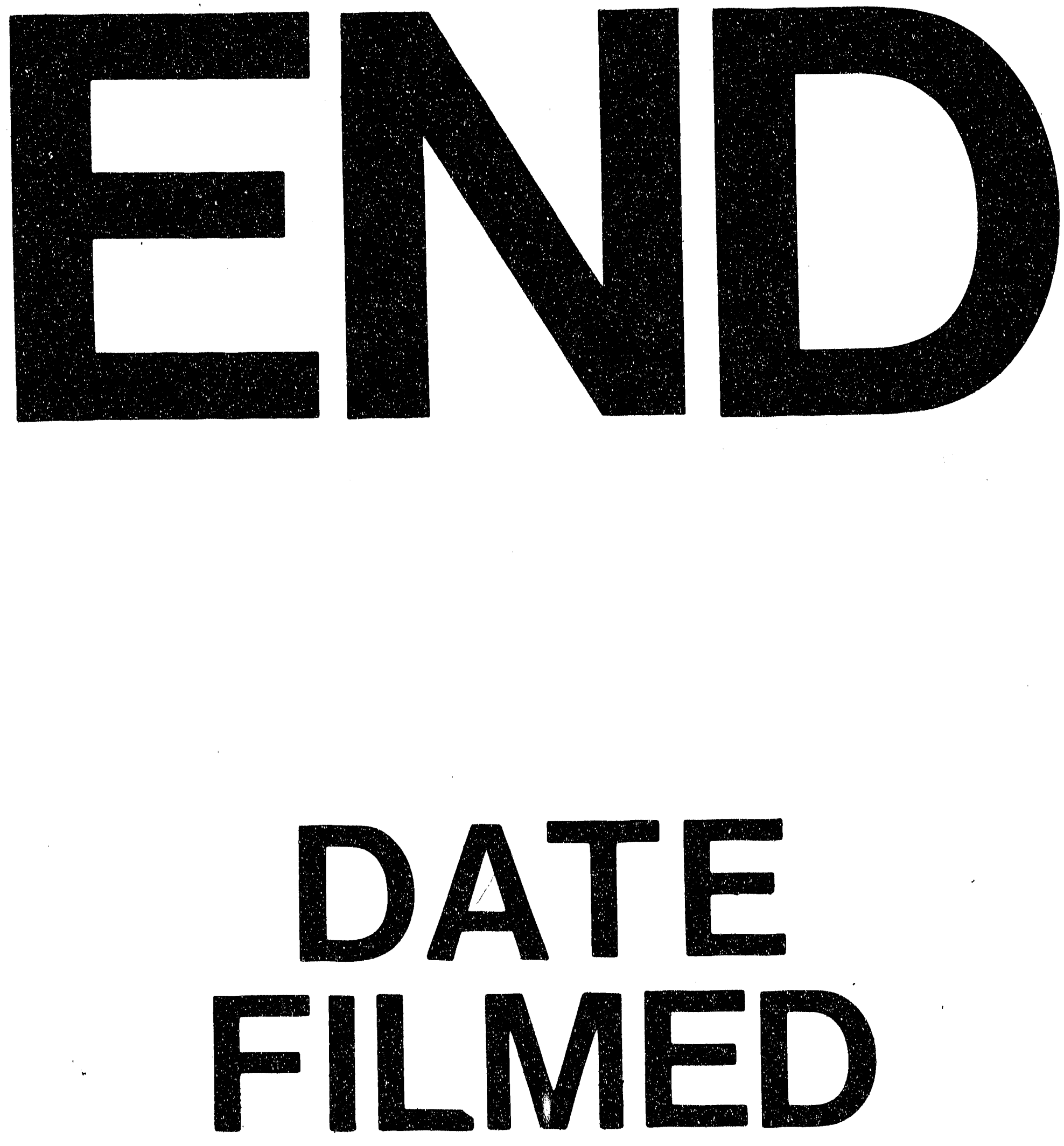

1

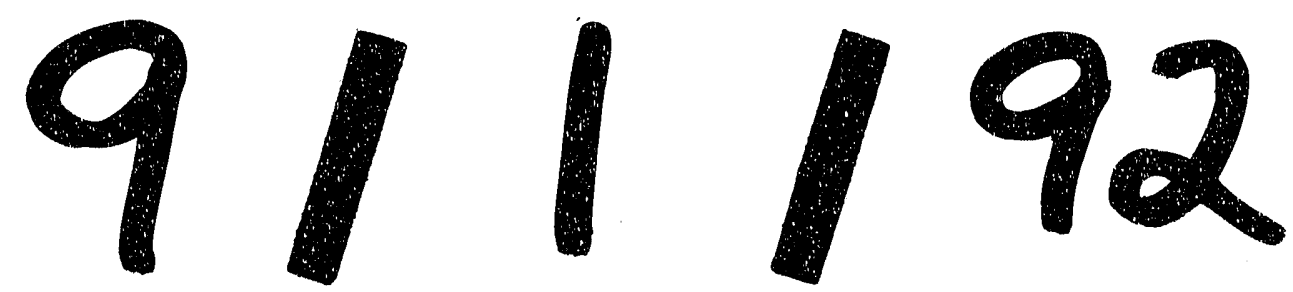


